\title{
Studien über Protozoen des nördlichen Russland.
}

Von

\author{
C. von Mereschkowsky
}

aus St. Petersburg.

Hierzu Tafel X und XI.

In Folge der Unterstittzung seitens der St. Petersburger Naturforscher-Gesellschaft, für welche ich derselben meinen innigsten Dank hier zu erklïren mich verpflichtet fühle, war es mir möglich während der Sommermonate 1876 and 1877 zwei Reisen nach dem Weissen Meere auszufuihren. Dort machte ich eine reiche Sammlung, die ich allmählich zu bearbeiten und deren gewonnene Resultate dem entsprechend zu veröffentlichen hoffe. Einiges (Hydroiden, Spongien, Würmer) ist schon bearbeitet und theils veröffentlicht, theils im Drucke. In dem VIII B. der Arbeiten der St. Petersburger Naturforscher-Gesellschaft habe ich alle von mir gefundenen, sowohl schon bekannten, als neuen Stisswasser- und Meeres-Infusorien, im Ganzen etwa 150 Arten, beschrieben. In der vorliegenden Arbeit will ich fast aussehliesslich die neuen von mir gefundenen Formen beschreiben und dann die allgemeinen Schltusse, zu denen ich gekommen bin, mittheilen. Es schien mir nämlich ganz besonders wichtig und interessant zu entscheiden, ob wirklich die Protozoenfauna verschiedener Meere so gleichförmig sei, als es verschiedene Forscher anzunehmen geneigt sind. So beschränkt auch das von mir untersuchte Gebiet ist, erlaubt es doch eine solche An- 
sicht ganz entschieden zu verwerfen. Wie es weiter sich erweisen wird, hängen die Infusorien ebenso von den äusseren Existenzbedingungen $a b$, wie alle höheren Thiere, und ich hoffe, dass mit den weiteren Fortschritten unserer Kenntnisse die Protozoen sich ebenso gut, wie alle übrigen Organismen zur Lösung verschiedener zoogeographischen Fragen verwenden lassen werden.

Cothurnia nodosa Clap. et Lachm.

Cothurnia nodosa Clap. et Lach. Eit. s. 1. Inf. p. 123, pl. II, Fig. 5.

Taf. $\mathrm{X}$, Fig. 1-5.

Diese rein nördliche Art ist weit im Weissen Meere verbreitet und bietet sowohl hinsichtlich der Form der Schale und der Anschwellung des Stieles, als der Lünge derselben grosse Variationen dar. Zunächst muss ich bervorheben, dass ich kein einziges Individuum fand, bei dem die Anschwellung ausserhalb der Schale liegt, wie dies Claparède und Lachmann beschreiben, vielmehr befand sie sich immer innerhalb derselben an deren Boden, und stellte im Wesentlichen nur eine Verbreitung des Stieles, der den Körper selbst trägt (vgl. Taf. X Fig. 1-5) dar. Was die Form der Anschwellung betrifft, so muss ich bemerken, dass Cothurnia nodosa des Weissen Meeres in dieser Beziehung eine besondere Varietiit vorstellt, bei der die letztere nicht oval und rundlich, sondern von dreieckiger oder pyramidaler Gestalt ist; der Grund des Dreieckes resp. der Pyramide ruht auf dem Boden der Schale. Viel seltener begegnet man Exemplaren mit runder Anschwellung, und ebenso ist die für Norwegen charakteristische wellige Oberfläche der Schale sehr selten, meistens ist sie im Gegentheil ganz glatt. Der Bodẹn selbst ist entweder regelmässig zugerundet (s. Fig. 1 und 3), oder umgekehrt etwas verengert und ausgezogen (s. Fig. 2, 4, 5). Endlich kann der die Schale tragende Stiel entweder sehr kurz, viel kürzer als ein Viertel der sämmtlichen Länge sein, oder, wie es gewöhnlich vorkommt, beträgt die Länge desselben ein Viertel der letzteren, oder - und das kam nur einmal zur Beobachtung - kann der Stiel die Länge der Schale sogar um eine Hälfte ubbertreffen (s. Taf. $X$ Fig. 5).

Von allen diesen Variationen ist bei Claparède und Lach- 
mann Nichts erwähnt, und daraus kann man schliessen, dass solche Formen an der norwegisehen Küste nicht vorkommen und dass diese Art in einem mehr polaren Meere, wie das Weisse, sich schon bedeutend verändert hat.

Die Taf. X, Fig. $1-5$ zeigt die grosse Mannigfaltigkeit der Formen, denen wir im Weissen Meere begegnen, die Alle, wie ich glaube, zu einer Art zu zählen sind. Hier sehen wir sowohl runde als dreieckige Verdickungen des Stieles mit einem conischen oder runden Boden der Schale, wir bemerken auch sowohl lange (Varietas longipes Fig. 5), als kurze Stiele; endlich variirt die Form der Schale selbst, die Ränder ihrer Mündung z. B. sind zuweilen ein wenig umgebogen (s. Fig. 3).

Die Länge eines typischen Exemplars $=0,09635^{\prime \prime \prime}$; die Länge der Varietas longipes $=0,1856^{\prime \prime \prime}$, die grösste Breite $=0,03525^{\prime \prime}$, die Länge des Stieles $=0,0846^{\prime \prime \prime}$, bei andern Varietäten erreicht. die'Länge der Schale bis $0,1057^{\prime \prime \prime}$.

Fundort: Weisses Meer. 1. Solowetzky-Inseln, unweit der Kloster-Bucht, pelagisch (auf der Oberflüche), auf den Conferven, die typische Claparèdesche Form (28. Juni 1877). 2. Eine eben solche typische zwischen Solowetzky-Inseln und Kem, $35^{\circ} 25^{\circ} \mathrm{ö}$. L., an der Tiefe von 12 Faden, steiniger Boden, an Hydroiden. 3. Der Onega-Busen, unweit Kem, bei der Insel Kiljakoff, an der Tiefe von 5 Faden, schlammiger Boden (5. Juli 1876), an einem Hydroide (varietas longipes). 4. Onega-Busen, seine stidöstliche Kuiste, an der Tiefe von 12 Faden, Boden schlammig und steinig, an einer rothen Alge (10. Juli 1876). 5. Im Weissen Meere zwischen Morschowetz und Ponoi, an der Tiefe von 20 Faden, Boden-Gerölle, an Sertularia abietina (28. Juni 1876).

Ist von Clap. und $\mathrm{Lachm}$. in Norwegen, unweit Christiania, gefunden.

Ausserdem fand ich einige Exemplare derselben Art auf einem Grönländischen Eudendrium sitzend. Der Stiel des Körpers war fast ganz unmerklich, er sass unmittelbar auf einer ovalen Anschwellung, der Stiel der Schale war sehr kurz. Die sämmtliche Länge des Thierchens $=0,094^{\prime \prime \prime}$, die grösste Breite $=0,0352^{\prime \prime \prime}$.

Cothurnia arcuata, nova species.

Taf. X, Fig. 8, 8a.

Die Schale ist eylindrisch, bogenförmig gekrimmt, so dass 
ihre runde Mtundung in einer schiefen, zur Körperaxe geneigten Fläche sich befindet. Ihre Oberfläche ist unglatt, wellig, darum auch der Contour wellig. Die Schale ist mittels eines kurzen Stieles befestigt, der annähernd ein Drittel der Körperlänge beträgt. Unten erweitert sich der Stiel kegelförmig und damit wird er an fremde Gegenstände befestigt. Der Körper selbst hat eine birnförmige, verlängerte Gestalt (d. h. im Zustande der Contraction, und nur in solche hatte ich Gelegenheit das Thierchen zu beobachten), mit einem kleinen Zapfen am Gipfel. Nach unten verengert er sich allmählich und befestigt sich endlich an den Boden der Schale ohne Vermittlung eines eigentlichen Stieles. Auf der Taf. X Fig. 8a ist ein Bild dargestellt, das bei starker Vergrösserung hervortritt. Die dicke Schalenwand wird gleichsam von einem Säulchen durchsetzt, das entweder eine Fortsetzung des Körpers, oder eine Art kurzen Stiel vorstellt. Das Stielchen aber der Schale selbst, wie es dieselbe Zeichnung deutlich macht, erweitert sich gar nicht nach oben und wird scharf rom kurzen Säulchen geschieden. Die Schale ist farblos. Die Länge der Schale ohne Stiel $=0,06$ ", die Breite derselben $=0,025^{\prime \prime \prime}$, die Länge des Stieles $=0,012^{\prime \prime \prime}$.

Ich beobachtete diese Art nur in einem einzigen Exemplare.

Fundort: Weisses Meer, Solowetzky-Inseln, Kloster-Bucht, an der Küste.

Torticella Pyrum, nov. sp.

Taf. X, Fig. 31, 32.

Der Körper dieser eigenthtümlichen Vorticelle besteht aus einem birnförmigen, oben stark angeschwollenen, nach unten rasch sich verengernden Theile und einem kurzen und breiten Cylinderchen, das dem ersten aufsitzt und ein ziemlich enges und gar nicht umgebogenes Peristom bildet. Der Form nach ist sie Epistylis coarctata, Cl., Lach. sehr ähnlich ${ }^{1}$ ). Das eben erwähnte Cylinderchen trägt oben einen Büschel Wimperhaare. Der Körper ist an der ganzen Oberfläche ziemlich deutlich quer gestreift; die Cutieula, obwohl diunn, ist doch, dank ihrem doppelten Contour, deutlich sichtbar. Der Inhalt besteht, ausser feinen Körnchen, noch aus einer grossen Zahl Fetttropfen, die nicht nur den $\mathrm{Nu}$ -

1) Claparède et Lachmann. Etudes etc. P. I., p. 113. 
cleus, sondern auch die Vacuole selbst zu beobachten hindern. Bei der Contraction des Thieres, wird das cylindrische Röhrchen hineingezogen, der Körper aber selbst behält seine birnförmige Gestalt, nur zieht er sich etwas zusammen, folglich sich der Kugelform ein wenig nähernd. Der Stiel ist verhältnissmässig ziemlich dick, sein Muskel ist breit und bietet nur wenige zickzackförmige Biegungen dar. Seine Länge ist unbedeutend; bei der Contraction legt er sich in Ringe zusammen. Die Länge des Thieres im Zustande der Contraction $=0,024^{\prime \prime \prime}$, die Länge des Stieles $=0,06^{\prime \prime \prime}$.

Diese Vorticelle, die ich in Meereswasser gefunden hatte, wird sehr leicht von allen übrigen durch ihren stark aufgeblähten, birnförmigen, oben mit einem kurzen Cylinderchen versehenen Körper unterschieden. Man trifft sie sehr oft, aber stets einzelweise.

Fundort: Solowetzky-Inseln, neben dem Kloster, auf Algen und Hydroiden, 21. Juni 1877.

\section{Zoothamnium marinum, n. sp.}

Taf. X, Fig. 36.

Diese Art ist die gewöhnlichste der Zoothamnien des Weissen Meeres, findet sich an Algen, Hydroiden und Bryozoen.

Die Körperform ist unregelmässig kegelförmig. Eine Seite (in Bezug auf den Stock - die innere) ist höher, so dass das Peristom zur Axe des Stammes schief gestellt ist, oder, mit andern Worten, beschreibt die Axe des Thieres einen Bogen.

Das Peristom ist wenig umgebogen, der Wimperdiscus desselben erhebt sich ziemlich hoch tiber dem letzteren; wenn das Thier sich contrahirt, so nimmt sein Gipfel entweder eine zugerundete Gestalt an, oder, falls die Zusammenziehung eine schwächere ist, bleibt dort noch ein enges Röhrchen übrig. Gewöhnlich schrumpft während der vollständigen Contraction das Körperparenchym am oberen Ende zusammen; es bildet sich hier eine Reihe regelmässiger Falten oder tiefer Runzeln, welche strahlenförmig von der Mitte einer kleinen Vertiefung ziehen, aus der noch zuweilen, wie oben erwähnt, ein kleines Röhrchen hervorragt. Diese Runzeln machen bei gewisser Lage des zusammengezogenen Thieres den Eindruck einer Reihe Zacken, die den oberen Rand des Körpers einfassen; 
doch liegen in Wirklichkeit keine Zacken, sondern nur Falten, im Profil betrachtet, vor. Der Oesophagus ist bei Z. marinum stark entwickelt, der Körper ganz glatt, ohne Streifen, der Inhalt feinkörnig. Der Nucleus ist nicht gross, regelmässig oval und neben dem Oesophagus, höher als die Mitte des Körpers, nahe der Wand des letzteren gelegen. Ein solcher nicht bandförmiger Nucleus unterscheidet ganz scharf die zu betrachtende Art von allen anderen benannten marinen Arten derselben Gattung und dadurch nähert sie sich auch etwas der Süsswasserform Z. Aselli. Der Stamm des Stockes ist lang, nicht gestreift und nicht gegliedert; er verästelt sich regelmässig dichotomisch, so dass der Stock meistens eine gerade Zahl Thiere und namentlich am öftesten 4, zuweilen 8, ein Mal sogar 12, trägt. Der Stielmuskel ist breit and hört nach unten sehr friih auf, so dass ein nicht unbeträchtlicher Theil des Stieles des letzteren entbehrt. Wenn Z. marinum in dem Jugendzustande nur aus einem einzigen Thiere besteht, so ist es durch kein Merkmal von Epistylis zu unterscheiden; dann können wir nur durch die Entwicklungsgeschichte oder den Vergleich mit ein wenig älteren Individuen, bei denen der Stiel aus einem muskellosen und einem anderen Theile besteht, die Täuschung vermeiden and uns überzeugen, dass wir mit keiner Epistylis, sondern mit einem Zoothamnium zu thun haben. Leider unterliess ich Messungen auszuführen.

Ich fand es sehr oft unweit der Solowetzky-Inseln pelagisch, auch ein Mal bei Sajatschy-(Hasen-)Inseln, an der Tiefe von 12 Faden, an Hydroiden (Campanularia, Sertularia).

Fundort: 1. Solowetzky-Inseln, an geringen Tiefen von 3 Faden, an ptilota, plumosa und pelagisch. 2. Sajatschy-Inseln, gegen Andrejewsky-Skit, an Hydroiden, an der Tiefe von 12 Faden, Grundsschlamm und Schalen. 3. Onega-Busen, bei Kiljaki (Inseln), unweit von Kem, Tiefe 5 Faden, Grundsschlamm, an Hydroiden (5. Juli 1876) ${ }^{1}$ ).

1) Obwohl ich aus dieser Lokalität das $Z$. marinum nur als Spiritusexemplar beobachtete, liess doch die Art der Verästelung, der Stiel, der Muskel, kurz - alle Merkmale keinem Zweifel Raum, dass uns die genannte Art vorläge, um so mehr, da ausser $\mathrm{ihr}$ im Weissen Meere nur noch Z. marinum vorkommt. Messung der Spiritusexemplare: Diameter des Thieres $=0,0535^{\prime \prime \prime}$; Breite des Stieles $=0,0094^{\prime \prime \prime}$. 
Epistylis Balanorum n. sp.

Taf. X, Fig. 37, und Taf. XI, Fig. 17.

Die Körperform ist cylindrisch, nach unten sich ein wenig allmählich verschmälernd (Taf. X, Fig. 37). Man kann in ihm den unteren grösseren Theil und den oberen oder die Krone unterscheiden. Der letztere wird von dem ersten durch eine ringförmige Einschnürung abgetheilt und besteht selbst aus vier Theilen oder Etagen. Die ersten drei Etagen stellen nichts anderes, als ziemlich dicke und breite Ringe vor, von denen zwei obere zum Wimperdiscus gehören und zwei Reihen Wimperhaare tragen, der dritte aber und untere Ring werden von dem leicht umgebogenen Peristom gebildet und tragen keine Borsten. Der oberste Theil des Trichters endlich besteht aus einem niedrigen Kegel mit breitem Grunde und gleich einem Dörnchen zugespitzten Gipfel. Wenn das Thier sich zusammenzieht (Taf. X, Fig. 17), so wird die Krone sammt dem Dörnchen ins Innere des Körpers hineingezogen und aussen bleibt nur die unterste Etage oder der Rand des Peristoms, welcher aber nicht umgebogen bleibt, sondern sich verengernd ein kleines Röhrchen oder Säulchen bildet, das niemals eingezogen wird. Das Parenchym, an den Rändern ziemlich durchsichtig, ist im Innern durch eine Menge feiner und gröberer Körner, sowie runder, stark lichtbrechender Kügelchen (wahrscheinlich Fetttropfen) getrübt. Ausserdem sind, wenn auch undeutlich und nicht zu jeder Zeit, grosse Kugeln, wahrscheinlich Nahrungsklümpchen sichtbar. Der Körper ist von einer deutlichen, doppelt conturirten Cuticula umgeben, keine Streifen sind an ihm bemerkbar. Im Innern, in der Mitte des Körpers, sieht man einen grossen, langen, bandförmigen Nucleus, der an den Enden ein wenig verbreitert, hufeisenförmig gebogen, und zur Körperaxe schief gelegen ist. Der Stiel ist ziemlich lang, von mässiger, an der ganzen Länge gleicher Breite, weder gegliedert, noch gestreift, ohne einen Centralcanal. Der Stock besteht aus nur wenigen Individuen und ist mehr oder weniger regelmässig dichotomisch verästelt.

Die Länge eines Stockes aus zwei Individuen $=0,15^{\prime \prime \prime}$; die Länge des Thieres im ausgestreckten Zustande $=0,051^{\prime \prime \prime}$, die grösste Breite $=0,027^{\prime \prime \prime}$, die Breite des Stieles $=0,001^{\prime \prime \prime}$.

Diesem ausserordentlich schönen Thierchen begegnet man 
massenhaft, aber ausschliesslich an den Kiemen der Balanen, wo es zuerst von Pr. Wagner bemerkt wurde, der es mir zur Untersuchung uberliess. Von da an fanden wir es mehrmals.

Ihrem kegelförmigen Dorne nach steht diese Art der E. umbillicata Clap. Lachm. ${ }^{1}$ ) nahe, die von ihm and d'Udekem im süssen Wasser gefunden war $^{2}$ ). Bei- dieser Gelegenheit will ich bemerken, dass es mir auch im Onega-See gelungen ist, eine Epistylis mit langem Körper, kurzem verzweigten Stiele and einem Gipfeldorne zu finden; leider war es mir nicht möglich, diese Form näher zu untersuchen und ihre Art zu bestimmen.

Fundort: Umgebung der Solowetzky-Inseln, an den Kiemen der Ktisten-Balanen, in Fülle.

\section{Tintinnus Ussowi, n. sp. \\ Taf. X, Fig. 40 .}

Ziemlich oft ist mit. T. inquilinus im Weissen Meere eine höchst schöne und elegante Form zu finden, die ich Dr. M. Ussow zu Ehren Tintinnus Ussowi nenne.

Der Form nach ist die Schale sehr beträchtlich verlängert und ihre Breite verhältnissmässig unbedeutend, so dass das Verhältniss der grössten Breite zur Länge nur $1 / 13$ ausmacht. Beim ersten Anblick scheint die Schale an dem grössten Theile ihrer Länge einen ganz regelmässigen Cylinder zu bilden, der unten in einen zugespitzten, kegelförmigen Dorn ausläuft; doch verhalten sich in Wirklichkeit die Dinge anders, namentlich ist der Diameter am obern Ende etwas grösser, als am unteren, im Verhältniss von $6: 5$, so dass die Schale keinen regelmässigen Cylinder, sondern einen regelmässigen, stark ausgezogenen Kegel darstellt. Am unteren Ende verengert sich die Schale ziemlich rasch und läuft dann in einen sich sehr allmählich verjüngenden kegelförmigen Dorn aus, der am Ende zugespitzt ist und eine Fortsetzung der Schalenaxe vorstellt. Der obere Theil aber der Schale, etwa ein Drittel derselben, zeigt höchst zierliche, regelmässig geordnete Ringe, die von kleinen Zähnen und mit diesen alternirenden runden Ausschnitten gebildet werden. Solche wegen der Feinheit und Regelmässig-

1) Etudes etc. p. 13, Pl. VII, Fig. 7.

2) d'Udekem. Description des Infusoires de la Belgique. Mém. de l'Acad. de Belg. 1862. 
keit der Zähne höchst elegante Ringe giebt es etwa 12-15, nicht mehr; die Ringe, die dem Ende näher sind, sind auch mehr ausgebildet, mit längeren Zähnen, tieferen Einschnitten und kleineren Abständen zwischen einander, während an den hintersten Ringen die Zähne sehr schlecht entwickelt sind. Die Ränder der Mündung sind ein wenig nach aussen umgebogen, und da jeder Ring nur die Stelle der frïheren Mündung bezeichnet, die ebenso ein wenig umgebogen war, so sind auch die Ränder der Schalenmündung, dort wo die Ringe sich befinden, ein wenig gekerbt. Die Schale ist ganz durchsichtig und farblos.

Was das Thier selbst betrifft, so unterscheidet es die Form gar nicht rom $\mathrm{T}$. inquilinus: wir begegnen hier derselben Cylinderform, die oben abgeschnitten und mit Wimperhaaren versehen ist, unten aber in einen Kegel ibergeht, durch welchen der Körper sich mit dem Stiele vereinigt; der Stiel hat dieselbe Form und ebenso befestigt er sich nicht am Boden der Schale, sondern an ihrer Seitenwand, ungefähr an der Stelle, wo die Schale sich zum untern Kegel verengert. Dies sah ich bei allen, ziemlich zahlreichen Exemplaren, die mir zur Beobachtung kamen.

Wegen der ungewöhnlichen Länge der Schale und des verhältnissmässig kleinen Stieles kann das Thier aus der Schale nach aussen sich nicht entfalten, und somit ist ihm die Bewegung anch unmöglich geworden. So glaube ich den Umstand erklären zu müssen, dass es mir niemals treischwimmenden Exemplaren zu begegnen gelang, - alle, die ich beobachtete, blieben, sich zum höchst möglichen Grade ausstreckend, dennoch ganz ohne Bewegung liegen; doch erzeugten sie im Wasser eine ziemlich starke Strömung, die ihnen Nahrungsmaterial zuführte. Nachdem ich mir also durch Claparède's und Lachmann's Beschreibungen die Tintinnen als sich blitzschnell bewegende Thiere vorstellte, war ich höchst überrascht, als ich zwei Arten in grosser Fülle fand, die unter dem Mikroskope ganz unbeweglich lagen. Diese Art steht ohne Zweifel dem Tintinnus subulatus am nächsten, der auch verlängert und am oberen Ende mit Ringen verseben ist; aber T. Ussowi unterscheidet sich von diesem, abgesehen von der allgemeinen Form, die ein wenig conisch ist, vornehmlich dadurch, dass die Ringe zierlich gekerbt sind; dies bietet ein sehr scharfes und constantes Merkmal dar, da ich es an allen Exemplaren beobachtete; ausserdem kommen noch die etwas umgebogenen Ränder 
der Mündung hinzu. Also steht es fest, dass T. subulatus, der im Baltischen Meere und an den Norwegischen Küsten wohnt, sich im kälteren Weissen Meere veränderte und die constante Art T. Ussowi lieferte.

Die Länge der Schale $=0,225^{\prime \prime}$, die Länge des Schwanzes mit dem unteren Kegel $=0,036^{\prime \prime}$, die Breite im oberen Theile $=$ 0,018“', und im unteren (früher als er in den Kegel übergeht) $0,015^{\prime \prime}$. Der Abstand zwischen den Ringen gleicht im Durchschnitt $=0,0054^{\prime \prime \prime}$. Die Länge $=0,06^{\prime \prime \prime}$.

Fundort: Weisses Meer, Solowetzky-Inseln, Kloster-Bucht, an der Küste, zwischen den Algen (Enteromorpha intestinalis und andere), in Menge, Sommer 1877.

\section{Oxytricha Wrzesniowskii, n. sp.}

Taf. X, Fig. 35.

Der Körper ist länglich-eiförmig, das hintere Ende zugerundet und ein wenig breiter, als das vordere, das mehr zugespitzt und kaum merklich links gebogen ist. Das Peristom zieht oben, an der linken Seite des Körpers, und erreicht fast die Mitte desselben, unter der Gestalt eines ziemlich breiten Spaltes, der unten zugerundet endet und zwei Biegungen bildet, von denen die obere links, die untere nach der entgegengesetzten Seite gewendet ist.

Die Stirnborsten, die ich nicht zählte (doch scheint ihre Zahl etwa $6 \mathrm{zu}$ erreichen), sind nicht sehr gross und liegen unregelmässig. Die Bauchborsten bilden mit den Randborsten zusammen 4 Reihen, die ungefähr an gleicher Höhe anfangen und bis zu dem untersten Ende herabsteigen. Die äusserste linke Reihe beginnt neben der Mitte des Körpers sich allmählich zu verlängern und so, sich immer verlängernd, gelangt sie bis zum unteren Ende, welches sich umbiegt, um die andere Seite zu erreichen. Am äussersten Körperende sind die Borsten sehr stark verlängert und bilden die sogen. Schwanzborsten; indem sie aber ganz allmählich in die linken Randborsten übergehen, von denen sie sich nicht scharf unterscheiden, ist es ganz unmöglich, ihre Zahl genau anzugeben.

Der Inhalt ist sehwach körnig, durchsichtig und farblos, ansser zwei gelben Kügelchen, die, wie ich glaube, für Nuclei zu halten sind. Die Bewegungen sind sehr langsam und unbedeutend. Die Länge des Thieres $=0,01^{\prime \prime}$. 
Oxytricha Wrzesniowskii begegnet man sehr oft im Weissen Meere, zwischen den Algen, und sie unterscheidet sich scharf von anderen Arten durch ihr langes, bis zur Mitte des Körpers reichendes Peristom, durch ihre zwei Reihen Bauchborsten and die Abwesenheit von scharf abgesonderten Schwanzborsten.

Der specifische Namen dieses Infusoriums ist Herrn Pr. August Wrzesniowsky in. Warschau, dem bekannten Infusorienkenner, der so wesentlich unsere Kenntnisse von diesen Thieren förderte, zu Ehren gegeben.

Fundort: Weisses Meer, Solowetzky-Inseln, Kloster-Bucht, zwischen den Algen, in nicht ganz frischem Wasser, in Fülle (im Sommer 1877).

Oxytricha oculata, n. sp.

Taf. X, Fig. 9, 10.

Die Körperform ist ziemlich variabel, doch ist die am meisten typische umgekehrt eiförmig oder birnförmig. Das hintere Ende ist viel enger als die Mitte und das obere Ende und läuft in einen kurzen, an der Spitze zugerundeten Schwanz aus. Aber zuweilen giebt es keinen solchen, und dann ist der Körper mehr weniger oval oder eiförmig. Von der Seite angesehen (Taf. X, Fig. 10) ist das Thier immer etwas bogenförmig gekrïmmt und hat einen convexen, buckligen Rücken. Das Peristom ist sehr kurz, reicht nur bis zum Drittel der Länge, ist nach rechts gerichtet und am Ende nicht zugerundet.

Die Stirnborsten, die ich nicht gezählt habe (doch scheinen sie etwa in Vierzahl vorhanden zu sein), sind nicht stark entwickelt; die Bauchborsten, in zwei Reihen, beginnen hoch oben, mit zwei Reihen Seiten- oder Randborsten, und erreichen das untere Ende. Von diesen 4 Reihen beginnt die äusserste neben der Mitte des Körpers sich zu verlängern und da, wo sie das untere Körperende umbiegt, erreichen die Borsten die grösste Länge und so bilden sie etwa 5 undeutlich abgegrenzte Schwanzborsten, die nach rechts gerichtet sind.

Das am meisten bei unserem Infusorium characteristische ist eben das Merkmal, dass an beiden Körperenden, in der Mitte derselben, sich ein „Augenkreis" bemerken lässt, der ganz dem von Ox. pellionella, abgesehen von der Abwesenheit des bei der letzteren ihn tragenden Pigmentfleckes, oder auch dem der Actinotricha 
saltans $\left.\operatorname{Cohn}{ }^{1}\right)$ ähnlich ist. Zuweilen, wenn auch seltener, wird nur ein "Auge" bemerkt. Die Bewegungen sind rasch, rastlos läuft sie an verschiedenen Gegenständén herum, niemals und nirgends stehen bleibend.

Der Inhalt besteht aus einer Menge Körner, die den Körper des Infusoriums ganz trüben.

Dieser Art, die noch einer näheren Untersuchung bedarf, begegnet man gleich oft und mit der ersten zusammen, von der sie aber, ausser der Körperform, sich leicht durch die Schnelligkeit der Bewegungen, zwei (oder ein) „Augen“ und das kurze Peristom unterscheidet. Zwei Reihen der Bauchborsten unterscheiden sie von Ox. pellionella. Sie steht ohne Zweifel der Ox. crassa Cl. Lach. nahe (Etudes p. 147, pl. VI, Fig. 7).

Fundort: Weisses Meer, Solowetzky-Inseln, Kloster-Bucht, an der Kiuste, in Menge (Juni und Juli 1877).

Epiclinthes auricularis Clap. Lachm., Stein.

Oxytricha auricularis Clap. et Lachm. Etudes, p. 148, pl. Epiclinthes auricularis Stein Infus. II. Abth. p. 150.

Taf. X, Fig. 16.

Diesem interessanten Thierchen begegnet man ziemlich oft im Weissen Meere. Zum ersten Mal war es von Claparède und Lachman $n$ beobachtet, die es unter dem Namen von $O x$. auricularis beschrieben. Später hat für dasselbe Stein in seinem bekannten Werke ein neues Genus Epiclinthes gegründet, nachdem er Gelegenheit hatte es im Baltischen Meere zu beobachten ${ }^{2}$ ). Da meine Zeichnungen und Noten nicht vollständig mit den Stein'schen übereinstimmen, so führe ich etwas ausführlicher das an, was mir hinsichtlich dieses Infusoriums zu beobachten gelang. Der Körper ist ausserordentlich verlängert und besteht aus drei deutlich geschiedenen Theilen: der vorderste (Taf: X, Fig. 16), der ein Viertel der Gesammtlänge ausmacht, besteht aus einem breiten Bande oder einer zusammengedrïckten Platte, welche am Ende abgestutzt und

1) Cohn. Neue Infusorien aus d. Seeaquar. Zeit. f. wiss. Z. XVI. 1866. p. 283, Fig. 24-26.

2) Früher noch begründete er diese Gattung im amtlichen Berichte der 37. Versammlung deutsch. Naturf. und Aerzte in Carlsbad, im September 1862, p. 162 und ausführlicher beschrieb er dieselbe in den Sitzungsber. der königl. Böhmischen Gesellschaft der Wissenschaften. 1864. S. 44-46. 
ein wenig nach dem Peristom gebogen ist. Der mittlere Theil, der ein wenig breiter und der Länge nach dem dritten oder Schwanztheile gleich ist, ist dicker als die beiden anderen, aufgebläht, indem er einen convexen, ovalen Körper bildet, der auch dann deutlich hervortritt, wenn das Thier dem Banche aufliegt; nur hier sind Nahrung und Körner bemerkbar. Der dritte Theil endlich der Schwanz - ist fast zweimal so lang als der erste, aber viel schmäler, ist auch zusammengedritckt, bandförmig und am Ende auch abgestutzt. Die Mundborsten und der Mundspalt beginnen an der Grenze des mittleren und vorderen bandförmigen Theiles und gehen dem Rande parallel, unter der Gestalt eines engen Spaltes. Der letztere ist unten zugerundet und bildet spiralige oder hakenförmige Biegungeu. Die Mundborsten aber, wenn sie den oberen Theil erreichen, biegen sich auf die andere Seite des Vordertheils um und gehen sebr weit herunter, bis zu seiner halben Länge. Sehr in die Augen springend sind besondere Stäbchen oder an den Enden zugerundete Säulchen, die in einer Reihe jederseits an den äussersten Körperrändern ziehen. Die linke Reihe beginnt fast von oben an, die rechte aber etwas niedriger, dicht am Orte, wo die Mundborsten aufhören (Taf. X, Fig. 16); also beginnen beide am vorderen, bandförmigen Theile und erreichen das äusserste Ende des Schwanzbandes. Ohne Zweifel übersahen Claparède und Lachmann dieselben an den meisten Körpertheilen, ausser dem Schwanze. Diese Säulehen sind ganz unbeweglich und stehen ziemlich dicht nebeneinander. An dem vorderen, bandförmigen Theile zählte ich nicht 3 (Stein), sondern 5 (oder 6) schiefe Borstenreihen, welche sich auch auf die Bauchseite fortsetzen, wo ihre Zahl bis 9 steigt. Je näher dem Schwanze, desto minder schief wird die Richtung der Borstenreihen und endlich gehen die 5 Reihen auf den Schwanz über, einander schon ganz parallel. Von diesen vergrössert sich immer die äusserste linke, indem sie sich scharf von den iibrigen trennt; die rechte Reihe aber verlängert sich nur am Ende, zugleich biegt sie sich um und umgiebt das ganze bintere Ende, wo die Borsten schon beträchtlich verlängert sind. In der Seitenansicht schien es mir, als ob der Schwanz am äussersten Ende nach oben umbiege, einen ziemlich grossen Haken bildend. Die Bewegungen des Thieres sind äusserst reissend und scheu; sein Temperament ist so zu sagen höchst nervös und reizbar, der Körper ist contractil, darum ist es schwer zu beobachten. 
Die Länge des Thieres = ungerähr $0,25 \%$.

Den späteren Beobachtern bleibt es zu entscheiden, ob die Differenzen meiner und der Stein'schen Beschreibung anf eine Ungenauigkeit der Beobachtung, oder auf das Vorkommen von zwei Species zurückzuführen sind.

Fundort: Weisses Meer, Solowetzky-Inseln, Kloster-Bucht, zwischen den Algen, ziemlich viel (10. Juli 1877). Nach Claparède und Lachmann-Bergen, Sertorä, ausserdem noch das Baltische Meer (Lieberkthhn, Stein-Wismar).

43. Urostyla Weissei Stein, nova varietas.

Oxytricha Urostyla Clap. et Lachm. Etudes. p. 141. pl. V. Fig. 2. Urostyla Weissei Stein. Infus. I. Abth. p. 192. T. XIII. Fig. 1-4.

Einige Exemplare dieser ziemlich seltenen Art fand ich im Onega-See. Alles, ausser den Bauchborsten, stimmt genan mit Stein's Beschreibung und Abbildungen iberein. Mit grosser Klarheit und Genauigkeit konnte ich ihrer 6 Reihen zählen, während nach Stein dieselben nur in Fünfzahl stehen sollen. Solch eine leichte Veränderung bei derselben Art ist wohl geeignet einige Zweifel uber den Werth dieses Characters als eines generischen Merkmals zu erheben.

Fundort: Onega-See, Powenetz, eine Bucht mit iuppiger Vegetation, wenig (27. Juli). West-Europa.

\section{Aspidisca Andreewi, n. sp.}

Taf. X, Fig. 42.

Die Körperform ist länglich rund, das untere Ende ist etwas breiter und runder als das obere; die rechte Seite ist convex, die linke etwas concav, besonders aber im oberen Drittel, so dass das obere Körperende gleichwie geneigt und nach links gebogen erscheint. Am unteren Ende, dem linken Rande etwas näher, bemerkt man einen dreieckigen oder herzförmigen Lappen, dessen Ende aber niemals den Körperrand überragt. Dem ganzen Körper entlang bemerkt man ziemlich scharf 6 Rippen verlaufen, und nur ausserhalb derselben, zwischen den ätussersten und dem Körperrande, werden Nahrungskörner angehäuft, das Innere aber des Körpers ist ganz durchsichtig, farb- und körnerlos, und nur selten findet man hier zerstreute, stark lichtbrechende Tropfen (ob Fett?). Die sieben Bauchborsten unterscheiden sich durch ihre Breite und Weichheit und sind in zwei Reihen, zu je 3 und 4, geordnet.

Aber am meisten für dieses Infusorium charakteristisch sind 
seine 6 hinteren Borsten ${ }^{1}$ ), davon 4 rechts von dem herzförmigen Lappen, zwei links von demselben Es hat mehrere Vacuolen von verschiedener Grösse; eine davon ist gewöhnlich grösser, andere 2-3 etwas kleiner. Einst beobachtete ich nur eine einzige bogenförmige Vacuole, die aber nach der Contraction als drei kleinere wieder erschien. Die Bewegungen sind langsam, meist steht das Thier bewegungslos an demselben Orte.

Die Länge $=0,025^{\prime \prime \prime}$, die Breite $=0,0195^{\prime \prime \prime}$; einmal traf ich ein Exemplar an, das 0,045"' lang war.

Dieses Infusorium ist eines der gewöhnlichsten im Weissen Meere und, da seine Bewegungen höchst langsam sind, so war es mir möglich, alle seine Eigenthümlichkeiten genau zu untersuchen. Davon ist am meisten dies charakteristisch, dass es immer nur 6 Schwanzborsten zeigt und daher diese Art also als ein Verbindungsglied zwischen den beiden Subgenera Aspidiscus, sensu strictiori und Onychaspis ${ }^{2}$ ) erscheint; eben darum macht sie ganz unmöglich die Zertrennung des Aspidiscus in zwei Genera, sich nur auf die Zahl der Schwanzborsten stiitzend, wie es Stein vermuthet, wenn er schreibt: „eine Art dieser Gattung (A. polystyla) entfernt sich jedoch nicht unerheblich von den iibrigen Arten, sie wird vielleicht später als eine besondere Gattung abgesondert werden (“3).

Den Namen gebe ich dieser neuen Form dem Herrn Arzte N. Andrejew zu Ehren, der uns 1876 als Gehiulfe des Herrn Prof. Wagner begleitete und neben den Umgebungen der SolowetzkyInseln eine reiche zoologische Collection gesammelt hat.

Fundort: Weisses Meer, Solowetzky-Inseln, Kloster-Bucht, an der Küste, zwischen den Algen etc., in grosser Menge (im Sommer 1877).

Sehr leicht kann es geschehen, dass auch A. polystyla im Weissen Meere sich begegnen werde. Ausserdem habe ich eine Zeichnung einer Aspidisca, bei der an der linken Körperseite, unten, der Körperrand von einem breiten, kegelförmigen Dorn überragt wird; bei ihr giebt es 5 Schwanz- und 7 Bauchborsten, die

1) Eine andere Species von Aspidisca, gleichfalls mit 6 Borten, ist die Aspidisca, sedigita Quen. s. Quennerstedt Bidrag till Sveriges Infusoriefauna II. Lunds Univ. Årsskrift. Tom. IV p. 30, pl. II, Fig. 2-3.

2) Stein, Infusorien I. Abth. p. 125.

3) Stein 1. c p. 121. 
auch sehr breit sind; im allgemeinen erinnert sie an Aspidisca leptaspis Fresenius 1), obwohl ich mit Sicherheit die beiden Arten nicht identificiren kann.

\section{Balantidium (?) Medusarum, n. sp. Taf. X, Fig. 11.}

Die Körperform ist ziemlich mannigfaltig, doch am gewöhnlichsten oval, mit dem hinteren zugerundeten und dem vorderen zugespitzten und von links nach rechts schief abgestutzten Ende. Zuweilen ist der Körper in der Mitte etwas aufgebläht und dann ist die Form fast eiförmig, zuweilen aber ist derselbe im Gegentheil sehr verlängert und verhältnissmässig schmal and cylindrisch. Im Querschnitte erscheint er fast vollkommen rund. Das Peristom liegt fast genau in der Mitte des Körpers, ein wenig nach rechts geschoben und erscheint als ein ziemlich breiter Spalt, der nach unten, wo er ein wenig nach links gewendet ist, sich allmählich verengert und fast die Mitte des Körpers erreicht. Die adoralen Wimpern sind ziemlich gut entwickelt und sitzen am linken Peristomrande; sie sind gar nicht länger als die Körperwimpern, aber viel dicker, kräftiger und dichter geordnet. Was die den ganzen Körper bekleidenden Wimpern betrifft, so unterscheiden sie sich durch ihre sehr beträchtliche Länge, sind aber sehr los und überall gleich, d. h. in Längsreihen, geordnet; diesem letzten Umstande verdankt wahrscheinlich der Körper seine Längsstreifung. Ausser dieser Längsstreifung ist zuweilen noch eine schwächere Querstreifung bemerkbar, doch sieht man zuweilen (und es geschieht sogar öfter als das Gegentheil) Nichts davon.

Der Körperinhalt ist gewöhnlich farblos und unbedeutend, so dass der Körper ziemlich durchsichtig erscheint; doch wird er zuweilen von einer Menge glänzender, runder Körperchen erfïllt, die das Thier ganz undurchsichtig machen. Gewöhnlich bemerkt man zwei contractile Behälter, die am hintersten Ende gelegen sind; übrigens fand ich gar nicht selten Exemplare, bei denen nur eine einzige pulsirende Vacuole vorkam, so dass die Zahl derselben unconstant zu sein scheint. Der ganz runde Nucleus liegt genau in der Mitte des Körpers, dicht unter dem Ende des Peristoms.

1) Fresenius. Die Infusorien des Seeaquariums. Zool. Garten, 1865, VI. Jahrg., Nr. 4 (April), p. 123. 
Die Länge des Thieres $=0,016^{\prime \prime \prime}-0,02^{\prime \prime \prime}$.

Ich beobachtete eine Conjugation zweier Individuen, die dieselbe vermittelst der Vorderende eingingen, auch Quertheilung.

Dieses interessante Infusorium ist wahrhaft das gewöhnlichste des Weissen Meeres. Es lebt vorwiegend in kleinen Medusen (Eucope-Obelia flabellata, Bougainvillia und anderen), in deren Magen und sogar in den radialen Canälen; ausserdem ist sie in den Eingeweiden eines Ringelwurmes (Brada) in sehr grosser Menge gefunden.

Keiner einzigen Meduse kann man begegnen, in der man dieses Thier nicht findet, dabei noch zuweilen in grosser Menge. Nicht selten geht es auch nach Aussen, ins Wasser, heraus und schwimmt hier, wie es scheint, ebenso munter wie im Innern der Meduse umher, so dass im vorliegenden Falle wahrscheinlich die Abhängigkeit des Parasiten von seinem Wirthe nicht in einem solchen Grade besteht, wie es bei den in Amphibien lebenden Süsswasser-Balantidien $\mathrm{zu}$ beobachten ist.

2. Juli 1877 hat Herr Prof. Wagner, indem er eine Brada zergliederte, eine ihrer Drüsen ganz von Infusorien vollgestopft gefunden. Er iibergab mir die letzteren zur Untersuchung und sie erwiesen sich als Balantidium Medusarum (später wurde sie nochmals in Brada gefunden). Ibre Bewegungen sind ziemlich langsam, Am nächsten steht diese Art dem B. Entozoon, unterscheidet sich aber sowohl durch die Körperform, als auch besonders durch ihre eigenthümlichen langen und losen Borsten, durch zwei Vacuolen, runden Nucleus, die Länge des Peristoms und endlich durch ihren Aufenthaltsort.

Fundort: Weisses Meer, Solowetzky-Inseln, in Medusen und Würmern (Brada), in sehr grosser Menge (im Sommer 1877).

\section{Glaucoma Wrzesniowskii, n. sp.}

Taf. X, Fig. 27, 27b.

Die Körperform ist zuweilen regelmässig oval, zuweilen eiförmig, nach hinten etwas verbreitert, nach vorn verengert, zuweilen ist umgekehrt der breitere Theil hinten, der schmälere vorn, d. h. dass die Form umgekehrt eiförmig wird. Ausserdem ist das Vorderende fast immer schief von rechts nach links abgestutzt. Die den ganzen Körper bedeckenden Wimperhaare sind 
kurz und ganz dicht, in Längsreihen geordnet, so dass die Körperoberfläche leicht längsgestreift erscheint. Zwei Lippen, die in dem Mitteltheile des Körpers etwas nach links geschoben sich befinden, sind sehr deutlich zu sehen; sie flimmern lebhaft und stehen fast senkrecht zur Körperoberfäche, indem sie einen engen Spalt begrenzen (Fig. 27b, f). Um die Lippen herum bemerkt man einen ovalen lichten Ring oder einen Saum (Fig. 27b, m), ohne jegliche Körner oder andersartige Körperchen, scharf von dem tibrigen Parenchym gesondert und mit einer ziemlich deutlichen, concentrischen Streifung (Taf. X, Fig. 27b). Es bleibt, so glaube ich, keinem $Z$ weifel Raum, dass dieses helle Feld oder der ovale Ring einen Theil des Parenchyms vorstellt, der speciell zum Zusammenklappen oder Bewegung der Lippen sich anpasste, dass er also gewissermassen einen Sphincter darstellt, natiirlich nicht aus echten Muskelelementen oder Zellen bestehend, sondern nur in der oben erwähnten Streifung sich kundgebend.

Der Nucleus liegt als eine regelmässige, ovale Bildung auch im Vordertheile des Körpers, etwas linksseitig; ferner befindet sich auch unweit davon, unter den Lippen, eine kleine contractile Vacnole.

Am meisten aber ist für dieses Infusorium die ungeheure Menge stäbchenförmiger Trichocysten characteristisch, die die ganze Körperoberfläche bekleiden, zu der sie senkrecht geordnet und ganz den Trichocysten der Paramaecien z. B. ähnlich sind. Sie sind an den Rändern, im optischen Durchschnitt, sehr deutlich als Stäbchen sichtbar, die in dem Parenchym liegen und den Contour des Thierchens fein-wellig machen. Bei der Hebung des Mikroskopes, so dass die Oberfläche des Infusoriums in den Brennpunkt desselben kommt, sieht man die Trichocysten von oben als kleine glänzende, stark lichtbrechende Kreise, die vollkommen regelmässig auf der ganzen Oberfläche geordnet sind; den Ausschluss bildet nur jener helle, die Lippen umgebende Saum, wo diese Gebilde gänzlich fehlen.

Im Innern des Körpers bemerkt man Diatomeen, Nahrungskörnchen, die vorwiegend im hinteren Körperende sich anhänfen, und damit erklärt sich wahrscheinlich, warum das letztgenannte Ende immer dunkel, zuweilen ganz schwarz erscheint. Die Bewegungen unterscheiden auch gut diese Art von den ubrigen Glaucomen: sie sind höchst langsam und eher stellen sie nur geringe Umdrehungen an demselben Orte, als Herumschwimmen vor. 
Die Länge $=0,068^{\prime \prime \prime}-0,09^{\prime \prime \prime}$; bei der letzten Länge ist die Breite $=0,045^{\prime \prime \prime}$.

Die am meisten also in die Augen springende Eigenthulmlichkeit der Gl. Wrzesniowskii sind ihre Trichocysten, ein Merkmal, das den uibrigen bekannten Arten der Gattung fehlt. Dann veranlassten mich auch übrige Merkmale für dieses Thier eine neue Art aufzustellen, die ich Herrn Pr. Wrzesniowsky zu Ehren, der so wesentlich unsere Kenntnisse sowohl uber die Infusorien im Allgemeinen, als auch über die der russischen Fauna insbesondere förderte, benenne.

Fundort: 1) Nördliche Dwina, etwas nach Sïden von dem Dorfe Beresniki, in einem Tumpel neben dem Flusse, in Menge (11. Juni 1877). 2) Onega-See, Powenez, in einer Bucht mit ippiger Vegetation.

Ausserdem muss ich erwähnen, dass ich im Meere (SolowetzkyInseln) noch ein Infusorinm mit zwei Lippen beobachtete, offenbar eine Glaucoma; ob es aber G. scintillans oder eine besondere marine Art wäre, das wage ich nicht zu entscheiden, da ich diese Form, die mir übrigens nur ein Mal zur Beobachtung vorkam, nicht näher untersuchte.

\section{Holophrya Kessleri n. sp. \\ Taf. X, Fig. 29, 30.}

Die Körperform ist oval, nicht zusammengedrückt, im Allgemeinen etwas variabel und inconstant. Man begegnet zuweilen Exemplaren, bei denen das Vorderende etwas breiter als das Hinterende ist, ähnlich $H$. discolor Ehr.; zuweilen fallen die Verhältnisse auch umgekehrt aus, das Hinterende mehr zugerundet, breiter, also sich der Eiform nähernd.

Eine kleine runde Oeffnung, die am Körperpole sich befindet, ist auf einem kurzen, kaum bemerkbaren Rohre oder am verengerten Körperende gelegen. Die ganze Körperoberfläche ist mit deutlichen, längslaufenden und dicht nebeneinander stehenden Rippen bedeckt, darum erseheint der Körper, wenn das Thier vertical steht, am Umfange stark gekerbt (Taf. X, Fig. 30). An der zur Ansicht kommenden Körperhälfte kann man etwa 12-15 Rippen zählen, im ganzen giebt es deren also 25-30. Die Oberfläche wird von sehr kleinen und dicht stehenden Wimpern, die iberall gleich lang sind, bekleidet. 
Der Nucleus liegt ungefähr in der Mitte des Körpers, etwas höher. Der Gestalt nach ist er ziemlich dick, hufeisenförmig oder bogenförmig, mit ein wenig angeschwollenen Enden, und nach der Längsaxe des Körpers, aber etwas schief, gestellt. Eine ziemlich grosse contractile Vacuole liegt im äussersten Hinterende. Ausserdem bemerkt man noch im Innern des Körpers gelbliche Körper und Körnchen.

Der Körper ist ziemlich durchsichtig und farblos oder etwas gelblich, er ist biegsam, aber nicht contractil, die Rippen also sind mit dem festen, unbiegsamen, aus Kieseltheilchen bestehenden Skelete der Gattung Coleps nicht zu vergleichen; im vorliegenden Falle stellen die Rippen nur eine einfache Verdichtung der Cuticula vor.

Die Bewegungen sind äusserst langsam und bestehen ausser dem Fortschreiten und Umdrehungen am Orte, auch noch aus einem Rotiren um die Axe, das doch zuweilen unterbleiben kann.

Die Lünge des Thieres in Wologda $=0,069^{\prime \prime \prime}$, die Breite $0,024^{\prime \prime \prime}$, im Onega-See ist die Maximallänge $=0,09^{\prime \prime}$, die Breite $=0,045^{\prime \prime}$.

Dieses interessante Infusionsthierchen unterscheidet sich von allen ubrigen Arten der Gattung Holophrya durch die Gestalt des Nucleus, besonders aber durch die eigenthümlichen Rippen, die in Längsreihen den ganzen Körper einem scheinbaren Skelette ähnlich bedecken. Dieser Umstand veranlasste mich anfangs H. Kessleri für einen Coleps zu halten; aber die Biegsamkeit ihres Körpers, die zum Vorschein kommt, wenn sie durch einen engen Raum sich durchdrängt, zeigte mir soeben, dass es sich um eine Holophrya handelt.

Ich benenne so dieses Thier dem hochverehrten Herrn Prof. Kessler za Ehren.

Fundort: 1. Wologda, ein Graben mit Pflanzen und nicht faulem Wasser; am Boden, im Schlamme und Sande, ziemlich viel (4. Juni 1877); 2. Onega-See, bei der Stadt Powenetz, Flussmündung mit uippiger Vegetation (27. Juli 1877).

\section{Podophrya cylindrica Perty.}

Taf. XI, Fig. 16.

Pod. cylindrica Perty, Zur K. d. kb Leb. p. 160, pl. VIII, f. 9.

Seit diese Art von Perty in der Schweiz gefunden und beschrieben war, sah dieselbe noch Niemand zum zweiten Male; 
darum halte ich es nicht für überflüssig, diese Art von Neuem za beschreiben und eine bessere Abbildung zu geben.

Die Körperform ist im Allgemeinen eine cylindrische, verlïngerte und davon rührt die Artbenennung her. Doch ist sie ziemlich variabel und mannigfaltig. Das obere und untere Ende sind immer zugerundet und zuweilen ist das untere ein wenig breiter, so dass die Gesammtform etwas kegelförmig wird (Fig. 28). Das Verhältniss der Länge zur Breite kann auch varïren, wie es Fig. 28 und 16, Taf. XI zeigen. Die Contouren sind entweder glatt oder wellig, mit Einschnürungen (Taf. XI, Fig. 16).

Der ganze Körper ist von einer ziemlich dünnen Cuticula bedeckt, die doch von zwei Contouren begrenzt ist. Der Stiel ist immer kurz, kegelfölmig, oben breiter als unten und mit dem Körper symmetrisch vereinigt, d. h. an der Mitte des unteren Endes, nicht an der Seite desselben befestigt, wie es Perty zeichnet. Die Saugröhren, um das ganze obere Körperende zerstreut, können sich sehr stark ausstrecken und sind dann am Ende mit einem deatlichen Knopf versehen; einst aber sah ich sie im $\mathrm{Zu}$ stande der Contraction, dann waren die Knöpfe nicht bemerkbar (Fig. 28).

Der Inhalt ist, wie gewöhnlich, körnig und wenig durchsichtig; in der Mitte des Körpers ist ein lïnglich-ovaler Nucleus sichtbar, der nach der Längsaxe des Körpers gerichtet ist; Perty spricht nicht davon. Die Vacuolen sah ich nicht.

Ich begegnete diesem, wie es scheint, sehr seltenen Acinetine in meinem Aquarium, dessen Wasser aus den Jelagin'schen Teichen stammte, auf Lemna und dazu noch ziemlich oft.

Fundort: S. Petersburg, Aquarium, auf Lemna, ziemlich oft (December 1876).

\section{Podophrya (Acineta) conipes, n. sp. Taf. X, Fig. 39 und Taf. XI, Fig. 15.}

Die Körperform ist unregelmässig kuglig, nach unten ein wenig ausgezogen and verengert, mit einer unebenen höckrigen Oberfläche. Der Körperinhalt besteht aus einem körnigen, undurchsichtigen, gelblich-braunen Plasma und aus einem ovalen, ziemlich grossen Nucleus, der ebenso wie die Vacuole nicht symmetrisch, d. h. nicht in der Mitte des Körpers, gelegen ist. Die Saugröhren gehen von der sämmtlichen Körperoberfläche oder, wie 
bei jungen Individuen, von seiner oberen Hälfte, ab; sie sind ein wenig länger, als der Körper, ziemlich dick und am Ende mit einer trichterförmigen Erweiterung versehen, mittelst welcher sie sich an die Beute ansaugen (Taf. X, Fig. 39a). Der Körper sitzt auf einem Stiele, der immer sehr lang und an seinem oberen Ende, wo er sich mit dem Körper vereinigt, sehr beträchtlich erweitert ist; hier aber steht seine Breite der des Körpers nur sehr wenig. nach, in jungen Individuen sind sogar beide gleich breit (Taf. $\mathrm{X}$, Fig. 39).

Von oben an beginnend verengert sich der Stiel allmählich und gleichmässig bis zum Grunde, wo er schon bedeutend enger als oben ist. Dies Verhältniss zwischen der Breite des Stieles am oberen und unteren Ende ist verschieden: zuweilen ist der Grund zwei Mal enger als das obere Ende, zuweilen fünf Mal, nicht selten noch mehr, 8-10 Mal.

So entsteht ein umgedrehter, sehr ausgezogener Kegel, der ausserdem noch niemals ganz gerade, sondern immer mehr oder weniger geschlängelt, bogenförmig gekrümmt ist.

Eine andere Eigenthümlichkeit des Stieles dieser Art besteht darin, dass er sehr fein quergestreilt ist. Diese Querstreifung ist bei schwächeren Vergrösserungen nicht bemerkbar, da die Streifen zu zart sind und zu nahe nebeneinander verlaufen; doch genügt schon Hartnack's Syst. VII, um die quer durch den Stiel ziehenden dünnen, parallel und regelmässig georlneten Streifen zu bemerken, die den ganzen Stiel gleichwie auf ebenso diinne, gleiche, ubereinanderliegende Scheibehen theilen. Zuweilen sind die Querstreifen höchst dentlich sichtbar, indem sie dem Stiele quer aufsitzenden Ringen gleichen (Taf. XI, Fig. 15a', $a^{\prime \prime}$ ).

Solche Form und Structur des Stieles ist bei diesem Thiere im Weissen Meere höchst constant und ich beobachtete sie an vielen Individuen, jungen und alten, ohne jegliche Abänderung. Also kann die beschriebene Art für eine bona species gelten, die für das Weisse Meer, vielleicht auch für polare Meere im Allgemeinen charakteristisch ist.

Was die Form des Stieles betrifft, so wird sie sehr leicht verständlich, wenn man ältere Individuen mit jüngeren vergleicht. Bei den letzteren sehen wir, dass die geringe Breite des oberen Theiles des Stieles der des Körpers selbst gleich ist; also wird der Stiel von der ganzen hinteren Körperfläche abgesondert und 
eben darum wird die Breite des Stieles ganz von der Breite des Körpers abhängen; je grösser die letztere ist, desto breiter wird auch der Stiel sein. Im ausgewachsenen Zustande wird der Stiel auch fast von der ganzen hinteren Körperfäche abgesondert. So wie aber im jungen Zustande der Acinetenkörper klein ist, so ist auch die absondernde hintere Fläche klein, darum auch die Breite des Stiels gering; da andererseits nach der Maassgabe der Nahrung und des Wachsthums des Thieres sich auch der Hintertheil vergrössert, so wird in demselben Verhältnisse sich auch der ab. zusondernde Stiel erweitern; es versteht sich von selbst, dass gleichmässiges Wachsthum auch einen sich gleichmässig erweiternden, d. h. kegelförmigen Stiel liefern wird. Wenn also wir uns eine Linie denken, die den Stiel nach der Längsrichtung halbirt, so wird die von einem seiner Ränder gebildete Curve den Gang des Wachsthums des Körpers selbst ausdrücken. Von demselben Standpunkt aus wird auch die Bildung der auf dem Stiele sitzenden und dessen vorübergehende Erweiterung anzeigenden Ringe verstïndlich: sie müssen ihren Ursprung einer eben solchen vorübergehenden Erweiterung des Körpers verdanken, die ihrerseits wahrscheinlich durch Aufnahme einer grossen Nahrungsmenge, z. B. durch Fang einer grossen Beute verursacht werden könnte.

Was die feinen Streifen, die am Stiele bemerkbar sind, betrifft, so ist es höchst wahrscheinlich, dass sie in Folge einer gewissen Periodicität des Wachsthums entstehen, die durch den Tagund Nacht-Wechse] bedingt werden soll; diese Vermuthung wird sowohl durch ihren geringen Abstand, als anch durch ihre grosse Zahl (mehr als 100) bestätigt, die, falls wir uns nicht irren, der Zahl der Tage im Leben des Infusoriums entsprechen. Dann würde uns die Form und der Bau des Stieles die ganze Geschichte, alle Ereignisse im Leben jedes Infusoriums zeigen: auf der Taf. XI F'ig. 15 z. B., sehen wir, wie viel Tage dies Infusorium lebte (der Zahl der Streifen nach), wie breit der Körper in den rerschiedenen Epochen ihres Lebens war (der Breite des Stieles nach); dieselbe Fig. zeigt z. B., dass am hundertsten Tage von der Geburt an es ihr gliickte, eine ungemein grosse Beute $\mathrm{zu}$ fangen, dass dasselbe sich nach 2, 3 Tagen wiederholte (nach den zwei Ringen), dass die Vergrösserung des Körpers weiter ganz gleich- und regelmässig ging. Dies alles werden leicht die künftigen Forscher durch Versuche entscheiden; ich aber konnte es, des Zeitmangels wegen, nicht thun. 
Podophrya conipes hat ohne Zweifel viel Aebnlichkeit mit P. Lyngbyi Ehr., die von Claparède und Lachmann in Nord-Norwegen beobachtet wurde; ohne Zweifel befinden sich beide Arten in einem ganz nahen genetischen Zusammenhange mit einander. Die Art des Weissen Meeres unterscheidet sich: 1. durch ihren kegelförmigen, nicht cylindrischen Stiel; 2. durch die Querstreifung desselben, die von Claparède und Lachmann, so geiibten Forschern, bei P. Lyngbyi nicht gesehen wurde.

Diese Acinete begegnete uns und nicht selten in grosser Menge auf rothen Algen (Ptilota plumosa, Ceraminm u. and.). Es ist eine der gewöhnlichsten und am meisten für polare Meere characteristischen Formen und wenn wir ihre unzweifelhafte verwandtschaftliche Beziehung zu A. Lyngbyi erwägen, so wird uns klar sein, dass auch Infusorien sich dem Einflusse der äusseren Bedingungen ebensowenig, wie andere Thiergruppen, entziehen, da so unweit von einander abstehende MLeere wie der nördliche Theil des Norwegischen einerseits und das wegen der Abwesenheit des Golfstroms mehr polare, kïltere Weisse Meer anderseits ilıre eigenen, obwohl einander nahestehenden Arten besitzen. Dasselbe sahen wir an T. Ussowi, der offenbar dem T. subulatus nahe steht, obwohl er gleichzeitig eine bona species vorstellt. Diesen zwei Thatsachen lege ich ein grosses Gervicht in der Entscheidung der mich interessirenden zoogeographischen Frage vow Einflusse der äusseren Bedingungen auf die Infusorienfaune bei. Sie scheinen mir ganz unzweifelhaft darzuthun, dass eine Art (Ac. Lyngbyi und T. subuIatus) beim Uebergange von einem Meere ins andere, mit dem ersten benachbarte, aber durch andere Bedingungen, wie kälteres Wasser z. B., sich unterscheidende, sich dem Einflusse dieser neuen Bedingungen unterordne und eine neue locale Art (Ac. conipes und T. Ussowi) gebe.

Die Länge des Thieres schwankt meistens zwischen 0,05 “' und $0,08^{\prime \prime}$.

Fundort: Solowetzky-Inseln, unweit der Kloster-Bucht, SO von Pesja Lada; Grund-Steine, viele Spongien und rothe Algen, Tiefe 8 Faden, sehr viel an Algen und Hydroiden (19. Juni 1877). Auch in anderen Orten, an geringen Tiefen (1877). 
Acincta mystacina Ehr., n. var.

Acineta mystacina Stein. Infus. Entw. 1859. pl. I. Fig. 14-20. Acineta mystacina Clap. und Lach. Etudes, Partie I, p. 387, P. I, p. 123.

Taf. X. Fig. 26.

In den Petersburger Gewässern begegnete ich einer Varietät der Ac. mystacina, die sich durch die ungewöhnliche Länge ihres Stieles, der die Körperlänge 5-7 Mal iubertrifft, unterscheidet. Diese Varietät, welche man Var. longipes nennen könnte, fand ich in grossen Mengen auf Lemna und Ceratophyllum sitzend, während ich der gewöhnlichen Form kein einziges Mal begegnete. In allen uibrigen Verhältnissen unterscheidet sie sich gar nicht von der typischen Ac. mystacina.

Die Gesammtlänge des Thieres . . . . $0,68^{\prime \prime \prime}$.

Die Länge des Stieles . . . . . . $0,6^{\prime \prime \prime}$.

Die Breite desselben . . . . . . . 0,028“".

Die Breite des Köpfehens . . . .. . 0,082“".

Nördlicher fand ich diese Acinete nur noch im Weliky-Ustjug, wo die Gesammtlänge nur $0,09^{\prime \prime}$, die Breite aber des Köpfchens 0,045" ausmachte; also lag hier die normale typische Form vor.

Fundort: 1. Petersburg, Jelaginsche Teiche, (im Aquarium) auf Pflanzen, Lemna und Ceratophyllum, in grosser Menge, im Winter 1876, Varietas longipes; 2. Weliky-Ustjug, im Teiche des Stadtgartens, auf den Lemna-Wurzeln, in grosser Menge (8.Juni 1877).

\section{Dinophysis arctica, n. sp.}

Taf. XI, Fig. 19.

Diese Art unterscheidet sich der Form nach gar nicht oder nur sehr wenig von den nahestehenden Arten, insbesondere D. laevis. Doch existirt ein Unterschied in der Sculptur der Oberfläche: Bei D. laevis ist dieselbe ganz glatt, während sie bei der Art des Weissen Meeres chagrinartig und mit sehr feinen und regelmässig geordneten Pünktchen bedeckt ist; solche Merkmale dienen zur Artenunterscheidung in dieser Gattung. Auch ist der Seitenfortsatz von etwas anderer Form und grösser als bei $D$. laevis, von welcher letzterer unsere Art auch durch ihre geringere Grösse abweicht. Ihre Länge nämlich übertrifft nicht $0,036 \mathrm{~mm}$, wäh- 
rend bei D. laevis sie $0,05^{\prime \prime \prime}$ ausmacht. Der Körperinhalt besteht meistens aus ziemlich grossen und unregelmässigen Körnern von gelblichbrauner Farbe, die vorwiegend den Rand einnehmen, so dass die Mitte des Körpers farblos und undurchsichtig ist. Hier eben sind am deutlichsten jene feinen, regelmässig geordneten Höckerchen, denen die Haut ihr chagrinartiges Aussehen verdankt, sichtbar. Was das Hälschen betrifft, so kann man auf ihm auch an einer Seite denselben diagonalen Streifen sehen, der bei D. laevis an der entsprechenden Stelle zieht.

Fundort: Weisses Meer, pelagisch, 21. Juni (nur ein Mal).

\section{Die Familie Uvellina mihi.}

Die Natürlichkeit dieser Familie scheint mir ausser Zweifel zu stehen. Sie enthält solche colonialen Monadinen, die aus Individuen bestehen, die mit einer oder mehr Wimpern versehen sind, nicht in chitinigen Bechern sitzen, zuweilen von einer für alle gemeinsamen Schleimmasse eingehüllt und miteinander nicht in Gestalt von verästelten Stöcken, sondern von Kugeln oder kugelförmigen Massen vereinigt sind, die meistens, mit dem Ausschluss nur der Gattung Anthophysa, die voribergehend an einem Stiele angeheftet ist, im Wasser frei schwimmen.

Alle hierher gehörenden Formen sind als ein Uebergang von einzelligen zu mehrzelligen Organismen, als jetztlebende Morulae zu betrachten, die die höheren vielzelligen Formen als ein Stadium ihrer individuellen Entwicklung durchlaufen. In der That ist die Analogie zwischen der Theilung eines die Kolonie bildenden Individuums und der Segmentation irgend eines mehrzelligen Individuums nicht abzuweisen "), ebenso ist die Analogie zwischen dem vollkommen ausgewachsenen Stocke und dem Mornlastadium desselben mehrzelligen Organismus nicht zu übersehen. Aber es giebt eine Form, die zu unserer Familie nicht gehört, die Monadine Polytoma uvella, und bei ihr sehen wir ein Stadium der Entwicklung, das um Nichts von einer echten Uvelline oder Morula abweicht, die aber nachher in ganz mit dem Mutterorganismus ähnliche Einzelwesen zerfällt.

1) Grimm, Beitrüge zur Kenntniss der Protozoen, 1877 p. 63 (in russischer Sprache). Höchst interessant sind seine Beobachtungen über die Segmentation der Parcella lamprosa Grimm. 
Diese Erscheinung deutet darauf an, dass sowohl Pol. uvella als wahrscheinlich viele andere Monadinen aus der Familie Uvelina entstanden sind, und zwar durch Aufhebung des Zusammenhanges, durch den die Einzeltheile hier zu einem Ganzen vereint sind, d. h. durch den Zerfall des Stockes in Einzelheiten, ähnlich wie es bei Entstehung der Pflanzen ans uvellenartigen Thieren geschah, wie ich es vor kurzem zu begründen versucht habe $\mathfrak{l}$ ).

Jetzt bin ich im Stande Folgendes zu behaupten. Jede successive Theilung einer Eizelle oder Cytode erst in 2, dann in 4 u. s. w. Theile betrachte ich als eine mit der Segmentation des Eies irgend eines mehrzelligen Organismus homologe Erscheinung. Und wie im Eie dieser Vorgang nichts anderes, als einen Uebergang von der Einzelligkeit zur Mehrzelligkeit darstellt, ebenso sehe ich iiberall, wo eine successive Theilung in 2, dann in $4 \mathrm{u}$. s. w. Theile vorliegt, eine Tendenz, die gelingen kann, wie es z. B. bei der Entwicklung aller vielzelligen Thiere oder andersartiger Pflanzen, z. B. Volvox globator, Pandorina, Eudorina u. s. w. geschieht; oder umgekehrt bleibt die genannte Tendenz ganz ohne Erfolg, so dass unmittelbar nach solcher Segmentation die einzelnen Segmente auseinander fallen und aus jedem bildet sich ein neues Individuum, wie wir es bei allen Pflanzen und einigen Monadinen, z. B. Polytoma uvella, sehen. Andere Monadinen endlich, und zwar die Familie der Uvellinen, bieten uns die mittlere Stufe dar, und namentlich desshalb, weil während des grösseren Lebenstheiles die Segmente mehr oder weniger mit einander verbunden bleiben und das selbstständige Leben jedes Einzeltheiles als selbstständigen Individuums nur verhältnissmässig kurze Zeit dauert.

Jede Thierart aus der Protozoengruppe, die eine Fähigkeit zu solcher successiven, an die Segmentation eines Eies erinnernden Theilung besitzt, stellt entweder die Folge einer ehemaligen Mehrzelligkeit derselben, die in Folge aus irgend welcher Ursache entstandener Verminderung des Zusammenhanges zwischen den Einzel-Segmenten aufgehoben war, demnach ein Ergebniss des Riickschrittes vor, oder umgekehrt ist es ein Anfang des Fortschrittes, eine Form also, die in den Zustand eines mehrzelligen Organismus überzugehen vorhat, also ein Rückstand jener längst verflossenen Epoche,

1) S. Protokoll der Sitzung der Zoologischen Section der Petersburger Yaturforscher-Gesellschaft, 8. Oktober 1877. 
in welchcr alle höheren Thiere als solche unbestimmte Colonien von Einzelindividuen existirten, die jeden Moment zum Zerfall bereit waren, wenn der Zusammenhang nur allmählich sich verstärkte, und wenn ebenso allmählich der Charakter der Colonie einzelliger Individuen sich änderte und in den eines mehrzelligen Individuums taberging. Solche Ueberbleibsel finden wir heute auch von den Amöben, Moneren und theils von den Häckel'schen Physemarien erhalten. Wenn aber alles wirklich so geschah, wenn die allmähliche Theilung wirklich dies bedeuten soll, so wäre zu erwarten, dass solche Thiere wie Moneren, die in ihrer Entwicklung sogar die Stufe einer Amöbe oder eines Eies nicht erreichten, uns keineswegs successive Theilungen in 2, 4, 8 u. s. w. Theile, kurz - die Erscheinungen der Segmentation darbieten sollen. Dies folgt wohl daraus, dass ein solcher Vorgang bei der Monere auf keinem der oben erwähnten Wege Statt finden konnte, weder durch Vererbung von mehrzelligen Vorfahren, denn solche giebt es bei ihr nicht, noch durch die progressive Tendenz von der Einzelligkeit zur Mehrzelligkeit überzugehen, da der Monere noch der lange und schwierige Weg -- der Uebergang von der Cytode zur Zelle - also sich einen Kern zu erwerben, bevorsteht. Und wirklich, wie es meiner Anschauung nach sein sollte, so eben verhalten sich die Dinge - die Moneren bieten niemals eine Segmentation dar. Der Vorgang aber, durch den eine ganze Monere in Theile zerfällt, ist höchst interessant und hat, wie es mir scheint, bisher noch die ibm gebührende Beachtung nicht gefunden. Bei allen Moneren geht die Theilung nicht allmählich vor siçh, sondern ihr Körper zerfällt plötzlich und gleichzeitig in mehrere Theile.

Wenn Cienkowsky in seinem bekannten Aufsatze ïber die Monaden die Theilung des Inbaltes bei verschiedenen Vampyrellen bespricht, so erwähnt er nirgends ausdricklich, dass bei ihnen die Theilung allmählich, zuerst in 2, dann in 4 Theile vor sich gehe; seine Ausdrucksweise ist im Gegentheil ziemlich unbestimmt und zwar soll sie bedeuten, dass man beobachten könne, wie der Inhalt in 2-4 Theile zerfalle, d. h. es kommen zum Vorsehein $2-4 T^{T}$ eile $\mathrm{e}^{\mathrm{l}}$. Bei Vampyrella pendula Cienk.

1) Cienkowsky, Beiträge zur Kenntniss der Monaden. Arch. f. mikr. Anat. 1865. B. I. p. 221 u. 222, Fig. 60 u. 67. 
z. B. "zerfällt (der Inhalt) in 2-4 Theile", wie er selbst schreibt; dasselbe gilt seinen Worten nach auch für V. Spirogyrae Cnk. Also kann man glauben, wie es auch an den Zeichnungen sichtbar ist, dass der Inhalt gleichzeitig in 2-4 Theile zerfalle. Häckel gibt in seiner "Monographie der Moneren" 1 ) von Vampyrella an: „der eingekapselte ruhende Körper zerfällt erst in 2, dann in 4 Theile, " aber dieses "erst" hat er selbst hinzugefiugt und durch weitere Untersuchungen an V. Gomphonematis $\mathrm{H}$. als unzutreffend erwiesen. So bei der Gelegenheit der Fortpflanzung dieser Monere schreibt Häcke1:?) „Neben diesen ganz mit Protoplasma erfüllten Blasen finden sich andere, bei denen die ganze Protoplasma-Füllung in vier gleiche Theile zerfallen ist. Dies sind die Tetrasporen, welche Cienkowsky anch bei seinen drei Vampyrellaarten beobachtet hat. Sie scheinen alle vier gleichzeitig zu entstehen, indem vier gleichweit von einander und vom Centrum der Kugel entfernte Protoplasmapunkte als Anziehungsmittelpunkte auf die umgebende Substanz wirken. Diese verdichtet sich dabei und presst eine geringe Quantität einer hellen Flissigkeit aus, die nunmehr die vier Plasmasporen von einander trennt. Wenigstens habe ich bei der Vantpyrella Gomphonematis niemals gesehen, dass die Plasmakugel erst bloss in zwei Stücke zerfiele, die sich dann nochmals halbiren." Offenbar, scheint es mir, theilt sich Vampyrella in 2-4 Theile gleichzeitig. Ich werde keine Citate aus Haeckel's Beobachtungen über Protomyxa auranticas ${ }^{3}$, Myxastrum radians ${ }^{4}$ ) und Protomonas Huxleyi ${ }^{5}$ ) anfuibren, wo der Inhalt gleichzeitig in viele Hunderte kleine Sporen zerfällt, von denen jede zu einem Organismus auswächst. Dieselbe Beobachtung war unlängst ron 0 . Grimm an seiner neuen Art, Protomyxa viridana Gr., bestätigt. „Der ganze Inhalt der Cyste," schreibt er ${ }^{6}$ ), „zerfällt gleichzeitig, wenigstens an der Peripherie, in eine Menge gesonderter Klümpchen, deren Zahl annähernd 200 erreicht."

Aus allem oben angeführten geht ohne Zweifel hervor, dass bei den Moneren Nichts an die Segmentation eines Eies erinnert.

1) Biol. Stud. I. Heft. 1870. p. 72.

2) 1. c. p. 165 .

3) l. c. p. 24.

4) I. c. p. 35 .

5) 1. c. p. 172 .

6) Grimm, Beiträge zur Kenntniss der Protozoen (russisch), 1877. 
Also kann man fir die Theilung jeder Plastide zwei Typen aufstellen:

I. Einc allmähliche Theilung der Plastide, erst in 2, dann in 4 u. s. w. Theile; dies ist die Segmentation s. str.

Ir. Eine gleichreitige Theilung derselben in mehr oder weniger Theile.

Die erste Art wird niemals bei den Moneren beobachtet, kommt aber nicht selten bei den einzelligen Monadinen, bei der Mehrzahl der Pflanzen und bei allen vielzelligen Organismen vor.

Also stehen offenbar jene Monadinen, die anfangs eine Tendenz zur Bildung einer mehrzelligen Colonie und dann, durch näluere Vereinigung der Einzelindividuen, eines ganzen, vielzelligen selbstständigen Individuums zeigen, höher als jene, die keine Spur solcher Tendenz darbieten und sich durch Segmentation nicht vervielfältigen.

Dieser Standpunkt ist für die Systematik der Monadinen sehr wichtig, da man die einzelligen Arten zunächst in eine solche Gruppe, die durch den Zerfall von mehrzelligen Organismen entstiinde, und in eine andere, in der die Einzelligkeit eine primäre Erscheinung, die folglich älter sei. Ebeh darum muss man die Entwicklungsgeschichte der Mehrzahl der Monadinen möglichst vollständig untersuchen.

Polytoma uvella Ehr.

Polytoma uvella. Ehr. Infus. p. 24, pl. I, Fig. $3_{2}$.

Taf. X, Fig. 19-25.

Diese interessante Monadine hat, wie bekannt zwei ziemlich lange und äusserst dünne Geisseln. Die Körperform ist regelmässig oval (Fig. 18), es giebt bei ihr keine äussere Membran wie es A. Schneider annimmt. Der vordere Körpertheil stellt vorwiegend eine contractile Partie vor, die fur verschiedenartige Bewegungen bestimmt ist: hier befindet sich eine oder mehrere pulsirende Vacuolen von verschiedener Grösse, die vorwiegend an der Peripherie des Körpers liegen, hier eben heftet sich die Geissel an den Körper an. Die hintere Hälfte stellt aber vorwiegend eine so zu sagen trophische Partie vor, da hier ausschliesslich sich Nahrungstheilehen und Körner anhäufen, die stark lichtbrechend sind (Fett?), während die vordere Hälfte ganz durchsichtig, farblos ist und kein einziges Körnchen enthält; hier befindet sich auch der runde Kern, von einem hellen Ringe umgeben. 
Besonders ist die Fortpflanzung der Monadine interessant. Sie theilt sich zuerst quer oder schief (Fig. 19, 20) in 2 Hälften, in 2 Segmente, dann ohne ihr schnelles Herumschwimmen zu unterbrechen, theilt sich jede Hälfte nochmals in 2 Theile (Fig. 21), welche nicht selten (immer?) eine sehr verlängerte, ovale Gestalt haben (Fig. 22), endlich entsteht aus den 4 Segmenten, durch weitere Theilung, ein Complex von 8 Abtheilungen, die eine kugelförmige Colonie - eine echte Morula - bilden (s. Fig. 23). Nach kurzer Zeit erhält jedes Segment kurze Wimpern, und dann unterscheidet sich die Colonie gar nicht von irgend welcher Uvella. Dieser Umstand beweist folglich, dass unsere Monadine jemals als ein den jetzt lebenden Uvellen ähnlicher Organismus existirte, und aus diesem dureh Zerfall der Colonie in Einzelindividuen entstand; dass der Unterschied also zwischen ihr und der Uvella darin besteht, dass bei der letzteren das Colonialstadium eine persistirende Erscheinung, während für Polytoma Uvella dasselbe nur eine rasch vortibergehende Entwicklungsstufe, und dass für sie vielmehr die besondere Existenz jedes Einzelindividuums eine normale, constante Erscheinung darstellt. Also kann darüber kein Zweifel bleiben, dass diese einzellige Monadine das Resultat des Zerfalles einer mehrzelligen Colonie darstellt; und in der That beginnt sehr rasch, nur einige Minuten nach der Bildung der achttheiligen Kugel, jedes Segment, schon mit einer Wimper versehen, aus der Gesammtmasse sich zu entfernen und ganz gleich dem Mutterorganismus zu schwimmen (s. Fig. 24).

Höchst wahrscheinlich bieten viele einzellige Monadinen ') dasselbe mehrzellige Stadium, dieselbe Tendenz einen mehrzelligen Organismus zu bilden, dar; doch scheitert diese Tendenz wegen des unzureichenden Zusammenhanges zwischen den einzelnen Segmenten.

Falls die Erscheinungen sich wirklich so verhalten, so muss die Classifikation, wie ich schon oben erwähnte, zunächst auf diese letzteren ihre Aufmerksamkeit lenken.

Wenn man eine grosse Individuenzahl dieser Monadine durchmustert, so kann man sehen wie sie zuweilen stehen bleiben, sich mit ihrer Spitze an den Objectträger oder an das Deckgläschen anheften und nach einiger Zeit sich mit einer ziemlich dicken

1) Siehe z. B. Schneider Beit. z. Nt. d. Infus. Müll. Arch. 1854 über Chlorogonium euchlorum. 
Cyste umgeben (s. Fig. 25); das weitere Schicksal dieser Cyste konnte ich nicht verfolgen, doch veranlassen mich Cienkowsky's Beobachtungen ${ }^{1}$ ) an andern Monadinen zur Annahme, dass diese Encystirung zum Sçhutz von Austrocknung dient und dass bei gïnstigen Bedingungen die Monadine durch einen Spalt aus der Cyste ausschlüpft, um ihr Leben wie früher fortzusetzen.

Fundort: Petersburg, in einer Heu-Infusion.

\section{Astasia guttula mihi.}

Astasia inflata, Fromentel Etudes p. 313. pl. XXIII, Fig. 34.

Die unter dem Namen von Astasia inflata Duj. bei Fromentel beschriebene Form stellt gar nicht Dujardin's Art vor, die durch eine ziemlich constante, ovale Form und deutliche Streifung der Körperoberflïche charakterisirt wird, während bei A. guttula keine Spur davon existirt und die Körperform höchst verinderlich, die Consistenz sehr fliussig ist, das Thier besteht nur aus einem von einem festeren Ueberzuge umschlossenen Plasmatropfen. Offenbar hat Fromentel weder die Zeichnung gesehen, (die ansserdem bei ihm noch nicht richtig eitirt wird), noch hat er die darauf bezïgliche Beschreibung gelesen. Der Inhalt dieser Monadine, die immer wenig durchsichtig, von gelblich-brauner Farbe ist, besteht aus vielen lichtbrechenden Körnern von verschiedener Grösse, von gelber Farbe oder farblos, die mir weder den Kern, noch die contractile Vacuole zu sehen erlaubten; doch sah die Vacuole Fromentel.

Diese Art gehört zu den sehr gewöhnlichen; ibre Bewegungen sind langsam, meist sind sie sogar nicht fortschreitend, sondern die ganze Monadine, die Stelle nicht ändernd, biegt und schlängelt sich auf verschiedenste Weise. Ihre Grösse ist bedeutend genug (sie ist grösser als Peranima cylindrica, die auch ziemlich oft gewöhnlich ist), die Geissel aber ist nicht lang, sehr dünn und höchst biegsam und thätig.

Ihr Diameter gleicht bei Powenetz beinahe 0,015".

Fundort: 1) Wologda, in einem Graben mit nicht ganz frischem Wasser und Pflanzen, viel (4. Juni 1877). 2) Onega-See bei Po-

1) Arch. f. Mikr. Anat. 1865. Bnd. I. 
wenetz, die Flussmündung mit reicher Vegetation (27. Juli 1877). 3) Petersburg, Jelaginsche Teiche, sehr oft (im Frubling 1877 und im Winter, im Aquarium).

Astasia deformis, Fromentel.

Astasia deformis. Fromentel, Etudes, p. 314, PI. XXIV, Fig. 21.

Taf. X, Fig. 32,

Aus der kurzen Beschreibung, die Fromentel giebt, ist nicht zu ermitteln, was für Fortsätze es seien, mit welchen der Körper der Monadine versehen ist. In Sumsky Possad gltickte es mir diese höchst interessante Monadine zu sehen, und dann stellte sich heraus, dass ihr ganzer Körper sich ganz nach Art einer Amöbe bewegt, indem er von der sämmtlichen Oberfläche kurze, kegelförmige Pseudopodien, sowohl wie die ziemlich lange, dunne und in der ganzen Ausdehnung biegsame Geissel aus- und einzieht. Im oberen Körpertheile bemerkt man einen ziemlich grossen, ovalen Kern, der sich durch sein dunkleres Aussehen unterscheidet; am hinteren Ende ist eine contractile Vacuole sichtbar, die energisch pulsirt. Der Körper selbst ist farblos, durchsichtig und enthält wenige kleine Körner. Keine fortschreitende Bewegung sah ich, ich beobachtete nur eine Oscillation an derselben Stelle, von der Bewegnng der Geissel verursacht; ausserdem geht eine continuirliche amöboide Bewegung vor sich, welche die Contouren des Körpers gleich wie bei einer Amöbe verändert.

Die Länge des einzigen Exemplars, das ich beobachtete, betrug ungefähr $0,015^{\prime \prime \prime}$.

Diese eigenthümliche Monadine ist insofern interessant, dass sie eine Uebergangsform zwisehen den Amöben und Monadinen vorstellt. Denn einerseits ist ihr Körper Fortsätze auszusenden und seine Form zu ändern befähigt, ganz den Amöben ähnlich, und ohne die Geissel kann sie als eine echte Amöbe betrachtet werden; andererseits hat sie eine Geissel, die ganz mit der bei allen Flagelaten vorkommenden identisch ist. Vielleicht wäre es nicht unpassend wegen solcher Beschaffenheit des Körpers sogar eine neue Gattung aufzustellen, zu der auch dann die aus einem amöbenähnlichen Körper mit einer langen Geissel am Vorderende bestehende Amöba monociliata Carter ${ }^{1}$ ) gehören

1) Carter. On Freschwater Rhizopoda of England and India. Annals and MIagazine of Natur. History. Vol. XIII. Number IXXIII. 1864. p. 21, pl. II, Fig. 19. 
sollte; aber diese unterscheidet sich von A. deformis Fr. dadurch, dass ihr Hinterende mit einer ziemlich grossen Zahl sehr kurzer Dörnchen oder Stäbchen versehen ist. Diese Art ist von Carter in den sïssen Gewässern Bombay's gefunden.

Jedenfalls stehen solche Arten sehr nahe der von Claparède und Lachmann aufgestellten Gattung Podomosta, bei der die Geissel eingezogen werden kann.

Merotricha bacillata. Nov. gen. et nov. sp.

Taf. X, Fig. 41.

Die Körperform ist regelmässig oval, nicht zusammengedrtickt; neben dem Vorderende ist eine kleine Vertiefung oder ein Grtibchen bemerkbar, von dessen Grunde sich eine lange, in der ganzen Ausdehnung biegsame Geissel erhebt. Der obere Pol enthält in dem Parenchym etwas kegelartig geordnete Stiibchen, die ziemlich glänzend und nebeneinander senkrecht zur Oberfläche gelegen sind. An anderen Körperstellen lassen sich solche Stäbchen gar nicht wahrnehmen. Diese Monadine ist tief grïn gefärbt und enthält ziemlich viele verlängerte Paramilkörperchen, die so gewöhnlich auch in anderen Monadinen und mit den lïngeren und regelmässig geordneten Stäbchen am oberen Körperende nicht zu verwechseln sind. Gerade unter dem Büschel dieser Stäbchen befindet sich die contractile Vacuole, die in der Mitte des Körpers gelegen ist; der Kern war unsichtbar wegen des undurchsichtigen Körperinhalts. Ich kann Nichts iuber die Bedeutung der sonderbaren Stäbchen angeben; vielleicht sind es Trichocysten.

Die seitliche Lage der Geissel, die aus einer besonderen Grube herausgeht, veranlasste mich für diese Form eine besondere Gattung aufzustellen; als Artmerkmal soll der Stäbchenbüschel des oberen Körperendes dienen, sowie die regelmässig ovale Form und die griine Farbe.

Ich fand dieses sonderbare Infusionsthier nur einmal, neben Powenetz, leider habe ich keine Messungen ausgefthrt.

Fundort: Onega-See, neben Powenetz, Flussmündung mit üppiger Vegetation (27. Juli 1877).

Euglena viridis, Müll., Ehr.

Euglena viridis Ehr., Infus., p. 108, PI. VII, Fig. 9. Englena viridis Dujardin, Hist. d. Infus. p. 361, Pl. VI, Fig. 9 et 19. Euglena viridis Fromentel, Etudes, p. 318, Pl. XXII, Taf. XI, Fig. 38 und 39. Fig. 6 et 7.

Diese schon längst und allgemein bekannte Monadine beob- 
achtete ich unter anderen in grosser Menge in Sumsky Possad, an der Ktiste des Onega-Busens des Weissen Meeres, in einem Stisswassertümpel, mit faulem Wasser und ohne Vegetation. Die Mehrzahl der Individuen schwamm rasch umber und war von auf Fig. 38, Taf. XI abgebildeter Körperform. Der ganze Inhalt mit Ausschluss des obersten Theiles war grtin und gleichmässig mit lebhaft gefärbten Paramilkörperchen erfüllt. Doch begegnete man ziemlich selten solchen Exemplaren, die sich durch äusserst langsame Bewegung auszeichneten; zugleich konnte man beobachten, dass bei ihnen (Fig. 38) der Schwanz oder Hintertheil des Körpers ganz farblos und dicht mit denselben Paramilkörperchen erfullt war, die bei den sich schnell bewegenden durch den ganzen Körpervertheilt waren, während sie bei jenen in andern Theilen ganz fehlten. Offenbar sammeln sie sich alle am Schwanzende. Endlich beobachtete ich noch ein weiteres Stadium, das in Fig. 39 abgebildet ist. Hier sieht man, dass eine Euglena sich mit einer Cyste umgeben hat, die mehr oder minder kugelförmig ist, ungefähr $0,015^{\prime \prime \prime}$ im Durchmesser hat und aus einer farblosen, doppelt conturirten Hulle besteht. Der Cysteninhalt ist grün gefärbt, feinkörnig, dabei aber formlos und nicht ganz den inneren Cystenraum erfullend; auch ist noch das rothe "Ange" deutlich wahrzunehmen (Fig. 39, oc.). Im Innern der Cyste, ihrer Wand angenähert, liegt ein fast allseitig von den grünen Ueberbleibseln der Euglene umgebenes kleineres Kügelchen, mit einer dünnen, einfach conturirten Hiulle (Fig. 39 a), in dessen Centrum sich ein anderes Kügelchen befindet, das nicht ganz den inneren Raum des ersteren ausfüllt und aus dicht aneinander liegenden Paramilkörnern (Fig. 39b) besteht; es sind dieselben Körner, die während des vorhergehenden Stadiums (Fig. 38) sich im Schwanze sammelten. Also ist es offenbar, dass unsere Merotricha während der Encystirung, ausserdem dass sie sich mit einer Hülle umgiebt, noch vorläufig die in ihrem Schwanze angehäuften Paramilkörner ausscheidet und sie mit einer besonderen Hülle versorgt. Was für eine Bedeutung und welch weiteres Schicksal dieselben haben, das alles war mir nicht möglich zu verfolgen.

Fundort: Von Wologda an, weiter nördlich längs der Nördlichen Dwina bis zu Arehangelsk, in grosser Menge, überall. Weiter nach Sumsky Possad (27. Juli 1877), Onega-See bei Powenetz und in St. Petersburg, Jelaginsehe Teiche. 
Urceolus Alenizini, nov. genus et nova species.

Taf. XI, Fig. 1, 2.

Die Körperform erinnert an eine Flasche mit verengertem cylindrischen, oben abgestutzten Hälschen. Der Körper selbst ist in der Mitte stark aufgebläht, dann verjtingt er sich allmählich nach hinten, um in ein kegelartiges, am Ende zugerundetes und mit dem Hälschen gleich langes Schwänzchen ỉberzugehen.

An der oberen, abgestutzten Fläche des Hälschens befindet sich eine weite runde Oeffnung. Das ist der Mund, der in einen Canal ubergeht. Dieser Canal oder Schlund zieht durch das ganze Hälschen, indem es sich allmühlich verjuingt und da, wo das Hälschen in den Körper übergeht, aufhört. Aus diesem Schlunde, von seinem Boden seitlich abgehend, ragt eine lange und dünne Geissel hervor, die am Grunde etwas dicker ist und dann sich allmählich verjünt. Nichts destoweniger ist die letztere an ihrer ganzen Ausdehnung beweglich, obwohl freilich der obere, dünnere Theil die Beweglichkeit im höheren Grade zeigt. Die Mundöffnung bleibt nicht immer so weit klaffend, wie es in der Fig. 1 abgebildet ist; zuweilen zieht sie sich zusammen (Fig. 2) und dann erscheint das Ende des Hälschens nicht abgestutzt, sondern zugerundet, aus der Mitte seine Geissel aussendend. Unter dem zusammengezogenen Munde bleibt doch immer der Schlund offen, indem die Schlundhöhle als ein Bläschen erscheint. Die Körperoberfläche ist mit einer dünnen, doppelt-conturirten Cuticula bedeckt. Der undurchsichtige Inhalt besteht aus feineren und gröberen Körnern und aus einer Menge grosser, stark lichtbrechender Tropfen (Fett?). Dies alles macht das Infusorium so undurchsichtig, dass ich weder den Kern, noch die Vacuole auszufinden vermochte.

Die Bewegungen dieser grossen Monadine sind langsam und gleichmässig; gleichzeitig mit der fortschreitenden Bewegung geht auch die Contraction und Formveränderung des Körpers selbst vor sich: bald verlängert sie sich etwas, bald zieht sie sich zusammen, und dann wird der Bauch noch mehr aufgebläht. Das Hälschen kann auch sich bogenförmig biegen und sich verlängern oder zusammenziehen. Doch sind alle diese Bewegungen unbeträchtlich, sie sind nicht im Stande die allgemeine Körperform zu verändern, die doch immer flaschenförmig bleibt.

Ich fand diese schöne Monadine nur einmal im Weissen Meere. Die Länge derselben $=0,039^{\prime \prime \prime}$, die grösste Breite $=0,024^{\prime \prime \prime}$. 
Ihre Form, namentlich aber die Eigenthümlichkeiten ihres Mundes, von dessen Boden eine Geissel abgeht, wird diese nene Gattung characterisiren. Ich war eine solche aufzustellen genöthigt, da ich diese Monadine zu keiner anderen zu zählen im Stande bin. Die specifischen Namen aber gebe ieh dem hochrerehrten Mag. Woldemar Alenizin zu Ehren.

Fundort: Weisses Meer, Solowetzky - Inseln, Kloster-Bucht, an der Oberfläche, zwischen den Conferven, sehr selten (18. Juli 1877).

\section{Heteromita sulcata, n. sp.}

Taf. XI, Fig. 12-14.

Die Körperform ist sehr mannigfaltig: entweder ist sie oval mit zugerundetem Hinterende, oder fast cylindrisch mit gerade abgestutztem Hinterende; das obere Ende ist immer schief abgestutzt. Die vordere Geissel ist entweder der Körperlänge gleich, oder übertrifft dieselbe ein wenig, die hintere dagegen ist kürzer als die vordere. Die Oberfläche ist durch ziemlich tiefe Furchen oder Striche gestreift; man sieht deren 3-4 auf der dem Beobachter zugekehrten Seite, welche ununterbrochen und einander parallel vom obern bis zum unteren Ende ziehen. Das obere Ende enthält eine ziemlich grosse und deutlich sichtbare contractile Vacuole, im unteren aber befinden sičh in grosser Menge Körner, von denen im oberen keine Spur zu bemerken ist. Das ist eine bei den Monadinen ziemlich allgemein verbreitete Erscheinung. Das Vorderende erscheint bei ihnen vorwiegend als Centrum aller motorischen, animalen Functionen, wie die Contraction der Vacuole, die Bewegung der Geissel; das hintere dagegen functionirt mehr als ein Organ vegetativen Lebens. Die Bewegungen sind gleichmässig unđ langsam.

Der Form nach kann man also Varietas ovata (Fig. 14) und truncąta (Fig. 13) unterscheiden, die in zwei ganz verschiedenen Localitäten gefunden waren. Ausserdem werde ich noch eine Heteromita erwähnen (Fig. 12), die ich mit der Var. ovata zusammen fand und die der letzteren sowohl der Form (das schief abgeschnittene Ende), als auch der Grösse der Geissel und Lagerung der Vacuole nach ganz ähnlich ist und sich nur durch vollständigen Mangel der Streifung unterscheidet; darum wage ich es nicht, dieselbe zu einer neuen Art zu rechnen and bin vielmehr sie entweder für eine besondere Varietas, die eine Uebergangsform 
von unserer Art zu anderen nicht gestreiften vorstelle, oder für eine junge, noch nicht vollständig entwickelte H. sulcata zu halten geneigt. Höchst wahrscheinlich ist die von Fromentel unter dem Namen von Plocotia vitrea Dujar. ${ }^{1}$ ) beschriebene Form eben unsere Heteromita; allenfalls stellt sie keineswegs die echte Dujardin'sche Ploc. vitrea ${ }^{2}$ ) vor, eine rein marine Art, die er dessenungeachtet citirt.

Fundort: Varietas truncata in Sumsky Possad, an der Küste des Weissen Meeres, ein Süsswassergraben mit faulem Wasser, ohne Pflanzen (23. Juli 1877). Varietas ovalis in Nördlicher Dwina, un. weit vom Dorfe Beresniki (11. Juni 1877).

Heteromita cylindrica, n. sp.

Taf. XI, Fig. 8.

Die Körperform ist cylindrisch, die Länge übertrifft mehr als zweimal die Breite, an beiden Enden ist sie ganz gleich und regelmässig zugerundet. Das hintere Flagellum ist mehr als zweimal länger als der Körper, das vordere nur wenig länger. Die grosse Vacuole liegt in der oberen Körperhälfte. Die Körner, deren es nicht zu viele giebt, sind im Körper mehr oder minder gleichmässig vertheilt. Sie bewegt sich so ziemlich ruckweise. Die Länge $=0,015^{\prime \prime \prime}$, die Breite $=0,0084^{\prime \prime \prime}$.

Diese Heteromita fand ich im Weissen Meere, an der Oberfläche.

Fundort: Weisses Meer, Solowetzky-Inseln, Kloster-Bucht, Mitte Juli 1877.

Heteromita adunca, n. sp.

Taf. XI, Fig. 4.

Diese Art stellt eines der kleinsten Infusorien und kommt sehr oft im Weissen Meere vor. Ihr Körper ist oval, hinten regelmässig zugerundet, vorn in eine lange Spitze, rostrum, ausgezogen, die stark nach der Seite gekrümmt ist und an dem zugespitzten Ende zwei Geisseln trägt. Die vordere ist ein wenig länger als der Körper; die hintere aber ist mehr als zweimal so lang als der letztere. Die contractile Vacuole lingt in der oberen Körperhälfte.

1) Fromentel. Etudes, p. 323, pl. XXIII, Fig. 52-53 und einem Citate nach Pritchard Infus. p. 512, pl. XXVI, Fig. 10.

2) Dujardin, Hist. nat. d. Infus. p. 316, pl. V, Fig. 3. 
Der Körper ist farblos und sehr durchsichtig, da die Körner sehr klein und in geringer Zahl vorhanden sind. Die Bewegungen sind äusserst schnell und ordnungslos, zickzackförmig, sie wirft sich so zu sagen nach allen Seiten.

Die Länge $=$ ungefähr $0,003^{\prime \prime}$.

Fundort: Weisses Meer, Solowetzky-Inseln, Kloster-Bucht, an der Oberfläche und in jeder Infusion, aber nur im Meereswasser, oft (im Sommer 1877).

\section{Rhizopoda. \\ Clathrulina Cienkowskii, nova species. \\ Taf. X, Fig. 34.}

Diese zweite Art der Clathrulina, die mir im Onega-See bei Powenetz vorkam, bietet den höchsten Grad der Schönheit und Eleganz dar.

Das kugelförmige Köpfchen sitzt auf einem sehr langen und dïnnen Stiele, der leicht gebogen und von überall gleicher Breite (ungefähr 0,001“") ist. Das Köpfchen hat 0,027"“ im Durchmesser, ist ganz regelmässig rund, mit runden Oeffnungen von $0,0051^{\prime \prime}$ im Durchmesser, die ganz symmetrisch vertheilt sind, so dass eine centrale Oeffnung von 6 peripheren umgeben wird. In einer dem grossen Kreise nach geordneten Reihe befinden sich etwa 10 Oeffnungen, so dass man von der dem Beobachter zugewendeten Seite im ganzen 5 solche Oeffnungen zählen kann, die der Reihe nach geordnet sind. Das Kieselskelet selbst, d. h. die das gitterförmige Köpfchen bildenden Balken sind ziemlich dünn und wo deren 3 zusammentreten, entsteht eine kleine dreieckige Fläche, die in ihrem Centrum, auf der Aussenfläche, je einen dornförmigen Fortsatz tragen. Diese Dorne sind ziemlich kurz, cylinderförmig, an ihren Enden zugerundet und zur Kugeloberfläche senkrecht gestellt. An den Balken selbst begegnet man solchen Dörnchen niemals und darum wird jede Oeffnung immer nur von 6 solchen Dörnchen umgeben, die der ganzen Oberfläche ein dorniges, bewaffnetes Aussehen verleihen.

Innerhalb dieser kieseligen Gitterkugel befindet sich ein schwer 
wahrzunehmender, runder, körniger, auch kugelförmiger Körper, der an seiner sämmtlichen Oberfläche lange, spitze und verhältnissmässig dicke Pseudopodien aussendet, die immer ganz gerade bleiben, sich niemals verästeln und anastomosiren, und scheinbar von sehr dichter Consistenz sind; in ihnen bemerkte ich keine Körnchenbewegung. Indem ich das Thierchen beobachtete, bemerkte ich nach kurzer Zeit, wie der kugelförmige Körper sich durch eine ringförmige Einschnürung zu halbiren begann; dessenungeachtet verblieben die Pseudopodien ebenso wie früher gestreckt; endlich trat eine fast völlige Theilung der Kugel in zwei Theile ein und das schien nicht im mindesten die Scheinfüsschen zu beeinflussen, die immer gestreckt verblieben, gleich ob Nichts geschehen wäre. Sowohl die Schale, als auch der Körper selbst dieser Art waren ganz farblos; nur enthielt der letztere zuweilen ziemlich viele gefärbte Körnchen. Es sass auf Klümpchen verwesenden organischen Stoffes.

Diese höchst elegante Art unterscheidet sich von der Cl. elegans sowohl durch die Länge des Stieles und grössere Regelmässigkeit der Gitterstructur des Köpfehens, als auch durch die Anwesenheit von kurzen, cylindrischen, an den Enden zugerundeten Dornen, die die Oberfläche des Köpfchens überziehen. Endlich dienen zum Unterschiede auch die verhältnissmässig dicken, sich nicht verästelnden Pseudopodien.

Die specifische Benennung gebe ich unserem hochverehrten Gelehrten, Herrn Cienkowsky, zu Ehren, der diese Gattung zuerst fand und aufstellte.

Fundort: Onega-See, neben Powenetz, Flussmiindung mit üppiger Vegetation, 27. Juli 1877.

\section{Pleurophrys angulata, $\mathrm{n}$. sp.}

Taf. X, Fig. 14 u. 14 a.

Die Form der Schale ist eiförmig-oval, mit einem regelmässig zugerundeten Hinterende und ein wenig engeren, gerade abgestutzten, mit einer weiten runden Mündung versehenen Vorderende. Die Schale ist gar nicht comprimirt, wie man sich leicht überzeugen kann, wenn sich das Thier vertical zum Beobachter stellt (Fig. 14a); doch ebensowohl ist sie auch nicht rund, sondern ganz deutlich sechsseitig, mit zugerundeten Kanten, so dass, wenn man sie der Axe nach betrachtet, die Contouren sich 
als ein deutliches Sechseck mit mehr oder minder zugerundeten Ecken darstellen.

Die Schale besteht aus ziemlich groben Sandkörnern, wodurch sie ganz undurchsichtig wird; sie hat keine bestimmte Färbung, oder ist bläulich-grau, wie es im Allgemeinen bei sämmtlichen Difflugien mit Sandkörnchen vorkommt.

Die Pseudopodien sind sehr lang und höchst dünn, fadenförmig, wenig verästelt, nicht anastomosirend. Ich bemerkte in ibnen keine Körnchenbewegung, im Allgemeinen kommen ihre Bewegungen und Veränderungen höchst langsam zu Stande. Thre Consistenz scheint sehr dicht zu sein. Das Thier bewegt sich fast immer Kopf abwärts und das Hinterende nach oben gewendet.

Die Breite der Schale = ungefähr 0,03“".

Diese Art stellt die zweite in dieser Gattung vor, die zuerst von Cl. und Lach. ${ }^{1}$ ) für die einzige Art Pl. sphaerica aufgestellt war. Die letztere ist jüngst nochmals namentlich von Hertwig und Lesser ${ }^{2}$ ) untersucht worden. Von dieser Art unterscheidet sich unsere vorwiegend durch die Form der Schale, die breiter und sechsseitig ist, dann noch durch die Abwesenheit der braunen Färbung, gröbere Sandkörner, dünnere, ganz durchsichtige, körnchenlose Pseudopodien.

Fundort: Onega-See, Mündung eines kleinen Flusses mit üppiger Vegetation.

Difflugia spiralis Ehr.

Difflugia spiralis Ehr. Monatsber. der Berl. Ak. d. Wissensch. 1840, p. 199. Difflugia spiralis Carter, on freschwater Rhizop. Ann. a. Mag. Nat. Hist. V. XIII. 1864, p. 29, pl. I, Fig. 9. Difflugia proteiformis var. spiralis. Wallich, Ann. a. Mag. of N. History 1864. V. XIII, p. 240, pl. XVI, Fig. 24, 25.

Taf. X, Fig. 15.

Es sind zwei Varietäten dieser Schale bekannt, deren eine mit regelmässigen verlängerten und ordnungslos zerstreuten Stäbchen bedeckt ist (ef. Wallich, Ann. and Mag. pl. XVI, Fig. 24), während bei der anderen die Schale von unregelmässigen Sandkörnchen gebildet wird (Wallich l. c. Fig. 25). Hertwig und Lesser glauben, dass die erste von Beiden jenes Substrat dar-

1) Etudes, p. 455 .

2) Hertwig und Lesser, Ueber Rhizopoden, Arch. f. mikr. An. B. X. 1874. Supplementheft p. 135, Taf. III, Fig. 4. 
stellen solle, an welches die Steinchen der zweiten angekittet werden, so dass also aus der ersten die zweite entstehen könne. Doch beweist die Form, die ich im Onega-See fand, dass jene Ansicht unrichtig ist und dass jenes Substrat nur von einer structurlosen dünnen Membran gebildet wird. Die von mir beobachtete D. spiralis hat wirklich eine Schale, die aus einem Häutchen besteht, das aber nicht ganz glatt, sondern mit kleinen und ganz unregelmässigen Vertiefungen bedeckt ist, dabei aber keine Spur von irgend welchen an ihrer Oberfläche angekitteten Stäbchen oder Sandkörnern zeigt. Darum ist die Schale ziemlich durchsichtig und es lässt sich die Contour des innern Körpers, sowie in diesem letzteren mehrere runde, ziemlich glänzende Kügelchen wahrnehmen, die wahrscheinlich Embryonen sind. Das ziemlich dünnflissige Protoplasma tritt aus dem Hälschen gleich einer kleinen Platte, die noch fingerartige, cylindrische Pseudopodien aussendet, hervor.

Die grösste Länge $=0,066^{\prime \prime}$, der Durchmesser $=0,048^{\prime \prime}$.

Fundort: Onega-See, bei Powenetz, Flussmündung mit üppiger Vegetation (27. Juli 1877).

\section{Difflugia Solowctzkii, nov. sp.}

Taf. X, Fig. 17.

Die Körperform ist eine herzförmig verlängerte, mit gleich wie bei $D$. acuminata zugespitztem Hinterende, und mit verengertem, stark eingeschnürtem, mit beträchtlich umgebogenen Rändern versehenem Vorderende. Die Schale besteht aus unregelmässigen Sandkörnern, die zum Hinterende sich immer verkleinern.

Die Länge $=0,09^{\prime \prime \prime}$, die grösste Breite $=0,052^{\prime \prime \prime}$.

Ihren umgebogenen Rändern nach steht diese Form der Dif. proteiformis var. lageniformis Wallich ${ }^{1}$ ) nahe; doch unterscheidet sie sich durch das zugespitzte Hinterende, das, wie es scheint, niemals bei der oben genannten Varietiit vorkommt.

\section{Hyalodiscus Korotnewi, nov. sp.}

Taf. XI, Fig. 20-26.

Diese höchst eigenthümliche Amöbine gehört zur Gattung

1) Annals and Mag. of Nat. H. Vol. XIII 1864, p. 240, pl. XVI, Fig. 15, 16. Diese Varietät, wie viele andere ihrer Varietäten, stellt eine selbstständige Art - D. lageniformis - vor. 
Hyalodiscus (Hertwig und Lesser, l. c. p. 54), mit der ich auch die Gattung Plakopus zu vereinigen mich genöthigt fühle. Diese letzte Gattung ist von Franz Eilhard Schulze') für solche amöbenartige Thiere aufgestellt, die an ihrer Oberfläche dünne und breite, plattenähnliche Pseudopodien aussenden. Er beschrieb nur eine Art, Plakopus ruber, die er in Deutschland, im suissen Wasser fand, und die sich durch ziegelrothe, dem Körper dieselbe Färbung verleihende Körner charakterisirt. Die zu beschreibende Art wurde von mir im Weissen Meere (im Juli 1877) gefunden. Sie stellt also eine zweite Art dieser interessanten Gattung vor and unterscheidet sich, abgesehen von der Abwesenheit der Färbung, durch ihre vollständige Farblosigkeit, sowie durch andere Details in der Form der Pseudopodien und Platten, worüber weiter die Rede sein wird.

H. Korotnewi kann die versehiedensten Formen, sowohl hinsichtlich der Körpergestalt selbst, als auch der Pseudopodien annehmen; es gelang mir viel grössere Mannigfaltigkeit, als es bei H. (Plakopus) ruber geschah, zu beobachten. Aber am meisten charakteristisch und augenfällig ist die Anwesenheit ausser gewöhnlichen Pseudopodien noch von besonderen Organen, die einem Segel oder einer farblosen Membran ähneln und die Nichts anderes als eigenthïmlich modificirte Pseudopodien sind. Die Fig. 20-26 der Taf. XI veranschaulichen die verschiedenen Stadien, die der Hyalodiscus unter meinen Augen durchmachte. Auf der Fig. 20 ist er in jenem Zustande abgebildet, wenn er eine fast regelmässige Kugelform, mit wenigen (5-8) kurzen, cylindrischen an den Enden zugerundeten Pseudopodien hat; hier sieht man keine Spur weder von plattenförmigen Pseudopodien, noch von anderen dünnen, zugespitzten Scheinfüsschen, die weiter unten noch beschrieben werden. Solche Form dauert aber nur kurze Zeit; indem man die Beobachtung noch ein wenig fortsetzt, kann man gleich bemerken, dass eins oder mehrere der cylindrischen Tentakel sich zu verlängern, zu verdünnen und am Ende, wo sie in einen höchst dünnen, sich aus dem Gesicht rasch verlierenden Faden übergehen, zuzuspitzen beginnen. Gleichzeitig bemerkt man, dass an den Seiten der Tentakel, von deren Grunde an beginnend, sich höchst dünne, voll-

1) Fr. E. Schulze, Rhizopodenstudien IV. Arch. f. mikr. Anat. B. XI 1875, p. 348. Taf. XIX, Fig. 9-15. 
kommen farblose und durchsichtige, anfangs kaum bemerkliche Häutchen bilden. Vom Körperrande an ziehen diese Häutchen an beiden Seiten der Pseudopodien, sich immer nach dem Ende zu verschmälernd (Taf. XI, Fig. 21). Dieses Häutchen oder Plättchen kann beim Grunde und dann weiter hin mit den Nachbarbäutchen, die den benachbarten Tentakeln angehören, zusammenfliessen; diese letztere mit ihrem Nachbarn u. s. w., bis endlich auf diese Art mehrere Pseudopodien sich durch dieses dünne Häutchen, anfangs beim Grunde und dann, nach der Massgabe der Entwicklung des Hảutehens, immer weiter und weiter, fast in der ganzen Ausdehnung vereinigen; und so entsteht etwas dem Froschfusse mit seiner Schwimmhaut ähnliches (s. Taf. XI, Fig. 24, 26 und 23). Doch überragen die Pseudopodienenden fast immer die Ränder des Verbindungshäutchens, und sind im Allgemeinen immer in ihrer ganzen Ausdehnung sichtbar, denn sie sind viel dicker als das Häutchen selbst, auf dem sie einem Blattnerven ähnlich verlaufen, und dabei noch mehr oder weniger Körner enthalten. In diesem Stadium giebt es ausser zugespitzten und hautartigen Psendopodien entweder gar keine andere (Fig. 26), oder, an den Stellen wo sich noch keine Hïutchen gebildet haben, auch kurze, cylindrische stumpfe Pseudopodien bemerkbar sind (Fig. 21). Als ein äusserstes Produkt der Entwicklung der Häutchen zeigt sich die Form, die auf der Taf. XI, Fig. 26 abgebildet ist. Hier sieht man den ganzen Körper von einer breiten, structurlosen Platte umgeben, die aus der Vereinigung der den einzelnen Pseudopodien angehörenden entstanden ist. Die letzteren gehen radienartig um den ganzen verlängert-ovalen Körper ab, ziehen über das Häutchen und, indem sie allmählich sich verjüngen, überragen sie die Ränder desselben noch um eine ziemlich grosse Strecke. In diesem. Stadium sieht man nicht mehr jene kurzen, stumpfen, cylindrischen Pseudopodien, die ausschliesslich auf der Fig. 20 vorkamen. Dabei ist noch zu bemerken, dass auch die Form des Körpers selbst, frtiher rund cylindrisch, sich verändern kann, indem sie entweder in eine ovale, oder spindelförmige, oder eiförmige übergeht. Alle diese Häutchenbildungen und die Vereinigung mehrerer Psendopodien mittelst derselben können nur auf einer Seite entstehen, während auf der anderen keine Spur davon zu sehen ist: dort verbleiben entweder die ursprünglichen, kurzen, cylindrischen 
Pseudopodien (Fig. 22), oder sie fehlen hier überhaupt ganz (Fig. 23).

Aber darin erschöpft sich nicht die ganze Mannigfaltigkeit der Gestalten, die.H. Korotnewi darbieten kann. Indem er beständig und verschiedenartig seine Form ändert, nimmt er zuweilen jene schon erwähnte Kugelform an, bei der auf einer Seite ein fächerartiges Häutchen mit darüber ziehenden spitzen Pseudopodien, auf der anderen gar keine Platten und Pseudopodien liberhaupt sich befinden (Fig. 23). Und dann, von dieser Form ausgehend, glückt uns zuweilen dieselbe fächerartige Platte auf einer Seite zu beobachten, aber die im vorhergehenden Stadium so deutlichen Pseudopodien sind ganz versehwunden, haben sich wahrscheinlich eingezogen, auch sind tiberhaupt keine Pseudopodien sichtbar (Fig. 25).

Zuweilen sieht man übrigens auf der entgegengesetzten Seite einfache, kurze, cylindrische Pseudopodien (Fig. 22) ohne jegliche Platten, während gleichzeitig das Häutchen sich auf dem grösseren Theil des Körperumfanges ausbreitet, und das so entstandene segelartige Scheinfüsschen verleiht dem ganzen Thiere ein höchst eigenthümliches Aussehen.

Was die Ränder der Platte betrifft, so sind sie meistens gerade, ausgezogen-wellig, zuweilen leicht gekerbt, zuweilen aber - ibrigens nur dann, wenn tiber die Platte keine Pseudopodien ziehen - konnte man bemerken, dass die Häutchenränder deutliche, ziemlich breite Kegel aussendeten, die wahrscheinlich jenen dünnen, nar einmal bei seinem H. ruber von F. E. Schulze beobachteten Fäden entsprechen ${ }^{1}$ ). Ich muss noch einen wichtigen Unterschied zwischen beiden Arten erwähnen. Der Hyalodiscus des Weissen Meeres, wie es aus den Zeichnungen deutlich ist, sendet seine Fortsätze nur an einem Körperumfange aus, nicht aber von der sämmtlichen Oberfläche, wie man es bei $H$. ruber beobachtet; deswegen können beim letzteren aus den Häutchen trichterförmige Vertiefungen entstehen, was ich niemals bei der Art des Weissen Meeres beobachtete, obwohl ich die Möglichkeit desselben nicht läugnen will.

Was den Körperinhalt betrifft, so besteht er aus einer dünnen Schicht eines gar nicht scharf abgesonderten, ein Häutchen bilden-

1) Arch. f. mikr. Anat. XI. p. 351. 
den Ectoplasmas und aus einem körnigen Endoplasma. Die letztere enthält in sehr reichlicher Menge Körner von verschiedenster Grösse, von denen einige stark lichtbrechend, aber alle ganz farblos sind; tuberhaupt lässt sich gar kein Pigment im Innern des Körpers beobachten. Wenn man die Bildung einer Platte beobachtet, so ist sie immer sehr scharf von dem körnigen Körper geschieden, indem sie immer farblos, durchsichtig und ganz ohne jegliche Körner bleibt. Anders verhalten sich die Pseudopodien, namentlich die cylindrischen, die eine grössere oder geringere Menge Körner enthalten können. Ausserdem bemerkt man im Körper ganz deutlich und scharf einen runden Kern, von ziemlich ansehnlicher Grösse, aber ohne ein helles Feld in seiner Umgebung; dann sieht man noch eine sehr scharf hervortretende Vacuole, die kleiner als der Nucleus ist und sich ziemlich energisch zusammenzieht. Bei $\mathrm{H}$. Korotnewi bemerkt man Nichts von jenen zahlreichen, von Fr. Schulze beobachteten Vacuolen. Die Consistenz des Plasma ist eine ziemlich dichte, das Thier "fliesst" nicht, die Bewegungen sind ruhig und langsam.

Nachdem ich den beschriebenen Organismus fand, stellten sich mir ziemlich grosse Schwierigkeiten entgegen: ich wusste nicht, ob ich ihn zur von F. Schulze aufoestellten Gattung Plakopus, oder zu dem von Hertwig und Lesser ${ }^{1}$ ) beschriebenen Hyalodiscus zählen müsse. Meiner Meinung stehen diese beiden Genera einander sehr nahe, wie es aus der Diagnosis der letzteren deutlich wird. Dieselbe lautet nämlich: „Körper schalenlos, scheibenförmig ohne Fortsätze, durch eine gleichmässige Contractilität aller seiner Theile sich vorwärts bewegend, in Ektosark und Endosark differenzirt. Das von homogenem Ektosark umschlossene Endosark bedingt eine buckelförmige Hervorwölbung desselben und enthält den Kern und die (contractilen?) Blasen."

Also erscheint bei seinem H. rubicundus am meisten ausser jener Art der Bewegung, noch die hyaline, dtinne, körnchenlose, nach Art einer Scheibe ringförmig den aufgeblähten, körnigen Körper umgebende Schicht. Dasselbe aber wird bei Plakopus ruber $^{2}$ ) und bei meinem Hyalodiseus beobachtet (s. Taf. XI, Fig. 22), so dass der wichtigste Charakter der Gattung Plakopus -

1) L. c. p. 54, Taf. II, Fig. $5 \mathrm{~A}$ und B.

2) F. E. SchuIze, Arch. f. mikr. Anat. XI. 1875. Taf. XIX, Fig. 9. 
die plattenförmige Bildung - sich in derselben Weise wie bei Hyalodiscus beobachten lässt. Der letzte unterscheidet sich aber darin, dass seine Platte höchst constant ist, weder verschwindet sie, noch wiedererscheint, sondern immer in demselben Zustande verbleibt. Weiter besteht noch ein Unterschied darin, dass uber die Platte keine zugespitzten Pseudopodien verlaufen, wie wir es bei den Plakopusarten beobachten, sowie tiberhaupt Pseudopodien fehlen. Aber auch dieser letztere Umstand kann nicht als Gattungsmerkmal dienen, da er höchst unconstant ist, wie es aus der Beschreibung deutlich sein muss; die Art des Weissen Meeres kann zuweilen eine solche Form annehmen, welche ausser der dunnen, durchsichtigen, den körnigen Körper fast allerseits umgebenden Platte keine Spur irgend welcher Pseudopodien darbietet, wie dies z. B. auf der Taf. XI, Fig. 25 oder noch besser 22 zu sehen ist: an der letzteren ist die Platte grösser, und auch ohne liber dieselbe ziebenden Pseudopodien. Also nimnt die beschriebene Art bald die Charactere der Gattung Hyalodiscus, bald die des Plakopus; und dies zeigt uns deutlich, dass es beide Gattungen in eine einzige $z u$ vereinigen nöthig ist, die der Priorität wegen den von Hertwig und Lesser gegebenen Namen erhalten muss. Was die grössere Constanz der Form bei Hyalodiseus betrifft, so kann dieses Merkmal als ein guter Artcharacter dienen, der H. rubicundus H. L. von H. ruber F. E. Schulze und H. Korotnewi mihi unterscheiden soll.

Den Artnamen gebe ich unserem Zoologen Alexis Korotnew zu Ehren.

Die Grösse ist sehr unbeträchtlich, ungefähr $0,009^{\prime \prime \prime}$ oder $0,01^{\prime \prime \prime}$ im Durchmesser.

Ich fand diese Form im Weissen Meere, in rein salzigem (nicht brackischen) Wasser.

Die kurze Charakteristik wird folgenderweise lauten:

Hyalodiscus, runder oder länglicher, ganz farbloser, dreierlei Fortsätze aussendend:

1) kurze, stumpfe, cylindrische Pseudopodien;

2) lange zugespitzte, sich allmählich verjüngende Pseudopodien;

3) dnrchsichtige, körnchenlose Häutchen, die immer (?) in einer Ebene entstehen, sich zuweilen mit den Pseudopodien der zweiten Art vereinigen, zuweilen aber ganz homogen, ohne blattnervenähnliche Gebilde sind. Der runde Kern obne helles Feld, 
eine einzige kleine, deutliche, pulsirende Vacuole. Die Fortpflanzung ist unbekannt. Lebt im Meere.

Fundort: Weisses Meer, Solowetzky-Inseln, in der Klosterbucht, zwischen den Algen (20. Juli 1877).

Amoeba verrucosa, Ehr.

Amoeba verrucosa, Ehr. Infus. p. 126. Taf. VIII, Fig. 11. Amoeba verrucosa Duj. H. N. d. Inf. p. 236.

Taf. XI, Fig. 33-35.

Nicht obne-gewissen Zwcifel zähle ich die vorliegende Form zur Ehrenberg'schen Art, von der sie sich durch ihre ziemlich rasche Bewegnng und zuweilen ziemlich lange, kegelformige oder cylindrische Pseudopodien unterscheidet. In Wologda hat sie einen Durchmesser $0,036^{\prime \prime}$, in Summa $0,02^{\prime \prime}$ und in Powenetz $0,025^{\prime \prime \prime}$. Die Körperform ist höchst veränderlich. Der Körper kann entweder gar keine Pseudopodien aussenden, oder sie sind lappenförmig;, oder endlich können sie sich ziemlich stark verlängern. Der Inhalt besteht ausser fremdartigen Gegenständen, Diatomeen und Algen, auch noch aus feinen und anderen das Licht stärker brechenden, grösseren Körnern. Im Onega-See kam mir Gelegenheit vor eine interessante Erscheinung zu beobachten. An einer Seite, am Rande, fing das Protoplasma ein kleines Höckerchen zu bilden an. Dieses Höckerchen vergrösserte sich immer dem Volum nach, und gleichzeitig verengerte sich immer der Isthmus, der es mit dem Mutterorganismus vereinigte. Noch während dieser Zeit nahm das Höckerchen verschiedenste Formen an, zeigte amöbenartige Bewegungen und, indem es endlich einen Durchmesser von annähernd $0,005^{\prime \prime \prime}$ erreichte, riss es ab und schwamm, sich ganz als eine kleine Amöbe bewegend, fort. Dieser ganze Embryo bestand nur aus dem durchsichtigen Ektoplasma, ohne jegliche Spur der Körnigkeit, ohne Kern und Vacuole. Nur dann wurde meine Aufmerksamkeit auf ein ganz ähnliches, sich bewegendes kleines Körperchen gelenkt, das neben dem Matterorganismus kroch and das sich offenbar von derselben Amöbe noch früher abschnürte. Also pflanzt sich diese Amöbe durch eine ganz regelmässige Knospung, d. h. durch einen Vorgang, der, obwohl der Theilung nahe steht, sich aber darin unterscheidet, dass hier die Erblichkeit nicht mehr so verständlich, wie bei einfacher Theilung erscheint, denn hier wird mit einem kleinen Stückchen des Ectoplasma allein auch die Fähigkeit sich einen Kern, Entoplasma, eine bestimmte 
Form, Consistenz u. s. w. auszubilden überliefert. So viel ich weiss, war bis jetzt der Vorgang der Knospung bei anderen Amöben nicht beobachtet.

Fundort: 1) Wologda, im Graben mit nicht ganz frischem Wasser (5. Juni 1877); 2) Onega-See, bei Powenetz, Flussmündung mit üppiger Vegetation (27. Juni 1877); 3) Petersburg, Jelaginsche Teiche und Aquarium, in Menge.

\author{
Amoeba crassa, Duj. \\ Amoeba crassa Duj., Hist. d. Inf. p. 238. \\ Taf. XI, Fig. 28.
}

Die zwei Amöben, die ich weiter beschreiben werde, gehören zu den "flüssigen" Amöben, d. h. zu solchen, die nicht kriechen, sondern "fliessen", wie ein Tropfen dicker Fliissigkeit.

Gegenwärtig ist es schwer mit Entschiedenheit zu sagen, ob die von mir in Menge im Weissen Meere aufgefundene Amöbe zu A. crassa Duj. gehöre, oder eine besondere Art darstelle; doch ist die erste Vermuthung sebr wahrscheinlich, um so mehr, da beide Arten im Meere gefunden sind. Darumi wird es nicht überfltissig sein, sowohl eine etwas detaillirtere Beschreibung als eine Zeichnung zu geben (Taf. XI, Fig. 28).

Amoeba crassa ist die grösste der von mir im Weissen Meere beobachteten marinen Amöben, indem ihr Durchmesser ungefâhr $0,03^{\prime \prime \prime}$ misst.

Sie besteht aus einem deutlichen durchsichtigen und körnchenlosen Ektoplasma und aus einem Endoplasma, dessen reichlicher brauner Inhalt aus grossen, ganz runden und glänzenden, kleinen Körnern, als aus.Diatomeen, Odontellen-Resten etc. besteht. Ausserdem bemerkt man dort selbstverständlich einen Kern und eine Vacuole (leider finde ich weder in den Noten, noch in den Zeichnungen etwas von der letzteren). Die Bewegungen dieser Art sind ziemlich rasch und werden am besten durch das Wort "Fliessen" characterisirt. Dabei fliesst sie nicht immer regelmässig, sondern zuweilen stossweise, bald langsamer, dann plötzlich schneller. Die Consistenz ist sehr flüssig, sie sendet eigentlich keine Pseudopodien aus, wenn man für solehe nicht die breiten Körperlappen mit dem breiteren Streifen des körnchenlosen Ektoplasma's hält. Da wo man die neue Anfahrt baut (gegen Swiatija Worota des Solowetzkyschen Klosters), wächst in Menge auf dem schlammig-san- 
digen Boden Enteromorpha intestinalis, und eben hier im Schlamme and Sande wimmeln Milliarden unserer Amöben.

Einst beobachtete ich den Theilungsvorgang bei einem besonders gut genährten Individaum: beide Hälften waren fast gleich, und schon durch einen engen Isthmus verbunden; in einer Hälfte war nur ein Kern zu bemerken, in der anderen zwei, ganz deutlich contourirt. Wahrscheinlich äusserten beide Hälften die grösste Anstrengung um ihr Ziel -- sich von einander abzutheilen zu erreichen; dabei bewegten sie sich nach entgegengesetzten Richtungen.

\section{Amoeba minuta, nov. sp.}

Taf. XI. Fig. 27.

Der Form, der Consistenz, den Pseudopodien nach ist sie sehr der vorhergehenden ähnlich und ebenso kommt sie in Menge vor. Darum kaun man leicht beide Arten umgrenzen, die sich im Folgenden unterscheiden: 1) durch verschiedene Dimensionen. Das ist ein sehr constantes Merkmal, und dass es sich nicht um eine junge, noch nicht reife Form derselben A. crassa handelt, wird dadurch bewiesen, dass ich auch hier die Theilung beobachtete. Der Durchmesser ist annähernd $0,009^{\prime \prime \prime} ; 2$ ) durch verschiedenen Körperinhalt, derselbe ist hier immer farblos, feinkörniger, es gibt keine Diatomeen oder andere gröbere Körper, so dass die Amöbe im Ganzen durchsichtiger und der Kern deutlicher ist. Die Bewegungen sind ebenso schnell, aber die Consistenz ist gleichsam ein wenig dicker, doch immer flüssig. Es ist ein interessanter Umstand, dass man sehr oft beobachten kann, wie diese Amöbe farblose, durchsichtige, der Länge nach 2-3 Mal den Durchmesser der Amöbe selbst uibertreffende Fäden aus ihrem Innern auslässt. Sie kriecht gleichsam von einem solchen Faden herab, und zuweilen kann ein Individuum mehrere Fäden ausstrecken. Ich glaube, dass es Rückstände der Nahrung sind, irgend welche Fäden mikroskopischer Pilze oder Odontellen, oder endlich eine Diatomeenart, die sich durch zwei dünne, biegsame, an den Enden ihres spindelförmigen Körpers angebrachte Fäden unterscheidet (Nitschiella). Ich begegnete ihr an derselben Stelle, wie der ersten Art, zuweilen aber fand ich sie massenhaft, während A. crassa nicht zu sehen war; dies spricht auch zu Gunsten der Selbstständigkeit beider Arten. Ich stelle für die beschriebene Amöbe eine neue Art auf, 
denn in der vorhandenen Literatur bietet sich mir keine dar, zu der man sie ohne Zweifel zählen könne.

Fundort: Weisses Meer, Solowetzky-Insel, Kloster-Bucht, an der Küste bei Swjatija Worota (Heiliges Thor), am Boden, im Schlamme und Sande, in Menge (im Sommer 1877).

Amoeba papillata, nov. sp.

Taf. XI, Fig. 31 und 32.

Diese schöne Amöbe kam mir nur in einem einzigen-Exemplare vor, in einem Süsswasser-Tümpel an der Nördlichen Dwina. Thre Form ist rund, sogar fast kugelförmig; sie ist ziemlich durchsichtig, mit dentlichem Ektoplasma and feinkörnigem Endoplasma. Im allgemeinen ist die Consistenz ziemlich dicht. Am meisten sind für diese Art ihre kurzen, cylindrischen, an den Enden zugerundeten Pseudopodien, die in grosser Zahl ganz regelmässig and symmetrisch vertheilt sind, ohne im mindesten die allgemeine runde Form der Amöbe zu beeinträchtigen. Im Innern, im Centrum, oder am Rande ist eine colossale contractile Vacuole gelegen and ein viel (zweimal) kleinerer matt aussehender Kern, der sehr scharf gesondert ist. Wenn die Amöbe sich bewegt (und ihre Bewegungen sind äusserst langsam, man kann sogar sagen unmerklich), so sendet sie an irgend einem Punkte einen breiten, fast ausschliesslich aus Ektoplasma bestehenden, kein Endoplasma ènthaltenden und keine Psendopodien tragenden Lappen aus. Dabei bleibt der grössere Körpertheil, seine Begrenzung und seine Tentakeln, unbeweglich. Der Körper misst ungerähr $=0,0075 \mathrm{~mm}$ im Durchmesser.

Fundort: Nördliche Dwina, am Halbwege zwischen WelikyUstjug und Archangelsk, in einem Tümpel nahe dem Flusse (11. Juni 1877).

Amoeba angulata nov. sp.

Taf. XI, Fig. 3.

Hinsichtlich der Amöben mit mehreren Vacuolen, die Claparède 1) der Aufmerksamkeit der Forscher besonders empfiehlt, kann ich zwei Arten erwähnen, die ich beschreiben werde (ohne die dritte marine - A. filifera zu zählen). Erstens beobachtete

1) Etudes etc. p. 440. 
ich in St. Petersburg A. angulata mihi, die sich durch ihre farbloses, durchsichtiges Plasma charakterisirt, das zweierlei Körner, äussert feine und andere (deren es nur wenige gibt), viel grössere und stark lichtbrechende enthält. Dann kann man im Körper ausser einem kleinen, runden Kern noch etwa 3 contractile Vacuolen finden, die aber nach aussen nicht wie bei A. emittens, von der später dic Rede sein wird, ausgeschieden werden, sondern sich im Innern des Körper's selbst zusammenziehen. Endlich sind noch die wenigen dicken, am Ende zugespitzten (doch nicht wie bei Am. filifera (s. S. 209), mit welcher Am. angulata viel Aehnlichkeit hat) und die Gestalt dicker, breiter Kegel habenden, vom Körper ausgehenden Pseudopodien charakteristisch.

Der Durchmesser $=0,0235^{\prime \prime \prime}$, die Bewegungen sind schnell.

Fundort: Petersburg, Jelaginsche Teiche, zwischen den Moosen und Algen (23. Mai 1877).

\section{Amoeba Jelaginia, nov. sp.}

Taf. XI, Fig. 29 und 30.

Diese von mir in den Jelaginschen Teichen, unweit Petersburg, aufgefundene Art unterscheidet sich von der vorigen dadurch, dass ihre Pseudopodien sich nicht zuspitzen, sondern aus ziemlich stumpfen, lappenartigen und zugerundeten Fortsätzen bestehen, sowie auch durch ibren stark-körnigen Inhalt, der diese Art undurchsichtiger als A. angulata macht.

Die Körperform ist höchst mannigfaltig. Der Körper sendet kurze, runde Lappen aus; die Bewegungen werden ubrigens nicht mittelst der letzteren, sondern des Ueberfliessens der ganzen Masse der Amöbe ausgeführt. Der Körperinhalt besteht ans feinen und gröberen Körnern, und sowohl die erste als auch die letzteren sind in grosser Menge vorhanden. Das Ektoplasma ist deutlich vom Endoplasma geschieden. Ausser dem Kerne sind noch einige Vacuolen sichtbar, die sich im Innern des Körpers sehr schnell zusammenziehen, nicht aber nach Aussen bersten, wie wir es bei Am. emittens sehen (s. S. 205). Die Consistenz ist flüssig, die Bewegung rasch. Der Durchmesser 0,02"'-0,04"“. Sehr gewöhnlich.

Fundort: Petersburg, Jelaginsche Teiche, am Boden, im Sande und Schlamme (23. Mai 1877), in grosser Menge. 
Amoeba emittens, nor. sp.

Taf. XI, Fig. 6-11.

Für diese Amöbe, die ich in Archangelsk und in Petersburg, in meinem Aquarium mit Wasser aus den Jelaginschen Teichen, beobachtete, ist sehr gut die Beschreibung, die Dujardin von Am. limax giebt, anwendbar. Er beschreibt nämlich die letztere: „Longue de 0,10, Large de 0,03 diaphane, arrondie aux deux bouts, très peu lobée, glissant sur le verre dans une direction presque rectiligne, contenant des granules très disctints et une vacuole trèz prononcée." In Vielem stimmt die Beschreibung mit meiner Amöbe, in Vielem aber weicht sie auch von derselben ab. Der Körper ist auch bei ihr immer verlängert, an den Enden zugerundet, fast keine Pseudopodien sind vorhanden, an der Stelle derselben sieht man bei ihr nur kaum bemerkbare Lappen des Körpers selbst. Der Körperinhalt ist aber verschieden: es giebt hier keine Körner, oder die letzteren sind so klein, dass sie gar sich nicht herausheben, man sieht nur einen Staub, im Ektoplasma bemerkt man sogar diesen nicht, es ist ganz durchsichtig. Ausserdem ist deutlich ein kleiner matt aussehender Kern und eine dentlich contractile Vacuole sichtbar, die immer im hinteren Körpertheile gelegen ist. Die Bewegungen bestehen aus einem Fliessen, das aber sehr eigentbümlich ist, es fliesst nur der Vordertheil und nur selten die Seitentheile, der ganze übrige Körper folgt aber dem Vordertheile und, da dieser immer geradlinig fliesst, so ist die Bewegung der Amöbe höchst regelmässig, indem sie nur sehr selten von dieser Richtung abweicht, aber wenn auch dies geschieht, so beginnt sie von neuem lange Zeit geradlinig fortzuschreiten. Während dieser Bewegung bleibt die Vacuole gleichsam zurïck, und darum nähert sie sich immer mehr dem hinteren Körperrande. Aber wenn sie auch diesen erreicht hatte, setzt sich noch ihr Zurückbleiben fort und dann überragt sie, von einer Ektoplasmaschicht umgeben, den Rand, indem sie höckerartig denselben vorwölbt (Fig. 9). Wenn dieser Höcker sich schon beträchtlich vergrössert, so dass die Vacuole ganz aus dem Körper herausgetreten ist Fig. 10, dann wird eine momentane Verschwindung der Vacuole beobachtet: die Ektoplasmawandungen platzen, der Vacuoleninbalt giesst sich nach aussen und nachher bemerkt man an der Stelle der früheren Vacuole noch während einiger Zeit eine geringe Erhebung, die auch rasch ver- 
schwindet, wonach der hintere Rand wie vom Anfange an zugerundet erscheint und die Amöbe eine Weile ohne Vacuole bleibt. Doch bemerkt man nach kurzer Zeit irn hinteren Drittel des Körpers ein kleines Pünktchen, das immer wächst, in eine contractile Vacuole übergehend, die von neuem dem hinteren Körperende sich nähert, dasselbe nach aussen vorwölbt und platzt, dann wird sie von neuem gebildet u. s. w. Ich beobachtete die Bewegungen dieser Amöbe während einiger Stunden und niemals gelang es mir zu sehen, dass die Vacuole, sich contrahirend, im Innern des Körpers verbleibe. Dieser Umstand, sowie die schöne, geradlinige, regelmässige Bewegung sind für diese Art sehr charakteristisch. Ihrer Vacuole nach ist diese Amöbe selrr der A. villosa ähnlich, doch hat sie mit der letzteren ausser diesem Verhältnisse nichts gemein. Bei beiden tritt aber mit auffallender Deutlichkeit die Bedeutung der Vacuole hervor. Hier sieht man unzweifelhaft, dass die Vacuole der Rhizopoden und Infusorien kein Analogon des Herzens oder Respirationsorgans, sondern im Gegentheil nichts anderes als ein Excretionsorgan darstellt, durch den das Plasma sich von dem überflüssigen Wasser befreit. Und dies ist selbstverständlich. Irgend welche Vorticelle z. B. erregt einen so heftigen Strudel und folglich einen Austansch der sie bespülenden Flüssigkeit, ausserdem nimmt sie mit der Nahrung zusammen eine für sie enorme Wassermenge, die noch durch das Imbibitionsvermögen des Protoplasma gesteigert wird. Bei der Amöbe spielt die Hauptrolle ausser dem bespülenden Wasser noch das ins Innere durch die eben erwähnte Eigenschaft durchgedrungene Wasser, so dass kein Mangel, sondern vielmehr ein Ueberfluss der Körperflüssigkeit sie stören könnte und folglich die speciell zur Irrigation der innern Körpertheile dienenden Vorrichtungen ganz überflüssig wären. Es wären eher Vorrichtungen zu erwarten, die zur Befreiung der Amöbe von zur Respiration unnitzem, durch Oxydation verdorbenem, seinen Sauerstoff verlierenden und mit Kohlensäure gesättigten Wasser dienen könnten. Wenn man sogar voraussetzt, dass die Amöbe immer noch wenig oxydirende Fliussigkeit habe, so wird auch dann sehr unbegreiflich sein, wie die contractilen Vacuolen solche Leistungen vollziehen können. Denn die Vacuolen selbst entstehen durch Zusammentluss in einem gemeinsamen Sammelpunkte einer Menge unbemerklicher winziger Strömungen, die von allen Theilen des Infusoriums herankommen; wird es dann logisch sein zu vermuthen, dass die Flüssigkeit von 
neuem dahin, woher sie kam, zurückkehre, um das Plasma, welches sie eben durchströmte, zu oxydiren? Ist also die Ansicht nicht angemessener, dass die Flüssigkeit, die das Infusorium durchtränkt, nachdem sie das Plasma so viel als möglich oxydirt hatte, fur dasselbe unbrauchbar werde und darum eliminirt werden müsse, sonst könnte nicht frischeres Wasser eindringen, denn der Organismus kann nur ein begrenztes Wasservolum enthalten und nichts mehr. Sowie aber diese Elimination ohne besondere Vorrichtung sich nicht vollziehen kann, da das Thier selbst im Wasser lebt, so sammelt sich das „Venen-Wasser" in eine Vacuole und aus dieser wird es durch die Contraction und den Druck des Plasma auf jenem oder anderem Wege nach aussen gestossen. Es wäre nicht der Mühe werth, dass sich ein fuir die Protozoen so complicirter Apparat wie die Vacuole ausbilden würde, um nur mehr Wasser aufzunehmen: dies kann durch den Mund oder durch die Imbibition viel einfacher erreicht werden. Anders dagegen ist es für die Befreiung vom Ueberschuss oder für die Ausscheidung desselben aus dem Körper. Zu diesem Zwecke ist eben ein solcher complicirter Apparat, eine Art Pumpe erforderlich, denn die Lebensbedingungen, d. h. das Wasser, lässt eine andere, einfachere Art der Wasserausscheidung, wie Verdunstung, Ausfluss u. a. nicht zu; hier wird eine gewisse mechanische Arbeit erforderlich. Die Consistenz des Thieres ist flüssig, es fliesst, die Bewegungen sind schnell. Die Länge in Archangelsk $=0,018^{\prime \prime \prime}-0,02^{\prime \prime \prime}$.

Fundort: 1) St. Petersburg, in meinem Aquarium, dessen Wasser aus den Jelaginschen Teichen (im Winter 1876) stammt; 2) Archangelsk, in einem Graben mit faulern Wasser und üppiger Vegetation (13. Juni 1877).

Amoeba alveolata, nov. sp.

Taf. XI, Fig. 40.

An der Küste der Solowetzky-Inseln, beim Eingange in die Kloster-Bucht, fliesst einer ganzen Reihe kleiner Inselchen gegenüber ein kleiner Bach süssen Wassers; bei seiner Mündung, da wo das Wasser, obwohl salzig, doch im beträchtlichen Grade, besonders während der Ebbe, mit süssem Wasser vermischt ist, wachsen Algen, zwischen denen, mit verschiedenen Infusorien zusammen, ich auch diese eigenthiumliche Amöbe fand. Ihre Form ist höclist 
variabel, sie sendet grosse kegelförmige Pseudopodien, oder kurze und breite Lappen aus. Am meisten ist für sie ihr Inhalt charakteristisch, der fast gänzlich aus einer grossen Menge (mehreren Zehnen) ziemlich grosser Vacuolen besteht; dieselben aber ziehen sich nicht zusammen, sondern enthalten eine helle Flüssigkeit, wahrscheinlich Meereswasser. Die Form dieser Vacuolen ist zuweilen regelmässig kuglig, öfter aber unregelmässig, doch ist ihre Grösse so ziemlich gleich. Diese Vacuolen sind so zahlreich and liegen so dicht nebeneinander, dass von dem Körper selbst dem Protoplasma nur ein unbeträchtliches Netz oder ein Geflecht Fasern und Balken bleibt, und nur von aussen eine ununterbrochene Schicht des Ektoplasmas das Ganze umgiebt. Also hat die ganze Amöbe eine höchst schwammige Structur. Ausserdem hemerkt man im Innern derselben zweierlei Körner: die einen sind fein, im Geflechte der Plasmafäden und theils in der äusseren ununterbrochenen Schicht gelegen; die anderen sina in einer sehr geringen Zahl (im Ganzen 4) vorbanden, grösser, regelmässig rund und stark lichtbrechend; aller Wahrscheinlichkeit nach sind es Oelkugeln. Endlich bemerkt man in der äusseren zusammenhängenden Schicht einen kleinen Kern. Hinsichtlich der Vacuolen erinnere ich mich Nichts, in meinen Noten ist Nichts davon gesagt. Die Grösse ist sehr bedeutend, die Amöbe hat beinahe $0,021^{\prime \prime 6}$ im Durchmesser; sie ist farblos und sehr durchsichtig, die Bewegungen sind langsam, die Consistenz ist mässig.

Es ist, meines Wissens wenigstens, keine Amöbe bekannt, bei der das Vacuolensystem so entwickelt und bei der die schwammige Structur so ausgeprägt wäre. Darum drängt sich unausweislich die Frage nach der Ursache solcher Structur, solcher ausschliesslichen Erscheinung auf. So wie diese Erscheinung äusserst ausschliesslich ist, so muss auch die Ursache davon eine eben so ausschliessliche sein, und dieselbe aufsuchend, miissen wir ausser Acht die gewöhnlichen Lebensbedingungen sowohl der oben beschriebenen marinen als der Süsswasser-Amöben lassen, unsere Aufmerksamkeit dagegen ganz auf die ausschliesslichen Bedingungen des vorliegenden Falles lenken. Dabei fällt gerade der Umstand auf, dass A. alveolata im Brackwasser lebt und dabei noch bei der Mündung eines Baches, folglich in einem Orte, wo Ebbe und Fluth ihren Einfluss ausüben können. Dies zeigt uns schon fast mit Gewissheit, dass die Ursache dieser Form, dieser 
Structur eben in dieser, ganz ausschliesslichen Bedingung liegen muss, da alle übrigen Amöben entweder ansschliesslich marin, oder ausschliesslich Süsswasserbewohner sind.

Betrachten wir nur, wie man die Entstehung dieser Form bei solchen Bedingungen zu erklären hat. Ich glaube, dass es folgenderweise geschehen kann. Setzen wir voraus, dass diese Amöbe anfangs rein marin, nur zum Leben im Meereswasser befähigt war. Wenn eine solche in die Bedingungen der A. alveolata gerathen ist, $d . h$. bei der Mündung eines Stisswasser-Baches lebt, dann bekommt es ihr während der Fluth, der Zunahme also des Salzgehalts bei der Mündung, wohl, das Wasser wird dann stark salzig, fast ganz dem Meereswasser ähnlich. Aber nach Abschluss der auf einiger Strecke sogar in den Bach hinauf steigenden Fluth tritt die Ebbe ins Spiel; darum verdünnt das immer zunehmende süsse Wasser den Salzgehalt bei der Mündung, das Wasser wird hier immer suisser; dann bekommt es der Amöbe. schlecht. Es werden sich selbstverständlich rasch und stark solche Eigenschaften entwickeln, die ihre Qualen vermindern werden; und gerade solcbe Anpassungen werden von jenen Räumen in Körper vorgestellt, die, während der Ebbe mit salzigen, im Organismus verbleibenden Meereswasser erfüllt, für die Amöbe das abwesende salzige Wasser ersetzen, indem sie von dem in ibrem Innern enthaltenen bespült wird. Diese Organisationsverbältnisse tragen also dazu bei, dass die Amöbe leichter die für ibre ungünstige Bedingung - die periodische Versüssung des Wassers - erträgt; kurz, dieses Reserviren des Salzwassers begünstigt ihre Anpassung an's umgebende Medium. Und je grösserer Vorrath des Salzwassers für die Amöbe möglich ist, desto mehr wird von ihm der Körper bespült werden, d. h. je mehr sie Vacuolen haben wird, desto vortheilhafter wird es dem Organismus sein; darum also sehen wir bei der Mündung eine Amöbe mit so enormer Vacuolenzahl.

Fundort: Weisses Meer, Solowetzky-Inseln, Miindung des in die Kloster-Bucht fliessenden Baches (Juli, 1877).

Amoeba filifera, nov. sp.

Taf. XI, Fig. $41-42$.

Die Körperform ist bei dieser Amöbe ziemlich constant, kugelförmig oder verlängert. Nach allen Seiten sendet sie Aus- 
wllchse, Pseudopodien aus, die ihrer Form nach höchst charakteristisch sind: am Grunde sind die Pseudopodien ziemlich breit und dann verengern sie sich rasch, so dass ein länglicher, doch nicht zu langer Kegel entsteht. Am zugespitzten Ende gehen die Psendopodien in einen diunnen Faden über, der sich bald aus dem Gesicht verliert. Zuweilen theilt sich der Kegel, anstatt sich zuzuspitzen um in einen Faden iberzugehen, und dann erscheint der Kegel mit zwei Fäden versehen. Im Innern des Körpers sieht man einen ziemlich grossen, matten Kern und zwei sehr beträchtliche Vacuolen (wahrscheinlich ist die Zahl 2 nicht als eine constante anzusehen). Ausserdem kann man im Innern des Körpers Nichts unterscheiden, man sieht kein winziges Körnchen, es ist ganz farblos und durchsichtig, wie die Tentakeln. Die Bewegungen sind äusserst langsam und ruhig; die Consistenz sehr dicht, die Amöbe fliesst nicht. Der Körperdurchmesser ohne Pseudopodien = beinahe $0,001 \mathrm{~mm}$. Für diese Art ist folglich die dicke Consistenz des Körpers, die im Innern desselben sich zusammenziehenden Vacuolen, die Form der aus mit einem Faden rersehenen Kegeln bestehenden Pseudopodien charakteristisch.

Fundort: Weisses Meer, bei den Solowetzky-Inseln, in der Kloster-Bucht, zwischen den Algen, ein Exemplar (18. Juli 1877).

\section{Monera Haeckel.}

Von den Moneren beobachtete ich nur 4 Arten, von denen drei marin, und eine Süsswasserbewohner ist. Aus den marinen stellt die Eine neue Gattung vor, die ich E. Häckel, dem Begründer der Gruppe, zu Ehren Häckelina ${ }^{1}$ ) nenne. Ausserdem fand

1) Jüngst wurde von Bessels ein Rhizopod gefunden, das er Haeckelina gigantea Bes. benannte. (Jen. Zeitschr. B. XV, 1874, S. 264-279.) Da aber dieselbe Art noch in den 50er Jahren von Sandall gefunden und unter dem Namen von Astrorrhiza beschrieben war, muss der letztere Namen der Priorität wegen erhalten werden und der Name Haeckelina bleibt folglich erledigt.

Hier will ich beiläufig in Betreff des Rhizopoden Astrorrhiza einige Bemerkungen machen: Seit Sandall fand man sie mehr als einmal und jeder Entdecker belegte sie mit einem neuen generischen Namen, so dass jetzt 
ich eine nene Art Protamöba, die ich Herrn O. Grimm zu Ehren P. Grimmi nenne.

\section{Haeckelina, novum genus.}

Alle bis jetzt bekannten Moneren haben jenes Merkmal gemein, dass sie freie Organismen darstellen, die während der thätigen Lebensperioden, also wenn sie nicht encystirt sind, herumwandern. Meine Gattung wird eben durch jenes Merkmal charakterisirt, dass sie nicht frei, sondern mittelst eines mehr oder weniger langen Stieles angeheftet ist, so dass das Thier nicht wandern kann. Ohne Zweifel erseheint ein solcher Sticl schon als ein Resultat der Differenzirung, einer gewissen Vervollkommnang, oder richtiger Complizirung; darum muss diese Gattung im System höher als jene gestellt werden, die das ganze Leben hindurch nur aus einem homogenen Plasmakliumpchen, ohne jegliche Organe, ausser den Pseudopodien bestehen. Aber, abgesehen von diesem Stiele, ist Häckelina in allen ubrigen Verhältnissen einer gewöhnlichen Monere ähnlich, der Körper besteht aus einer ProtoplasmaKugel ohne Kern und Vacuole, die an der ganzen Oberfläche Tentakeln aussendet, folglich böchst mögliche Einfachbeit darbietet. Also ist die Diagnosis dieser neuen Gattung, die bisweilen nur eine Art einschliesst, wie folgt:

Diagnosis. Der Organismus besteht aus einem Protoplasmakörper, ohne Kern und Vacuolen, mit dünnen, keine Geflechte bildenden Pseudopodien, und aus einem mehr oder weniger langen Stiele, dessen unteres Ende an fremde Gegenstände angeheftet ist, während am oberen Ende der Körper selbst sitzt. Der Stiel besteht nicht aus dem Plasma, sondern ist eine Ausscheidung desselben. Die Fortpflanzung ist unbekannt. Lebt im Meereswasser.

\section{Haeckelina borealis, nov. sp.}

Taf. XI, Fig. 5.

Als ich an die Solowetzky-Inseln im Jahre $1877 \mathrm{kam}$, so

zwischen den Synonymen der Gattung Astrorrhiza sich folgende Benennungen finden: Astrodiscus, Arenistella, Ammodiscus und Haeckelina.

Jedenfalls, so viel ich weiss, war der von mir der Monere des Weissen Meeres gegebene Namen ausser dem obigen Rhizopoden noch keinem Thiere gegeben. 
brachte ich schon nach der ersten Excursion (an der Kïste) Algen, die in der Tiefe der Kloster-Bucht wachsen, und auf einer solchen Conferven fand ich diesen interessanten Organismus. Er sitzt auf einem beinahe $0,15^{\prime \prime \prime}$ langen und verhältnissmässig sehr dünnen Stiele, da die Breite desselben 0,0025“" nicht übertraf. Dieser Stiel ist ganz farblos und durchsichtig, gewöhnlich aber nicht ganz gerade, sondern verschiedenartig und zierlich gebogen. Uebrigens erreicht er nicht immer eine so beträchtliche Höhe, denn später, 28. Juni, fand ich auf einer andern, pelagiseh d. h. mittelst des Miiller'schen Netzes gefangenen Alge, ein Exemplar dieses Organismus, bei dem der Stiel fast zweimal kürzer war, obwohl die Breite unveränderlich blieb. In der Mitte des Stieles kann man keinen Canal bemerken, seine Contouren sind einfach, also ist er nicht bohl. Seine Bildung erkliirt sich ebenso wie bei Podophrya Lyngbyi, deren Stiele er ganz analog ist; das ist eine Ausscheidung des Protoplasma, die beständig nur immer an demselben Orte, an der unteren Oberfliche vor sich geht. Die Breite des Sticles bleibt überall gleich. Am oberen Ende desselben ist der runde, oft regelmässig-kugelförmige Körper der Monere selbst angeheftet. Die Contouren dieser Kugel sind sehr scharf; wenn man sie während langer Zeit beobachtet, dann sieht man wie sie ein wenig ibre Form ändert: dies geht langsam vor sich und die Kugel wird dadurch etwas eckig. Nach einigen Stunden bemerkte ich, dass die früher regelmässig kugelförmige Gestalt in eine etwas verlängerte, birnenfơrmige überging, so dass also der Körper eine wenn auch sehr geringe Bewegung zeigt. Der Inhalt besteht aus Körnern von verschiedener Grösse, einige sind etwas grösser und grünlich oder rosafarbig, andere kleiner und farblos. Zuweilen giebt es gar keine gefärbte Körner. Ausser diesen Körnern benerkte ich in einem Individuum 3-4 ganz runde, stark lichtbrechende Kugeln, wahrscheinlich Oeltropfen. Weder ein Kern noch eine Vacuole waren vorhauden.

Anfangs bemerkte ich gar nicht die Pseudopodien, so dünn und schwer sichtbar sind sie. Man muss gut den Spiegel des Mikroskopes einstellen, um sie deutlich zu sehen. Sie sind äusserst dünn und farblos, in grosser Zahl vorhanden, verästeln sich aber nicht und bilden niemals Geflechte. Der Durchmesser der Kugel oder des Körpers der Monere selbst gleicht 0,021“".

Leider konnte ich die vielleicht viel interessantes darbietende 
Entwicklungsgesehichte dieser Monere nicht verfolgen, da noch viele andere Arbeiten meine Zeit beanspruchten und mir weniger, als ich es wünschte, mit den Urthieren mich zu beschäftigen gestatteten. Nachdem ich einen ganzen Tag hindurch an dieser Monere ohne Erfolg arbeitete, warf ich die Sache ohne Weiteres weg, den andern Beobachtern, die nach mir die Solowetzky-Inseln besuchen werden, meine Beobachtungen zu vervollständigen uberlassend. Dies wird um so leichter sein, als meine Monere in Menge in der Bucht selbst vorkommt (z. B. bei Swiatija Worota, wo auf dem Sande in Menge die grüne Alge - Enteromorpha intestinalis - wächst). Es kann aber daran kein Zweifel sein, dass bei ibr die Cysten- und Sporenbildung vorkommt, dass folglich sie zur höheren Gruppe der Moneren, der Lepomoneren, gehört; zu Gunsten dieser Ansicht spricht anch die differenzirte Form dieses Organismus. Also wird die Diaunosis dieser Art des Weissen Meeres folgende sein.

Haeckelina borealis n. sp. Der Stiel ist durchsichtig, farblos, solid, ohne Canal in der Axe, lang und schmal, an der ganzen Ausdehnung von gleicher Breite $=0,0025^{\prime \prime \prime}$, mit einem Ende an den Algen angeheftet. Der Körper sitzt auf dem anderen Ende angeheftet, er ist kugelförmig, farblos, erreicht beinahe $0,021^{\prime \prime \prime ~ i m ~}$ Durchmesser, wenig seine Form durch Contraction ändernd, und enthält ziemlich viele verschiedenartige Körner. Die Pseudopodien sind sehr zart und dünn, der Länge nach sind sie fast dem Kugeldurchmesser gleich und dicht tiber seine ganze Oberfläche zerstreut. Die Fortpflanzung ist unbekannt.

Fundort: 1) Weisses Meer, Kloster-Bucht, neben Swiatija Worota, auf den Algen, die an der sandigen Küste wachsen, viel (16. Juni 1877). 2) 28. Juni, ebenda, auf den Conferven, die pelagisch gēfangen wurden.

Diese Monere ist in jener Hinsicht höchst interessant, dass sie vielleicht als eine Stammform verschiedener niederer, ebenso angeheftet an einem Orte lebender Organismen zu betrachten ist: so z. B. für Acineta, Podophrya, Clathrulina etc. Was die Acineten betrifft, so ist es noch eine Streitfrage, da ihre Entwickelungsgeschichte daræuf hinweist, dass diese Formen ehemals eben solche freischwimmende Organismen, als die übrigen Infusorien waren, ihre Sangröhrchen stellen kein Analagon der Pseudopodien der Rhizopoden vor. Was aber die Clathrulina betrifft, so besteht wirk- 
lich zwischen beiden eine grosse Aehnlichkeit und höchst wahrscheinlich auch ein naher verwandtschaftlicher Zusammenhang.

Protamoeba Grimmi, n. sp.

Taf. XI, Fig. 36 und 37.

Der Körper besteht ans einem äusserst kleinen farblosen Protoplasmaklümpchen, das farblos, ganz körnerlos, von runder oder ovaler Form ist und circa 0,0045" im Durchmesser hat. Der Körper sendet nach allen Seiten (5-7) sehr lange, den Körperdurchmesser viel übertreffende (etwa $8 \mathrm{Mal}$ ) und unmessbar dünne Pseudopodien. Mittelst dieser Pseudopodien bewegt sich die Monere ziemlich schnell, indem sie dieselben nach allen Richtungen biegt, und erinnert der allgemeinen Figur nach an irgend welche langbeinige Spinnen (z. B. Phalangium). Die höchst charakteristische Schlankheit und Länge dieser Pseudopodien, die unbeträchtliche Grösse des Körpers selbst and die Abwesenheit irgend welcher Körner unterscheidet sebr scharf diese Art von allen ubrigen der Gattung Protamoeba, zu der ich diese Form zu zäblen für mäglich halte, indem ich mich auf eben solche zuverlässige oder richtiger unzuverlässige Gründe stiutze, wie die bei der Aufstellung anderer Arten gebräuchliche, denn es gelingt nicht immer die Fortpflanzung durch einfache Theilung zu beobachten, und noch schwerer ist es sich zu tiberzeugen, dass die vorliegende Form niemals Cysten bilde.

Die Consistenz des Körpers ist sehr dick, die Veränderungen des Körpers selbst sehr langsam.

Fundort: Weisses Meer, Solowetzky-Inseln, Ende Juli 1877, zwischen den Algen.

Die wenigen Feraminiferen, die ich bis jetzt Gelegenheit hatte $\mathrm{zu}$ bestimmen, sind folgende: Truncatulina lobatula, Miliola seminulum L., Polystomella umbillicatula, Rotalina inflata (?), Rotalina nitida, Nonionina Jeffreysii, Patellina corrugata, Textilaria sp. (mit Sand incrustirt) und Spirillina byalina nor. sp. (völlig hyalin und durchsichtig, glatt und ohne Poren). Was die Radiolarien betrifft, so konnten Herr Professor Nic. Wagner und ich, obgleich wir darnach suchten, kein einziges Exemplar finden. 


\section{Allgemeine Folgerungen und Schlüsse über die geographische Verbreitung der Infusorien.}

In meiner russisch geschriebenen Arbeit ${ }^{1}$ ) führte ich im Ganzen 150 Arten (jetzt sind es 151 Arten) der Urthiere aus den verschiedensten Gruppen auf, darunter befinden sich 37 für die Wissenschaft ganz neue Formen, die theils in die alten, theils aber in neu aufgestellte Gattungen vertheilt sind. Alle diese 150 Arten sind für's Weisse Meer und für's Nördliche Russland uberhaupt ganz neu, da wir in der Literatur (mit Ausschluss von Petersburg und Jaroslawl) keine Anzeigen hinsichtlich dieses Theiles der Fauna weder für süsse Gewässer, noch für das Weisse Meer selbst finden. Am zahlreichsten werden unter den Protozoen - die Infusorien repräsentirt (121 Arten) und zwischen diesen nehmen der Art nach die erste Stelle der höheren Infusorien die Ciliata und dann die Flagellifera ein. Von Rhizopoden wurden am meisten die Amöbinen oder die nackten Wurzelfüssler aufgefunden. (Wir sehen dalei von den marinen Foraminiferen ab, die ohne Zweifel den bedeutendsten Theil der Rhizopodengruppe bilden.) Dies Alles zeigt die folgende vergleichende Tabelle:

I. Infusorien :

Zahl der aufgef. Arten: Davon sind neu:

1. Ciliata . . . . . $82 \quad 14$

2. Acinetina (Suctoria) . . 992

3. Flagellifera . . . . $30 \quad 8$

II. Rhizopoda.

1. Heliozoa . . . . . . 5

2. Monothalamia . . . . 8

3. Amoebina . . . . . $11 \quad 8$

III. Monera

$\begin{array}{crrr}\cdot . \quad \cdot \quad \cdot & 4 & 2 \\ \text { Im Ganzen . . . } 150 & 37\end{array}$

Sowie für meine weitere Zwecke es nöthig sein wird die Süsswasserfauna mit der marinen zu vergleichen, so führe ich der

1) Arbeiten der St. Petersburger Naturforscher-Gesellschaft, 1877 (in russischer Sprache) T. VIII (1877). 
grösseren Bequemlichkeit wegen ein Verzeichniss aller bis jetzt von mir gefundenen marinen Arten an, die in der allgemeinen $\mathrm{Ar}$ beit zu sebr zerstreut sind, um eine Gesammt-Uebersicht zu gestatten. Im Ganzen fand ich 48 Arten der marinen Protozoen.
1. Cothurnia maritima.
25. Freia ampulla.
2. C. nodosa.
26. Balantidium Medusarum.
3. C. compressa.
27. Cyclidium citrinum.
4. C. grandis.
28. Uronema marina.
5. C. arcuata.
29. Loxophyllum rostratum.
6. Vorticella Pyrum.
30. Podophrya fixa.
7. V. colorata.
31. P. conipes.
8. Zoothamnium alternans.
32. Acineta patula.
9. Zooth. marinum.
33. A. tuberosa.
10. Epistylis Balanorum.
34. A. Saïfulae.
11. Tintinnus inquilinus.
35. Ceratium divergens.
12. T. denticulatus.
36. Dinophysis arctica.
13. T. Ussowi.
37. Euglena deses.
14. T. intermedius.
38. Urceolus Alenizini.
15. Halteria pulex.
39. Heteromita cylindrica.
16. Strombidium sulcatum.
40. Heteromita adunca.
17. Oxytricha retractilis.
41. Hyalodiscus Korotnewi.
18. 0. Wrzesniowskii.
42. Amoeba crassa.
19. O. oculata.
43. A. minuta.
20. Epiclinthes auricularis.
44. A. alveolata.
21. Euplotes charon.
45. A. filifera.
22. Styloplotes norwegicus.
46. Haeckelina borealis.
23. Aspidisca Andreewi.
47. Protamoeba Grimmi.
24. Ervillia monostyla.
48. Protamoeba polypodia.

Wenn die Zahl der Stisswasser-Arten, die mir zur Beobachtung kamen, bedeutend die der marinen übertrifft, so kann man es, mindestens theilweise, durch jenen Umstand erklären, dass ich dem Studium der marinen Arten viel weniger Zeit widmen konnte, als für die Untersuchung der süssen Gewässer. In der That glaube ich aber, dass das Meer in dieser Hinsicht kaum den Flüssen, Sümpfen und Seen nachstehe, die nur darum ein solches verhältnissmässiges Reichthum zeigen, dass sie viel mehr Aufmerksamkeit auf sich lenken und eine grössere Zahl Naturforscher sich dem Studium ihrer mikroskopischen Fauna widmete.

Aus der beigefügten vergleichenden Tabelle kann man den 
verhältnissmässigen Reichthum der marinen und Süsswasser-Arten nach den einzelnen Abtheilungen sehen:

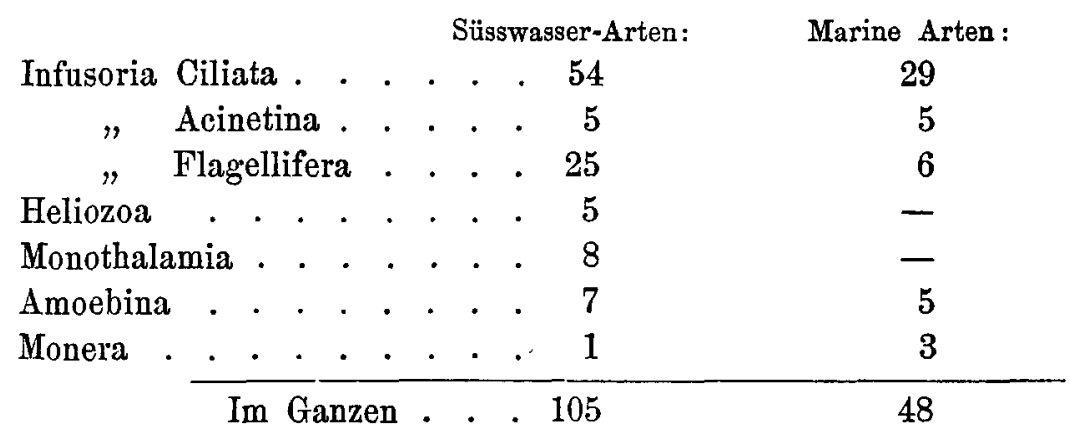

Wie man aus dieser Zusammenstellung sieht, ist das Meer am reichsten mit Acinetinen versehen, sowohl der Zahl der Arten, als auch sebr oft der der Individuen nach. (A. patula, A. tuberosa, P. conipes.) Der gewöhnliche Reichthum aber an Ciliaten im Vergleich mit anderen Gruppen, sowie an Flagelliferen im Vergleich mit Suctorien (Acinetinen) wird im Meere ebenso als in süssen Gewässern erhalten.

In den weiteren Betrachtungen werde ich von den Rhizopoden, grösserer Genauigkeit und Bestimmtheit wegen, ganz absehen und nur die Infusorien, als die einzige mit ziemlicher Ausfuhrlichkeit und Gründlichkeit durchforschte Gruppe, in Betracht ziehen, indem die Amöbinen und Monothalamien so wenig (und dabei nur in wenigen Orten, gelegentlich) bekannt sind, dass irgend welche vergleichende Uebersicht hier noch ganz unmöglich ist. Aber bei diesem Verfahren, d. h. indem ich von den Rhizopoden absehe, muss ich zugleich bemerken, dass eine solche Beschränkung meine Schliusse eher beeinträchtigt, als sie unterstlitzt, dass vielmehr mit den Rhizopoden zusammen die Zahlen noch anschaulicher und frappanter jene Verhältnisse zeigten, die sie auch ohne dieselben deutlich machen.

Zunächst will ich auf den Unterschied hinweisen, der zwischen der Suisswasser- und marinen Fauna existirt. Als ich von den Gräben und Flüssen Archangelsk's gerade zu den Meeresktisten der Solowetzky-Inseln tiberging, so fand ich anfangs keine der von mir schon in Archangelsk und frïher aufgefundenen Arten, der ganze Charakter der Fauna änderte sich plötzlich; hier springt der Unterschied zwischen beiden Faunen am auffallendsten 
in die Augen. Alle weiteren Ergebnisse sind anschaulich in der folgenden Tabelle zusammengestellt:

Arten des Aus denselben sind Das \%-Verhäln. d.

W. Meeres. mit den Süsswasser faun. gemeinen Arten zu

\begin{tabular}{|c|c|c|c|c|}
\hline Ciliata . & . & 29 & $\underset{1}{\text { gemein. }}$ & $\begin{array}{c}\text { den marinen. } \\
3,4 \%\end{array}$ \\
\hline Acinetina . & . & 5 & 1 & 20 \\
\hline Flagellifera & . & 6 & 1 & $16,6 ”$ \\
\hline $\operatorname{Im~Ga}$ & & 40 & 3 & $7,5 \%$ \\
\hline
\end{tabular}

Also erwiesen sich aus den 40 von mir aufgefundenen marinen Arten nur 3 oder 71/2 pCt., namentlich Euplotes charon, Podophrya fixa und Euglena deses (diese letzte Art ist aber höchst zweifelhaft, so dass vielleicht nur $5 \mathrm{pCt}$.) mit den Formen der stissen, ans Weisse Meer angrenzenden Gewässer identisch; dies zeigt uns schon gleich, in welch' hohem Grade die Meeresfauna selbstständig und von der der stissen Gewässer unabhängig ist, und in welch' hohem Grade die veränderten äusseren Lebensbedingungen der Infusorien, wie der Salzgehalt und die chemische Zusammensetzung im Allgemeinen, Temperatur etc., dieselben tief beeinflussten, indem sie eine vollständige und vollkommene Umbildung des Charakters der Fauna hervorgerufen hatten. In dieser Hinsicht also ist gar kein Unterschied zwischen den Infusorien und böheren Gruppen der Thierorganismen, wie Krebse, Fische etc. zu finden; doch gründet man aus den hinsichtlich der letzteren gewonnenen Thatsachen verschiedene Theorien und Hypothesen uber die Verwandtschaft der Meere, uber die Ver:̈nderungen der Begrenzung der Meere und des Festlandes, während man die Infusorien in dieser Hinsicht für ganz bedeutungslos hält. Einige Materialien, die wir in dieser uns interessirenden Frage zu Hülfe ziehen können, befinden sich in Claparède's und Lachmann's Arbeit, wo diese Forscher eine Menge Thatsachen hinsichtlich der Verbreitung der Infusorien zusammenbrachten. Indem ich alle in ihrem Werke zerstreuten marinen Arten zählte, den die genannten Beobachter an der Norwegischen Kuiste, von Bergen an, begegneten und deren Zahl sich beinahe zu 75 ergibt, fand ich nicht mehr als zwei Arten mit den Stisswasserformen gemein, d. h. nicht mehr als 2,4 pCt.; alle tibrigen sind ausschliesslich marin. Erinnern wir uns ferner der Menge mariner Rhizopoden, Foraminiferen, die Nichts mit den Süsswasser-Monothalamien gemein haben, dann der Süsswasser-Heliozoa und marinen Radiolarien; so wird 
dies alles uns deutlich zeigen, dass die marine Protozoen-Fauna etwas ganz anderes, als die der süssen Gewässer ist, dass die niederen Thiere also sich gar nicht so indifferent gegen äussere Bedingungen verhalten, gar nicht so unveränderlich in allen Orten, wo wir sie finden, sind, wie es beim ersten Anblick wegen der äussersten Einfachheit ihrer Organisation scheinen könnte.

Solche einfachen Pflanzenformen wie die Diatomeen und Desmidiaceen, die wohl keineswegs für höher als Protozoen und namentlich Infusorien organisirt zu halten sind, bestätigen auch jenen Schluss, zu dem wir durch Vergleich der Sïsswasser- und marinen Formen gekommen sind. Die Süsswasser-Diatomeen stellen eine ganz selbstständige und von der marinen verschiedene Flora; noch schärfer tritt es an den Desmidiaceen hervor, die ausschliesslich im stissen Wasser leben, und von denen bis jetzt keine einzige Art im rein marinen Wasser gefunden war. Und doch gehören sowohl Desmidiaceen als Diatomeen zu den möglichst einfachen and im Vergleich mit so hoch, obwohl eigenthimlich entwickelten und differenzirten Thieren, wie die höheren Repräsentanten der Infusorien - die Ciliata erscheinen, stehen diese Algen auf einer viel niedrigeren Stufe. Daraus folgt, dass die Einfachheit der Organisation keineswegs eine solche Bedingung vorstellt, die den verändernden Einfluss der äusseren Bedingungen auf den Organismus ausschliesse.

So sind wir zum ersten, ganz unzweifelhaften Schlusse gekommen, dass die marine Infusorienfauna, wie die aller ubrigen Thiergruppen sich dem Einflusse der äusseren Bedingungen unterordnend, ganz von der der süsen Gewässer verschieden ist.

Indem wir weiter den Gegenstand verfolgen, drängt sich die Frage auf, ob es nicht Unterschiede zwischen den Infusorienfaunen versehiedener Meere, die sich durch ihre physischen und chemischen Verhältnisse unterscheiden, gebe; ob nicht in jedem Meere eine eigentliche Infusorienfauna und $o b$ nicht eine vollständige Analogie hinsichtlich der geographisehen Verbreitung der einfachen Organismen mit den in Betreff der Repräsentanten höherer Gruppen bekannten Thatsachen bestehe. $\mathrm{Zu}$ diesem Zwecke haben wir die Fauna des Weissen Meeres mit der irgend eines anderen zu vergleichen, und demselben wird am besten und passendsten die Fauna der Norwegischen Küste entsprechen, sowohl wegen der verhältniss- 
mässigen Nachbarschaft dieses Meeres mit dem Weissen, als auch darum, weil die Fauna der Klisten Norwegens hinsichtlich der Urthiere ziemlich gut bekannt und, was dabei von besonderer Wichtigkeit ist, annähernd mit demselben Grade der Vollständigkeit, wie es mir hinsichtlich der Infusorienfauna des Weissen Meeres gelang, erforscht ist.

Wie schon oben erwähnt, haben Claparède und Lachmann in ihren Etudes unter anderem ihre faunistischen Untersuchungen hinsichtlich der Protozoenfauna der Norwegischen Kusten dargestellt. Im Meere beobachteten sie etwa 73 rein marine Arten, die sich in stissen Gewässern nicht finden; indem man diese Arten mit denen des Weissen Meeres vergleicht, findet man 17 (d. h. 43 pCt.) beiden Meeren gemeine Arten, die nach verschiedenen Abtheilungen folgenderweise sich vertheilen:

Norw. M. Weiss. M. Gem. Arten. \%-Verh. der gem. Arten

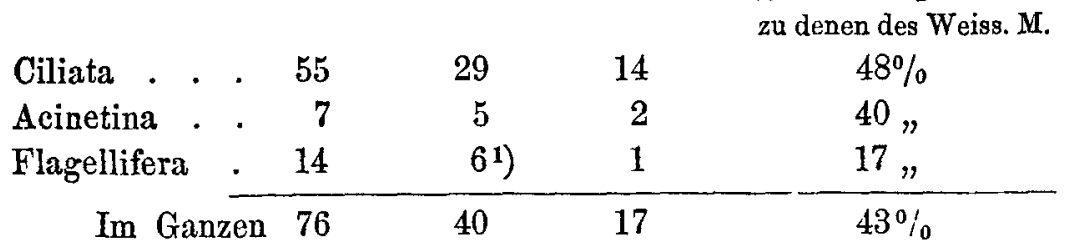

Daraus folgt also, dass $43 \mathrm{pCt}$, d. b. fast eine Hiilfte der Arten des Weissen Meeres, aus den mit den Norwegischen Küsten gemeinen Arten zusammengesetzt wird, also steht die Fauna des Weissen Meeres der der benachbarten Norwegischen Küsten am nächsten; in der That, wenn man aus der Zahl der Arten des Weissen Meeres solche Arten ansschliesst, die nur diesem Meere eigenthümlich sind (bis jetzt wenigstens), d. h. alle 18 neue Arten oder 45 pCt., so bleibt nur noch ein sehr unbeträchtlicher Theil, nämlich 12 pCt, aller Arten des Weissen Meeres, die theils aus bei Norwegen nicht gefundenen und ir taderen Meeren, wie das Baltische, das Nordmeer, das Mittel] ändische etc., vorhandenen, theils aus kosmopolitischen Arten bestehen. Freilich sind andere Meere verhältnissmässig sehr wenig in dieser Hinsicht untersucht,

1) Diese $Z$ ahl ist ohne $Z$ weifel niedriger als die wirkliche, sowie die 2 folgenden. Das hängt wahrscheinlich davon ab, dass ich grössere Aufmerksamkeit den aller Wahrscheinlichkeit nach zahlreichen Repräsentanten der Familie Peridina, die bekanntlich in allen nördlichen Meeren massenhaft vorkommen, nicht widmen konnte. 
um aus dem Vergleich ihrer Faunen irgend welche Schlüsse zu gestatten, doch ist für mich im vorliegenden Falle genügend auf jenes jedenfalls unstreitige Ergebniss hinzuweisen, dass die Infusorienfaunen des Weissen Meeres und Norwegens eine grosse Verwandtschaft zeigen und im hohen Grade ähnlich sind.

Diesen Schluss ins Ange fassend, müssen wir jetzt jenen Umstand beriicksichtigen, dass ausser jenen 17 gemeinen Arten, die sowohl im Weissen Meere als bei Norwegen leben, auch noch 18 Arten (d. h. 45 pCt.) existiren, die nur dem Weissen Meere eigenthümlich, nur in ihm gefunden sind, und an den Norwegischen Küsten nicht vorkommen. Man könnte gegen diese Behauptung einwenden, dass vielleicht mehrere meiner neuen, von mir ausschliesslich im Weissen Meere gefundenen Arten sich auch im Norwegischen Meere finden, dass sie aber bis jetzt wegen der Vernachlässigung dieses Theiles der Fauna nicht gefunden seien, dass Schlïsse, nur auf dem Mangel gewisser Arten begründet, nicht plausibel seien, namentlich aber in diesem Falle, wo die geographische Verbreitung überhaupt so wenig bekannt ist. Diese Einwendung scheint mir aber vollständig durch jenen Umstand entkräftet zu werden, dass beide Faunen annähernd mit demselben Grade der Vollständigkeit untersucht sind, dass Claparède und Lachmann ihre Fauna sogar etwas vollständiger durchforschten, als es mir im Weissen Meere gelang. Es ist folglich unmöglich zu vermuthen, dass diese bewährten Beobachter zufallig gerade jene Arten übersahen, die ich im Weissen Meere beobachtete, um so mehr, als einige darunter in grosser Menge vorkommen, z. B. Zoothamnium marinum, Epistylis Balanorum, Tintinnus Ussowi, Oxytricha Wezesniowskii, O. oculata, Aspidisca Andreewi, Balantidium Medusarum, Podophrya conipes; alle diese Arten gehören zu den gewöhnlichsten des Weissen Meeres, so dass, wenn sie auch in dem Norwegischen existirten, es ganz unglaublich wäre, dass Claparède und Lachmann ihnen nicht begegneten und sie darum übersähen. Wir müssen vielmehr zugeben, dass jene Arten wirklich dem Norwegischen Meere fehlen, dass sie ausschliesslich dem Weissen Meere angehören oder später auch in anderen, rein polaren Meeren zu finden sind, in Meeren also, die kälter als die verhältniş̧ässig ziemlich warmen Norwegischen sind.

Wenn für die gleich angeftuhrten Arten im hohen Grade wahrscheinlich ist, dass sie speciell dem Weissen Meere angehören, 
oder überhaupt an den norwegischen Küsten nicht vorkommen, so wird für zwei Arten, namentlich Tintinnus Ussowi und Podophrya conipes, diese Wahrscheinlichkeit zur vollständigen Gewissheit. Und wirklich, obwohl diese zwei Arten zwei bonae species mit sehr constanten Merkmalen vorstellen, stehen sie im nächsten genetischen Zusammenhange, eine mit T. subulatus, die andere mit P. Lynbyi und stammen ohne Zweifel von den letzteren her (oder umgekehrt); doch fand ich weder diese, noch jene Art, die höchst gemein in Norwegen sind, im Weissen Meere. Dagegen sind hier T. Ussowi und P. conipes äusserst gemein und sind keineswegs zu ubersehen. Darum glaube ich, dass in Norwegen gewiss weder T. Ussowi, noch P. conipes vorkommt. Diese zwei Arten haben sich unter dem Einflusse der veränderten Bedingungen des umgebenden Mediums umgebildet und verwandelten sich in zwei besondere, die mässigeren Meere charakterisirende Arten. Aus allem obigen geht also hervor, dass nicht nur die Meeresfauna der Infusorien von der der sïssen Gewässer verschieden ist, dass aber auch die Faunen benachbarter Meere, zuweilen sogar von einander ganz unweit abstehender, wie z.B. das Weisse und Norwegische Meer, desto nicht weniger sehr bedeutend oder jedenfalls mehr oder weniger von einander abweichen können, sich dem Einflusse der veränderten Bedingungen des umgebenden Mediums unterordnend.

Wenn man sogar zulässt, dass nicht alle 45 Arten wirklich rein polare oder dern Weissen Meere eigenthlimliche Arten, dass einige davon noch in Norwegen zu finden seien, bleibt doch unzweifelhaft, dass andere und gerade die gewöhnlichsten, am öftesten vorkommenden Arten stets beide Faunen unterscheiden und ganz unstreitig beweisen, dass zwei benachbarte Gebiete, die sich von einander durch Temperatur, Salzgehalt ${ }^{1}$ ) und andere Bedingungen unterscheiden, auch durch den Charakter der Infusorien-

1) Aus der chemischen Analyse, die unser Chemiker Sehmidt ausgeführt hat, folgt, dass der Salzgehalt des Weissen Meeres an der Oberfläche ziemlich bedeutend hinter dem Salzgehalte des Oceans steht. Doch ist immer zu berücksichtigen, dass dieser Schluss nur die Meeresoberfläche betrifft. Was aber den Salzgehalt der Tiefe betrifft, so wurden in dieser Hinsicht noch keine genaueren Beobachtungen, d. h. chemische Analysen, gemacht; es kann aber sehr leicht geschehen, dass hier der Salzgehalt entweder dem des Oceans gleiche, oder von ihm viel weniger als der der Oberfäche sich unterscheide. 
fauna von einander abweichen und in dieser Hinsicht sogar keinen wesentlichen Unterschied von den in Betreff aller anderen Thierund Pflanzengruppen bekannten Thatsachen darbieten. Hier wäre es auch nicht übertlüssig zu erinnern, dass die Foraminiferen oder marinen Rhizopoden in sehr hohem Grade die Abhängigkeit ihrer Organisation von äusseren Einflïssen zeigen; die Faunen verschiedener Meere weichen ziemlich stark von einander ab.

Dann lenke ich die Aufmerksamkeit auf jenen interessanten Umstand, dass trotz meiner Bemtihungen und namentlich der Nachsuchungen des Prof. N. Wagner, wir beide keinen einzigen Repräsentanten der Meeresradiolarien auffinden konnten, obgleich sowohl N. Wagner als ich das Weisse Meer schon zum zweiten Male besuchten. Also ist offenbar, dass es entweder gar keine Radiolarien in diesem Meere giebt, oder, wenn sie sich dort auch befinden, so sind sie so wenig zahlreich, dass es schwer ist ihnen zu begegnen. Und doch begegnet man in wärmeren Meeren und selbst an den Küsten Norwegens, besonders aber im Mittelmeere den Repräsentanten dieser Gruppe der Protozoen in grosser Menge.

Das ist auch eine sehr viel bedeutende Thatsache, die uns zeigt, dass das Studium der Protozoenfauna verschiedener Gebiete keineswegs den Schluss gestattet, zu dem einige Forscher gekommen sind, nämlich, „dass die einfachsten Organismen sich am indifferentesten gegen das sie umgebende Medium, gegen die äusseren Bedingungen, verhalten, da sie der Einfachheit ihrer Organisation wegen am meisten stabil sind". Die Einfachheit der Organisation scheint hier gar keine Rolle zu spielen, die einfachste, ebenso wie die complicirteste Maschine ändern sich in gleicher Weise unter dem Einflusse des sie umgebenden Mediums, beide verrosten in fenchter Luft; wenn aber die complicirtere Maschine in jener Hinsicht minder beständig ist, dass sie eher verderben wird, so hängt es gar nicht von den äusseren Bedingungen, sondern von dem Functioniren, von der Arbeitleistung der Maschine selbst ab. Solch eine Ansicht kann aber ohne Weiteres auf eine Zelle nicht übertragen werden, denn der Lebensvorgang wirkt keineswegs zerstörend auf ihre Structur selbst, wie es in einer Maschine geschieht, dann lässt sich auch der Lebensvorgang mit der Arbeit einer Maschine nicht vergleichen. Folglich stellt sich a priori kein Widerspruch der Annahme entgegen, dass auch die einfachsten Thiere sich unter dem Einflusse der äusseren Bedingungen verän- 
dern können. Doch ist auch ,ein einfachstes Thier" gar nicht so einfach, wie es scheinen möge; es ist nur morphologisch einfach, physiologisch aber ist es sehr complicirt, da es alle Leistungen der höheren Organismen vollzieht: es nährt sich, es athmet, es bewegt sich, es vermehrt sich, es empfindet. Die höheren Organismen aber sind nur darum complicirt, dass sie aus einer Menge niederer Individuen oder Zellen, aus denselben Amöben oder Infusorien zusammengesetzt sind; doch sind die letzteren weit einfacher und weit einseitiger entwickelt, als die freilebenden Zellen; und in der That ist irgend welche einzellige Drüse, die ibr ganzes Leben hindurch nur eine Arbeit leistet, nur eine bestimmte Flüssigkeit ausscheidet, viel einfacher als eine Amöbe, und um so mehr als ein Infusorium, besonders aus der Ciliatengruppe. Warum aber werden die äusseren Bedingungen auf einen Complex sehr einfacher und einseitig entwickelter Zellen mehr Wirkung austuben, als auf eine hochorganisirte freilebende Zelle - ein Infusorium? Man könnte antworten, dass bei einem vielzelligen Organismus die inneren Verhältnisse ${ }^{1}$ ), Dank der Mannigfaltigkeit der ihn zusammensetzenden Elemente, auch viel mannigfaltiger ausfallen werden, darum werde ihre Anpassung auch an eine grössere Zahl äussere Verhältnisse stattfinden, folglich mïsse auch eine grössere Veränderlichkeit hervorgerufen werden; aber ich erlaube mir zu zweifeln, dass die inneren Verhältnisse, also Gelegenheiten für den Einfluss äusserer Bedingungen, bei irgend einem Hydroide oder Schwamme mannigfaltiger als bei einem Infusorium mit Cuticula und Wimpern, mit Ekto- und Endoplasma, mit einem deutlich differenzirten Nahrungskanale, mit Nesselorganen, mit besonderen Organen, Nucleus und Nucleolus, mit einer pulsirenden, zuweilen in ein ganzes System von Kanälen entwickelten Vacuole etc., seien; darum wird auch das Leben des Infusoriums oder „die Anpassung" mit gleicher Mannigfaltigkeit als in, höheren Thieren, in Hydroiden oder Schwämmen z. B. sich vollziehen; in einem Infusorium wird sie sogar mit grösserer Concentration vor sich gehen, Dank dem kleineren Raume, in dem die Differenzirung concentrirt ist.

Alle diese Betrachtungen werden auch durch Thatsacben be-

1) Das Leben ist eine stetige Anpassung der inneren Verhältnisse eines Organismus an die äusseren (H. Spencer). 
stätigt, sowohl durch die oben angeführten, als auch durch die hinsichtlich der Verbreitung der niederen Algen, z. B. der Diatomeen bekannten: die letzteren sind keineswegs höher, im Gegentheil viel einfacher als irgend ein Infusorium; doch ist die Diatomeenflora verschiedener Meere verschieden und in so hohem Grade, dass man aus den Thatsachen der Verbreitung derselben verschiedene Schlïsse ïber die Verwandtschaft dieser Meere und Bassine zieht, ganz wie man auf Grund des Studiums höherer Thiere und Pflanzen verfährt.

Wir kommen also zum zweiten Schlusse, dass die Infusorien(Protozoen)faunen verschiedener Meere, die durch ungleiche Bedingungen sich unterscheiden, verschieden sind und dass die Infusorien sich in dieser Hinsicht beinahe ebenso verhalten, wie jede beliebige Gruppe höherer, mehr entwickelter und vollkommenerer Thiere.

Dieser Schluss zeigt uns die Bedeutung, die das Studium der Infusorienfauna verschiedener Meere hat. Das letzte galt bis in die jüngste Zeit für ganz überflüssiges, nutzloses, keine Schlüsse gestattendes; solche Gedanken drängen sich wenigstens auf, wenn man die vollständige Vernachlüssigung der Infusorienfauna verschiedener Meere berücksichtigt. Es scheint mir, dass ein solches sonderbares und, man kann sagen, nur auf Vorurtheilen begründetes Verfahren binsichtlich der Infusorien jetzt weggeworfen werden muss und dass man das Studium der geographischen Verbreitung der Urthiere auf der Oberfäche der Erdkugel, namentlich in Meeren mit eben solcher Genauigkeit und Fleiss aufnehmen muss, mit denen man in dieser Richtung das Studium anderer Thiergruppen verfolgt. Man kann dabei entschieden die Hoffnung hegen, ich meinerseits bin sogar daron überzeugt, dass solche Bemühungen durch interessante Entdeckungen vollständig belohnt werden, die sowohl zur Erörterung der Geschichte der Erde überhaupt, als auch der der organischen Welt im Besonderen beitragen werden.

Einer der merkwürdigsten Schlüsse, die aus dem Vergleich der Süsswasserarten mit den marinen zu ziehen sind, ist derjenige, dass die Mehrzahl der neuen Infusorienformen, die im vorigen Capitel beschrieben wurden, za den Meeresinfusorien gehören, während die Zahl der neuen S üsswasserinfusorien, die sich in den ans Weisse Meer angrenzenden Localitäten begegnen, höchst unbedeutend ist. Ich werde dabei nochmals hervorheben, dass 
solche Arten wie Zoothamnium marinum, Epistylis Balanorum, Tintinnus Ussowi, Oxitricha Wrzesniowskii, 0. oculata, Aspidisca Andrewi, Balantidium Medusarum, Podophrya conipes und mehrere andere zu den gewöhnlichsten, überall und in grosser Menge dem Beobachter vorkommenden Thieren gehören. Wenn man ausserdem beriicksichtigt, dass Claparède und Lachmann ziemlich sorgfältig die Infusorien der norwegischen Küsten untersuchten und beschrieben, so wird es einleuchten, dass alle diese Arten bei Norwegen höchst wahrscheinlich nicht vorkommen, und fürs Weisse Meer oder iberhaupt für polare Meere charakteristisch sind. In solchem Falle miussen wir aber annehmen, dass das Weisse Meer, obwohl es dem Norwegischen sehr nahe liegt, sich nichts desto weniger ziemlich bedeutend dem Charakter der Fauna nach unterscheidet: von allen 40 Arten von mir im Weissen Meere aufgefundenen Infusorien sind mindestens 18 oder $45 \mathrm{pCt}$. ganz neu; während gleichzeitig in den süssen Gewässern sowohl der Solowetzky-Inseln (Swiatojie Osero, Heiliger See), als auch in den von Archangelsk und Sumky Possad (auch in und an der nördlichen Dwina), bei sorgfältigerer und vollständigerer Untersuchung, als die am Neere ausgeführte, nur 6 oder $7 \mathrm{pCt}$. neuer Arten finden konnte; alle tibrigen aber - $93 \mathrm{pCt}$. - gehören zu der Fauna des westlichen Europa. Dies alles wird durch die hinzugefügte Tabelle verdeatlicht:

\begin{tabular}{|c|c|c|c|c|c|c|c|c|}
\hline & \multicolumn{3}{|c|}{ Süsswasserarten } & \multirow{2}{*}{ 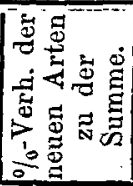 } & \multicolumn{3}{|c|}{ Marine Arten } & \multirow{2}{*}{ 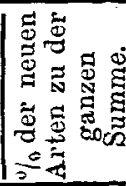 } \\
\hline & alte. & neue. & Ganz. & & alte. & neue. & $\begin{array}{c}\operatorname{im}_{\text {Ganz. }} \\
\text { Gan }\end{array}$ & \\
\hline Ciliata. & 52 & 2 & 54 & $3,7 \%$ & 17 & 12 & 29 & $41,4 \%$ \\
\hline Acinetina & 5 & - & 5 & 0, & 3 & 2 & 5 & 40, \\
\hline Flagellifera & 21 & 4 & 25 & $16 "$ & 2 & 4 & 6 & 66,6 \\
\hline Im Ganzen & 78 & 6 & 84 & $7 \%$ & 22 & 18 & 40 & $45 \%$ \\
\hline
\end{tabular}

Aus dieser Tabelle kann man ganz deutlich sehen, dass während die Süsswasserfauna sich fast gar nicht von der des westlichen Europas anterscheidet, die marine dagegen für's Weisse Meer 
sebr characteristisch ist und ziemlich bedeutend sogar von der der sebr naheliegenden, die norwegiseben Küsten bespülenden Meere abweicht.

Also kommen wir zum dritten, meiner Meinung nach interessantesten Schlusse oder Gesetze, nämlich, dass die marine Protozoenfauna weit mehr in verschiedenen Meeren sich ändert, als die Süsswasser-Protozoenfaunaverschiedener Länder.

Man könnte einwenden, dass unsere Kenntnisse über die Verbreitung der Infusorien so unbedeutend und unvollkommen seien, dass aus ihnen irgend welche Schliusse und Folgerungen zu ziehen mindestens vorzeitig wäre, und alle solche auf so unsichern Thatsachen gegründeten Ansichten keine Garantien für ihre Gultigkeit und Gewissheit darbieten.

Aber eine solche Einwendung wäre zu allgemein und hätte ihre Berechtigung nur dann, wenn ich den Vergleich aller Meere, die zu wenig oder gar nicht in Betreff der Infusorien bekannt sind, beabsichtigte. So aber verfahre ich nicht, sondern griunde alle Schlüsse ausschliesslich auf dem Vergleich der Faunen des Weissen und des Norwegischen Meeres. In der That ist es unstreitig, dass z. B. die Infusorienfaunen des Baltischen, des Nord, des Schwarzen, des Mittelländischen und anderer Meere zu vergleichen ganz undenkbar ist und keinen einzigen nur ein wenig genauen, unzweifelhaften und positiven Schluss liefert. Dies bezieht sich aber nicht auf die Fauna der Norwegischen Küsten, denn dieselbe war, wie schon erwähnt, ziemlich vollständig und gründlich von zwei bekannten Forschern untersucht.

Wenn ich unter den Repräsentanten dieser Fauna etwa 15 im Weissen Meere höchst gewöhnliche und verbreitete Arten nicht finde, so kann ich mit Fug und Recht behaupten, dass die Fauna des Weissen Meeres sich beträchtlich von der des Norwegischen unterscheidet; wenn es sich ausserdem erweist, dass ich in den an's Weisse Meer angrenzenden süssen Gewässern Nichts ähnliches bemerkte und fast gar keine neue Formen fand, so glaube ich mich auch ohne jeglichen Anstand zu behaupten berechtigt, dass die marine Fauna verschiedener Meere sich mehr als die Süsswasserfauna verschiedener Länder unterscheidet.

Also wird die gegen meine Ansicht oben angeführte Einwen- 
dung ganz entkräftigt, sie ist folglich meine Schltisse im mindesten zu erschittern nicht im Stande.

Zur Unterstuitzung derselben kann ich noch folgende mir bekannte Thatsachen der Verbreitung sowohl niederer Thiere, als anch niederer Pflanzen anfuhren. Aus Carter's Untersuchungen ist z. B. bekannt, dass die Indischen Süsswasserinfusorien fast ganz mit den europäischen identisch sind; dasselbe folgt aus den Thatsachen, die Schmarda in Africa sammelte, wo er eine Menge europäischer Arten in süssen Gewässern fand; endlich kann man noch zu diesem Zwecke auf die in den Aufsätzen Baley's hinsichtlich der Nord-Americanischen Arten angefiuhrten Thatsachen hinweisen. Anderseits aber ist uns bekannt (und es wäre die Aufmerksamkeit der Forscher darauf zu lenken wïnschenswerth), dass z. B. die Radiolarienfauna verschiedener südlicher und nördlicher Meere im hohen Grade von einander abweicht, dass die Infusorien aus der Fam. der Peridinina besonders zahlreich und mannigfaltig in den nördlichen und polaren Meeren sind, dass die marine Rhi=zopodenfauna den verschiedenen Gebieten nach auch verschieden ist. Dazu ist noch eine sehr interessante Thatsache hinzuzuftigen, die uns die geographische Verbreitung der sehr einfach organisirten Desmidiaceen darbietet. Es erweist sich: 1) dass Desmidiaceen ausschliesslich in süssen Gewässern (auch im brackischen, niemals aber im rein marinen Wasser) leben; 2) dass die Floren verschiedenster Localitäten sowohl in Europa, als auch in America fast ganz untereinander identisch zu sein scheinen ${ }^{1}$ ).

Während meines letzten Ausflugs nach dem Weissen Meere beobachtete und untersuchte ich unterwegs auch an den SolowetzkyInseln selbst die dortigen einzelligen Algen, insbesondere aber die Desmidiaceen. Daraus ergab sich, dass die Flora dieser Algen im iiussersten Norden Russlands fast im Nichts sich nicht nur von den Europäischen Arten (Deutschlands, Englands) unterscheidet, sonder sogar mit der nordamericanischen fast ganz identisch ist; von den ungefähr 30 von mir aufgefundenen und schon bestimmten Arten erwiesen sich nur 2 oder 3 als neu (etwa $7 \%$, alle übrigen $93^{0 /}{ }_{i}$ sind gemein). Gleichzeitig zeigen die Diatomeen, die gar nicht niedriger als Desmidiaceen organisirt sind und die sowohl in Meeren, als in süssen Gewässern leben, hinsichtlich ihrer Ver-

1) S. Ralfs, British Desmidiaceae, Introduction. 
breitung in verschiedenen Meeren in einem eben solchen Grade die Abhängigkeit von den verschiedenen Bedingungen, wie es in Betreff höherer Algen und Thiere bekannt ist ${ }^{1}$ ).

Wenn aber Alles sich wirklich so verhält, wenn die marine Fauna wirklich in verschiedenen Meeren weit mehr von einander abweicht, als die Stisswasserfauna in verschiedenen Ländern, so drängt sich natürlich die Frage auf: welche Ursache liegt doch dieser sonderbaren und geheimnissvollen Erscheinung zu Grunde, die sogar unglaublich, eher auf unseren ungenügenden Kenntnissen der Verbreitung der Infusorien, als auf festen und überzeugenden Thatsachen gegrïndet zu sein schien? Wenn man aber dem obigen Gesetze eine gentigende Erklärung geben wird, wenn man seine Ursache erörtert, dann verliert er selbst in hohem Grade an Unglaublichkeit, und die oben angefuihrten Thatsachen werden sich sowobl ihrer Zahl, als Bedeutung nach ganz zur Annahme desselben geniigend erweisen.

Wie bekannt hängt der Character irgend einer Fauna nicht nur von den äusseren Bedingungen, die mittelbar oder unmittelbar die Organismen beeinflussen und die lokale Formen erzeugen, ab, sondern auch zuweilen in hohem Grade von den Bewegungs- oder richtiger den Uebertragungsmitteln eines Organismus, die ihn von einem Orte in andere übertragen. Betrachten wir also über welche Mittel die Infusorien und die Urthiere überhaupt in dieser Hinsicht verfügen. Bekanntlich sind fast alle Urthiere sich $z u$ encystiren befähigt. Indem es sich mit einer festen Hiulle umgibt, kann ein encystirtes Infusorium vortrefflich allen äusseren feindlichen Einflüssen, z. B. der Austrocknung in der Luft, widerstehen; in diesem Zustande ist es jenen winzigen und leichten Sporen der Schimmel- und anderer Pilze ähnlich, die stetig und überall in der

1) Für die Meeresdiatomeen ist mir wenigstens bekannt, dass die Meeresflora verschiedener Meere verschieden ist. Ich kann nicht entscheiden, in wie weit dasselbe auch für die Süsswasserdiatomeen gilt, doch erwarte ich a priori, dass die Flora der letzteren sich weit weniger unterscheiden wird, als wir es bei den Meeresformen sehen. Darum wäre es interessant z. B. die DiatomeenHlora des Weissen Meeres und der angrenzenden süssen Gewässer mit anderen Floren zu vergleichen. Es ist zu erwarten, dass die Flora des Weissen Meeres sich als eine rein arctische, polare, während die Süsswasserflora als eine mehr oder weniger cosmopolitische sich erweisen werde. 
Luft schweben und mit grösster Leichtigkeit sich von einem Orte in einen andern übertragen.

In den süssen Gewässern kommen die Infusorien in besonderer Fülle nicht in den schnell fliessenden und reinen Flüssen und Bächen, sondern in Tümpeln, Sumpfen, Gräben und Teichen vor. Wenn ein solcher Tümpel oder Graben im Sommer während starker Hitze allmählich vertrocknet, so verwandelt sich die Mehrzahl der sie bewohnenden Infusorien in jene winzigen sporenähnlichen Kügelchen, die ich eben mit den Pilzsporen verglich. Es ist von selbst verständlich, dass, Dank ihrer unbedeutenden Grösse und eben darum - ibrer Leichtigkeit, für solche Cysten der geringste Wind genuigt, um sie massenhaft in die Luft $z \mathfrak{u}$ erheben und durch die Luftströme getrieben, werden sie dann auf grosse Strecken zerstreut. Natürlich kann ein etwas stärkerer Wind, um so mehr ein Sturm eine enorme Masse solcher encystirten Infusorien auf unermessliche Flächen iibertragen, und dadurch verschiedenste Gewässer in verschiedensten Orten des Erdballs mit ihnen versehen.

Setzen wir z. B. voraus, dass ein starker Wind eine Menge encystirter Infusorien aus Frankreich nach England itbertragen hätte, so werden ihrerseits die Cysten der englischen Arten bei veränderter Windrichtung in Frankreich uibertragen, und es entsteht also eine vollständige Vermischung der französischen und englischen Arten, darum die Infusorienfauna sowohl Englands als Frankreichs stets identisch sein müssen. Dasselbe, nur in grossartigeren Verhältnissen, muss auch auf der ganzen Erdoberfläche stattfinden.

Wir sehen also, dass die Encystirung, als ein Uebertragungsmittel, eine wichtige Rolle in der Bestimmung des Characters einer gegebenen Localität spielen muss. Betrachten wir darum, wie sich dieses Agens gegen die Meeresfauna verhält.

Das Meer bildet weder Teiche, noch Sümpfe und Gräben; das Meer trocknet weder im Sommer noch im Winter aus; darum werden die marinen Infusorien, ihre Cysten, äusserst selten (jedenfalls seltener als die Süsswasserinfusorien) der Luft und folglich auch dem Winde ausgesetzt; darum spielt dieses (d. h. die Uebertragung der Cysten durch Winde) in der Oeconomie der Süsswasserinfusorien so wesentliches Agens keine Rolle für die marinen Arten, oder es ist hier auf eine ganz unbeträchtliche Bedeutung 
zurtickgeführt ${ }^{1}$ ). Dies ruft aber ihrerseits jenen Umstand hervor, dass die Faunen verschiedener Meere entweder gar nicht mit einander sich vermischen, oder wenn es auch geschieht, so geht die Vermischung in einem sehr schwachen Grade, jedenfalls viel schwächeren, als bei den Stisswasserarten, vor sich ${ }^{2}$ ); darum konnten unter dem Einflusse localer Bedingungen ziemlich selbständige Faunen entstehen. Freilich unterordnen sich die Süsswasserarten nichts weniger als die marinen dem Einflusse äusserer Bedingungen (anders wäre absurd zu denken), und dieser Einfluss kann gleich bei beiden neue Formen erzeugen ${ }^{3}$ ), doch können die letzteren in stissen Gewässern niemals locale Arten bilden, Dank dem Umstande, dass die leichten Cysten, von dem Boden eines ausgetrockneten Tümpels oder Sumpfes ergriffen, sich nach und nach uber die ganze Erdoberfläche zerstreuen. Setzen wir z. B. voraus, dass Paramecium Aurelia aus Frankreich nach England übertragen wurde und dort unter dem Einflusse der localen Bedingungen in P. Bursaria tiberging; eben wie dies geschieht, wird auch die gleich erzeugte und bisweilen noch locale Art in grossen Mengen nach Frankreich ibertragen.

Dies ist meiner Meinung nach die Ursache, die das obige Gesetz der Verbreitung der einfachsten Thiere und Pflanzen bedingt.

Es wird hier auch passend sein an jenen Umstand zu erinnern, dass die Pilze, deren Sporen so leicht durch den geringsten Wind übertragen werden, dieselbe Erscheinung in Betreff ihrer geographischen Verbreitung zeigen, die wir bei den Süsswasserinfusorien fanden, - sie sind nämlich überall ähnlich, besonders aber die Schimmelpilze (Mucor, Penicillium, Aspergillus etc). So haben wir die horizontale Verbreitung der Infusorien abgehandelt; jetzt bleibt

1) Doch ist im Meere ein anderes Element zu berücksichtigen - die Strömungen nämlich.

2) Von der Vermischung der Meeres- und Süsswasserfauna kann gar keine Rede sein, da es, wie mir scheint, genügend bewiesen ist, dass beide von einander äusserst verschieden sind, d. h. dass das Salzwasser eine für die Süsswasserformen ungünstige Bedingung (mit seltenen Ausnahmen) vorstellt und vice versa.

3) Sonst, wenn die äusseren Bedingungen auf die Organisation niederer Pflanzen und Thiere keinen Einfluss ausübten, wie könnte dann eine so enorme Mannigfaltigkeit der uns bekannten Formen entstehen? 
uns noch etwas tiber deren verticale Verbreitung den verschiedenen Tiefen nach mitzutheilen.

Bis jetzt, soviel mir die Sache bekannt ist, giebt es keine Angaben hinsichtlich der Frage, wie weit die Infusorien anf verschiedenen Tiefen verbreitet sind und dies stellt eine ziemlich sonderbare Litcke im Vergleich damit, was wir von den Foraminiferen oder Meeresrhizopoden wissen, vor. Mir gelang es freilich äusserst wenig Thatsachen dariber zu sammeln, nichts destoweniger halte ich es für nicht überflüssig, auch sie anzuftuhren, in dem ich hoffe, dass die Zukunft vollständigere und gründlichere Thatsachen zur Beantwortung dieser Frage liefern wird.

Hinsichtlich der Untersuchungsmethoden muss ich bemerken, dass sie so zu sagen höchst primitiv waren, d. h. ich untersuchte nur jene Formen, die ich von verschiedenen Tiefen an Algen, Hydroiden, Bryozoen und anderen Gegenständen sitzend fand. Es versteht sich von selbst, dass auf solche Weise nicht zu viel Thatsachen zu bekommen sind, da der Mehrzahl nach die Infusorien freischwimmende Thiere sind. $\mathrm{Zu}$ einer vollständigeren Untersuchung dieser Frage wäre etwa ein solcher Apparat nöthig, der vom Boden verschiedene Gegenstände mit Wasser zusammenfasse und, sich hermetisch in der Tiefe zuklappend, Alles nach oben liefere. Bei den Mitteln, über die ich verfügte, war es nur möglich solche Formen, als Vorticella, Zoothamnium, Cothurnia, Freia, Acineta, Podophrya, zu untersuchen.

Allerdings erwies es sich, dass die Infusorien eine ziemlich bedeutende Tiefe erreichen können; und in dieser Hinsicht gehen nach den bis jetzt erhaltenen Erfahrungen die Acinetinen am weitesten. So fand ich einige Exemplare Acineta tuberosa in der Tiefe von 75 Faden, an Hydroiden (Campanularia und Calycella) sitzend. Es war an der Grenze des Weissen und des Eismeeres, etwas von Swiatoj Noss (an der Murmanschen Kiiste) nördlich ${ }^{1}$ ). Hier war noch ein anderes Infusorium, doch war es unmöglich dasselbe nach einem Spiritusexemplare zu bestimmen. Ausserdem fand ich dieselbe Ac. tuberosa mit Ac. Saifulae zusammen an einem anderen Orte in der Tiefe von 35 Faden, aber Cothurnia nedoza und Freia ampulla in einer geringeren Tiefe, nämlich von 20 Faden.

1) Acineta tuberosa war an Spiritusexemplaren gefunden. 
So kann man alle von mir hùnsichtlich der verticalen Verbreitung der Infusorien gesammelten Thatsachen in einer folgenden Tabelle zusammenstellen.

\begin{tabular}{|c|c|c|c|c|c|c|c|c|c|c|c|}
\hline & & & fen. & & & & & & & & \\
\hline $\begin{array}{l}\text { Namen der } \\
\text { Arten. }\end{array}$ & $\begin{array}{l}\text { An der } \\
\text { Oberfläche. }\end{array}$ & $\begin{array}{c}3 \\
\text { Faden }\end{array}$ & $\mid \begin{array}{c}5 \\
\text { Faden }\end{array}$ & $\begin{array}{c}8 \\
\text { Faden }\end{array}$ & $\begin{array}{c}10 \\
\text { Faden }\end{array}$ & $\begin{array}{c}12 \\
\text { Faden }\end{array}$ & $\begin{array}{c}16 \\
\text { Faden }\end{array}$ & $\begin{array}{l}18 \\
\text { Faden }\end{array}$ & $\begin{array}{l}20 \\
\text { Faden }\end{array}$ & $\begin{array}{l}35 \\
\text { Faden }\end{array}$ & $\begin{array}{c}75 \\
\text { Faden }\end{array}$ \\
\hline 1. Zoothamni- & & & & & & & & & & & \\
\hline $\begin{array}{l}\text { um alternans } \\
\text { 2. Acineta pa- }\end{array}$ & $t$ & + & & & & & & & & & \\
\hline 3. Podophrya & + & + & + & + & & & & & & & \\
\hline $\begin{array}{l}\text { conipes } \\
\text { 4. Cothurnia }\end{array}$ & + & + & + & + & & & & & & & \\
\hline 5. $\underset{\text { Vorticella }}{\text { maritima }}$ & + & + & + & + & + & & & & & & \\
\hline $\begin{array}{l}\text { Pyrum } \\
\text { 6. Cothurnia }\end{array}$ & + & + & + & + & + & & & & & & \\
\hline 7. Mrandis & . & . & + & + & + & & & & & & \\
\hline $\begin{array}{l}\text { ticulatus ') } \\
\text { 8. Zoothamni- }\end{array}$ & - & • & . & • & • & . & + & & & & \\
\hline 9. Cothurnia & + & + & + & + & + & + & + & $t$ & & & \\
\hline $\begin{array}{l}\text { nodosa } \\
\text { 10. Freia am- }\end{array}$ & + & + & + & + & + & + & + & + & + & & \\
\hline pulla & + & $t$ & + & + & + & + & + & + & + & & \\
\hline $\begin{array}{l}\text { fulae } \\
\text { 12. Ac. tube- }\end{array}$ & . & & + & + & + & + & + & + & + & + & \\
\hline- & + & + & + & + & + & + & + & + & + & + & + \\
\hline
\end{tabular}

Wie ungentigend auch die von mir gesammelten Thatsachen erscheinen mögen, die in der hinzugefïgten Tabclle zusammengebracht sind, nahm ich doch keinen Anstand sie zu veröffentlichen, da sie bisweilen die ersten und einzigen in dieser Hinsicht vorstellen. Ich werde mein Ziel für erreicht halten, wenn es mir auch nur gelingen wird die kiunftigen Forscher und Reisenden anzuregen, in dieser Hinsicht das Meer etwas grindlicher zu durchforschen. Dies ist Alles was mir auf Grund meiner Untersuchungen zur Erlüuterung der Zoogeographie der niederen Thiere und namentlich der Infusorien gelang. Es versteht sich von selbst, dass

1) Wie ich schon früher erwähnt hatte, fand ich nur die Schale dieses Infusorium, und darum zweifle ich sehr, ob man es an solchen bedeutenden Tiefen im lebenden Zustande treffe. Uebrigens, a priori ist zu erwarten, dass solche Arten dieser Gattung wie $T$. Ussowi und $T$. inquilinus auch an den Tiefen zu begegnen sind, da der erste gewöhnlich nicht schwimmt, der zweite aber mit seinem Hinterende sich an verschiedene fremde Gegenstände anheftet. Doch wird die.Mehrzahl der Tintinnus-Arten immer pelagisch sein. 
die Schltisse, zu denen ich gekommen bin, später mehr oder minder verändert und auf dem Grunde neuer Thatsachen, mit denen die Wissenschaft beständig bereichert wird, vervollständigt werden. Auch ist es nattirlich nicht möglich, meine Schltisse mit vollständiger Gewissheit auf alle besonderen Fülle anzuwenden, da die Materialien, die mir zur Verfügung standen, höchst unzureichend sind; doch hoffe ich wenigstens, dass die Schlüsse, zu denen ich gekommen bin, die anderen Forscher veranlassen werden dieselben zu pruffen, ich hoffe, dass meine Arbeit die Aufmerksamkeit der die Meeresfauna studirenden Zoologen auch auf die Protozooen lenken wird; kurz dass sie, wenn auch nur wenig, zur Beseitigung jenes Vorurtheils beitragen wird, dass die Kenntniss der Infusorien für die Zoogeographie, für die Geschichte der Erdoberfläche und der Begrenzung des Festlandes und der Meere, als auch der organischen Welt ïberhaupt gar unnütz sei.

\section{Einige allgemeine morphologische Bemerkungen.}

Es giebt keine andere grössere Thiergruppe, bei welcher die Asymmetrie der Körperform so scharf ausgepriigt wïre, wie wir es in der Classe der Infusorien beobachten. Alle übrigen Thiere sind von mehr oder weniger symmetrischem Bau, und zwar erscheinen sie entweder bilateral symmetrisch, d. h. in zwei gleiche, rechte und linke Hälften theilbar, oder radiär symmetrisch, d. h. mit vielen gleichen Strahlen (Antimeren), die um eine gemeine Axe g'elegen sind, wie es z. B. bei den Hydroiden vorkommt, welche eine bipolare (d. b. mit der Grundzahl 2) Symmetrie darbieten ${ }^{1}$ ), oder bei den Echinodermen (bei denen die fünfstrahlige Symmetrie, d. h. nach der Grundzahl 5 vorherrscht). Bei den Infusorien finden wir Nichts ähnliches; bei irgend welcher Oxytricha, Vorticella, Glaucoma oder beliebigen anderen Formen finden wir keine antimerenähnliche Bildungen; es giebt bei ihnen keinen rechten oder linken, vorderen oder hinteren, dorsalen oder ventralen Theil, die einander gleichen.

Nun liegt die Frage nahe: was für eine Ursache habe eine

1) Siehe meine "Studies on the Hydroida" Ann. and Magaz. of Nat. Hist. Ser. V, vol. I. 
solche ausschliessliche Erscheinung hervorgebracht, wie sei diese sonderbare Eigenschaft zu erklïren, warum finden wir keine vollkommen symmetrisch gebauten Infusorien? Freilich erreichen einige Formen fast eine vollkommene Symmetrie, aber solche Beispiele stehen ganz einzeln da, sie erscheinen ganz ausschliesslich und dazu stört noch immer bei den genannten Formen irgend ein Organ, irgend ein Körpertbeil die Symmetrie. Die Zahl solcher Formen, wie Coleps, Holophrya, Didinium ist im Vergleich mit der Zahl ganz unsymmetrischer Infusorien verschwindend klein, und doch wird auch bei ihnen durch den Nucleus und die Vacuole, d. h. für Infusorien sehr wesentlichen Organe, die Regelmässigkeit gestört, denn die genannten Bildungen liegen seitlich, in der Wandschicht des Parenchyms.

Die Ursache dieser Erscheinung wird aber ziemlich verstänlich, sobald wir den engen, genetischen Zusammenhang bericksichtigen, welcher zwischen Infusorien und Amöben besteht. Doch ist es wohl bekannt, dass Amöben keine beständige Körperform besitzen, dass ihre Gestalt sich fortwïhrend verändert, indem sie gleich einem Tropfen dicker Fliissigkeit fliessen und bald kurze und dicke Lappen, bald mehr oder weniger diinne und lange Fortsätze aussenden. Diese Veränderungen werden durch irgend welche uns unbekannte, dem Protoplasma selbst inh:̈rente Kräfte verursacht. Wenn die Wirkung dieser Krïfte aufhört, so veranlasst bei der Amöbe der nach allen Seiten gleichmässige Druck des Wassers, in dem sie lebt, eine reguliir-symmetrische Form; das kommt zu Stande, wenn z. B. sie sich encystirt. Also haben die Stammältern der Infusorien, die Amöben, eine vollkommen asymmetrische Form. Und auf welche Weise entstanden die Infusorien aus Amöben? Bekanntlich besteht der Infusorienkörper aus einem flüssigeren Entoplasma und consistenteren, dichteren, dickeren Ektoplasma; die äusserste, dünne Schicht des Ektoplama oder Cuticula kann man für einen noch mehr verdichteten, dazu noch etwas chemisch veründerten Theil des Protoplasma halten. Also muss die Veränderung beim Uebergange der Amöben in Infusorien zunächst darin bestehen, dass ihre äussere Schicht oder Ektoplasma sich immer verdichtete und auf solche Weise die jeweilige Form, welehe die Amöbe darbot, fixirte. Stellen wir uns diesen langsamen, vielleicht einen sehr bedeutenden Zeitraum in Anspruch nehmenden Vorgang als unter unseren Augen nur in 
wenigen Momenten zu Stande kommend, so erscheint uns zuerst ein Tropfen dicken Protoplasmas, beständig seine Form ändernd, also ganz unsymmetrisch, im Wasser schwimmend. Dann beginnt seine Oberflächenschicht sich nach und nach $\mathrm{zu}$ verdichten; natürlich wird dadurch die Veränderlichkeit des Körpers beschränkt, da die erstarrte Schicht den Veränderungen einen grösseren Widerstand leistet. Gleichzeitig werden aber die Pseudopodien, dank weiter unten zu besprechenden Ursachen, immer schlanker und nähern sich der Wimperform mehr. Endlich erstart dieser immer mehr sich verdichtende Tropfen unter der jeweiligen unsymmetrischen Gestalt, welche die Amöbe angenommen hatte und damit schliesst der Vorgang ab, das Infusorium ist fertig. Es versteht sich von selbst, dass die zufalligen Formen, unter welchen ein Tropfen amöboid beweglichen Protoplasmas erstarren kann, höchst verschieden ausfallen werden, auch ist bei solcher Vorraussetzung die vollkommene Abwesenheit der Symmetrie eben so erklïrlich. Der letztere Umstand, sowie die grosse Mannigfaltigkeit der Infusorien muss gerade eine unvermeidliche Folge soleher Entstehungsart sein - anders könnte es nicht geschehen.

Wie die asymmetrischen Formen der Infusorien der Asymmetrie der Amöben ihren Ursprung verdanken, welche durch „Erstarrung", d. h. durch Verdichtung der äussern Schicht, eine bebeständige Form bekamen, ebenso rief diese Verdichtung der äussern Schicht eine andere für Infusorien characteristische Erscheinung hervor - ich meine die aus diunnen, mehr oder weniger langen Wimpern bestehenden Bewegungsorgane. Bei Amöben von flüssiger Consistenz, die einigermassen fliessen, können natürlich die Pseudopodien nur als kurze, breite, zugerundete Lappen erscheinen. Hier geschieht etwa dasselbe, was wir an einem in die Luft geworfenen Tropfen dicker, syrupartiger Znckerlösung sehen, in Folge der Erschuitterung sendet der letztere kurze und dicke Lappen aus. Wenn aber umgekehrt das Plasma irgend welches amöbenartigen Organismus eine bedeutendere Consistenz besitzt, wenn dasselbe züher ist, wie z. B. Protamoeba Grimmi oder andere, dann erscheinen die Pseudopodien als lange, dünne, fadenartige Bildungen; unser oben erwähntes Beispiel weiter verfolgend, werden wir jetzt auch die Analogie mit einem durch Evaporation sehr dick gemachten Syrup hervorheben: denn ein solcher lässt sich mittelst eines Stäbchens in sehr lange und dünne 
Fäden ziehen. Dies kann sogar verallgemeinert werden: je ein dicker, minder flüssig organischer, nicht krystallinischer Stoff ist, desto dünnere und längere Fortsätze oder Pseudopodien wird er aussenden, und dies gilt sowohl für das Plasma, als auch für Zucker- oder Gummi-Lösungen, für Harz etc.

Diese Abhängigkeit der Form der Pseudopodien, also des ganzen Habitus der Amöbe, welcher vorwiegend die ganze Mannigfaltigkeit der Amöbenformen bedingt und zur Unterscheidung von Arten dient, tritt mit grosser Deatlichkeit aus der folgenden Tabelle hervor. Ich versuchte in derselben die zerstreuten, hierauf beziiglichen Thatsachen zusammenzustellen; leider gelang es mir bei weitem nicht im befriedigenden Maasse, denn nur sehr selten finden wir in den Beschreibungen der Amöben auch Angaben über die Consistenz ihres Plasmas. In der Tabelle sieht man ausser der Abhängigkeit der Form der Pseudopodien von dem Grade der Dichtigkeit des Plasmas auch den Zusammenhang zwischen der Schnelligkeit der Locomotion und derselben Dichtigkeit. Die fliissigeren Arten bewegen sich gewöhnlich ziemlich schnell oder, um den nicht unpassenden Ausdruck anzuwenden, sie fliessen, dagegen bewegen sich meistens die dichten Amöben, Protamoeba Grimmi z. B., langsamer.

\begin{tabular}{|c|c|c|c|}
\hline Namen der Art. & Form d. Pscudopodien. & Consistenz. & Bewegung. \\
\hline $\begin{array}{l}\text { 1. Amoeba crassa } \\
\text { Duj. }\end{array}$ & $\begin{array}{l}\text { Sehr kurze u. breite, } \\
\text { zugerundete Lap- } \\
\text { pen. }\end{array}$ & Sehr flüssig. & $\begin{array}{l}\text { Sehr schnelles } \\
\text { Fliessen. }\end{array}$ \\
\hline 2. A. minuta $\mathrm{m}$. & $\begin{array}{l}\text { Eben solche lappen- } \\
\text { artige Pseudopo- } \\
\text { dien, wie bei der } \\
\text { vorigen Art. }\end{array}$ & Sehr flüssig. & Sehr schnell. \\
\hline 3. A. emittens m. & $\begin{array}{l}\text { Fast ganz ohne Pseu- } \\
\text { dopodien oder mit } \\
\text { unbedeutendenLap- } \\
\text { pen. }\end{array}$ & Flüssig. & $\begin{array}{l}\text { Ziemlich schnelles } \\
\text { Fliessen. }\end{array}$ \\
\hline 4. A. elaginia $\mathrm{m}$. & $\begin{array}{l}\text { Stumpfe, zugerundete, } \\
\text { kurze Lappen. }\end{array}$ & Flüssig. & Schnell. \\
\hline 5. A. $\operatorname{limax}$ Duj. & $\begin{array}{l}\text { Fast ohne Pseudopo- } \\
\text { dien oder unbedeu- } \\
\text { tende breite Fort- } \\
\text { sätze. }\end{array}$ & Flüssig. & $?$ \\
\hline
\end{tabular}




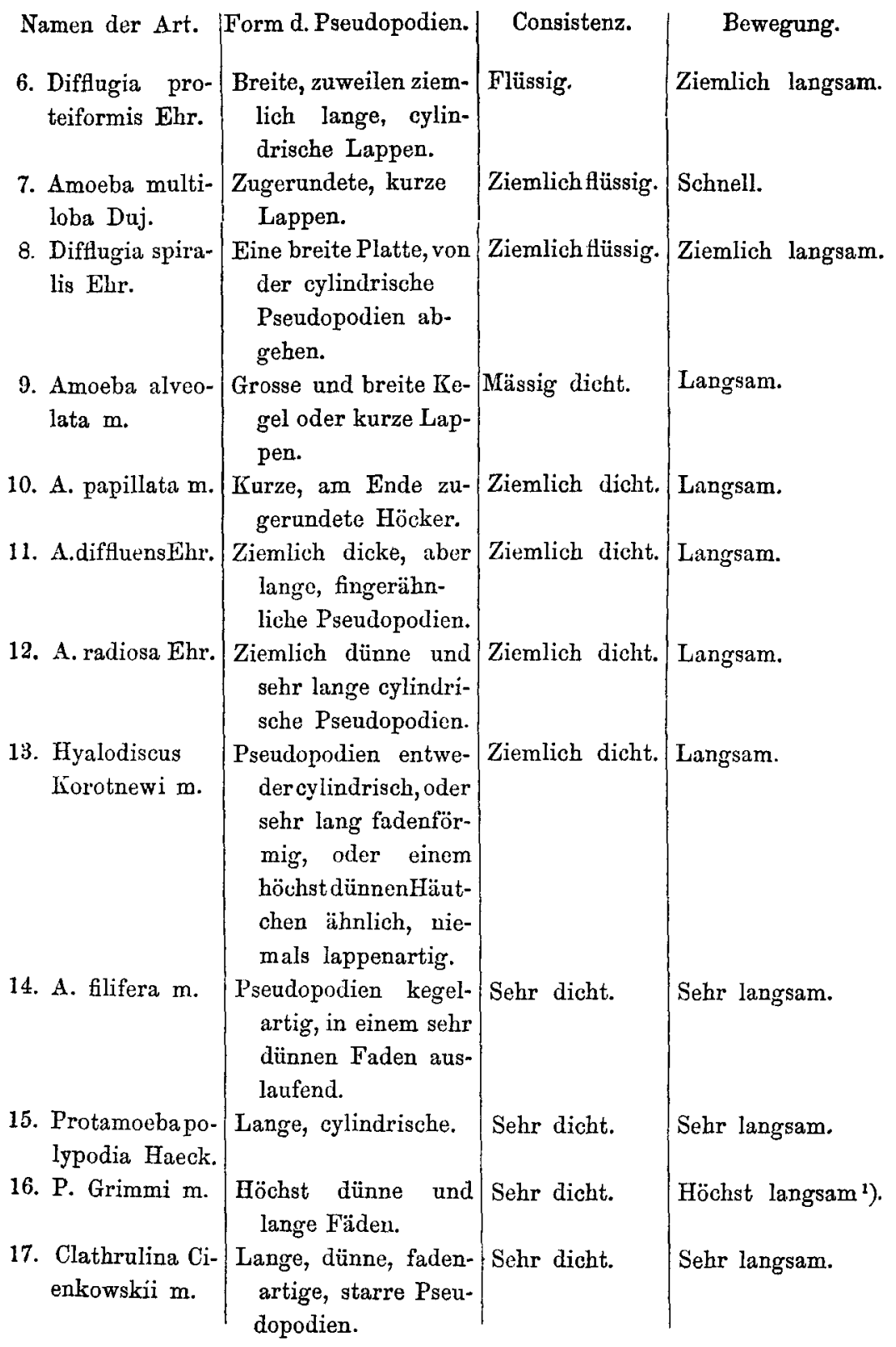

1) Uebrigens schlängelten die Pseudopodien selbst ziemlich schnell, aber das Erscheinen und Verschwinden der Pseudopodien, sowie die Veränderung der Körperform ging ziemlich langsam vor sich. 


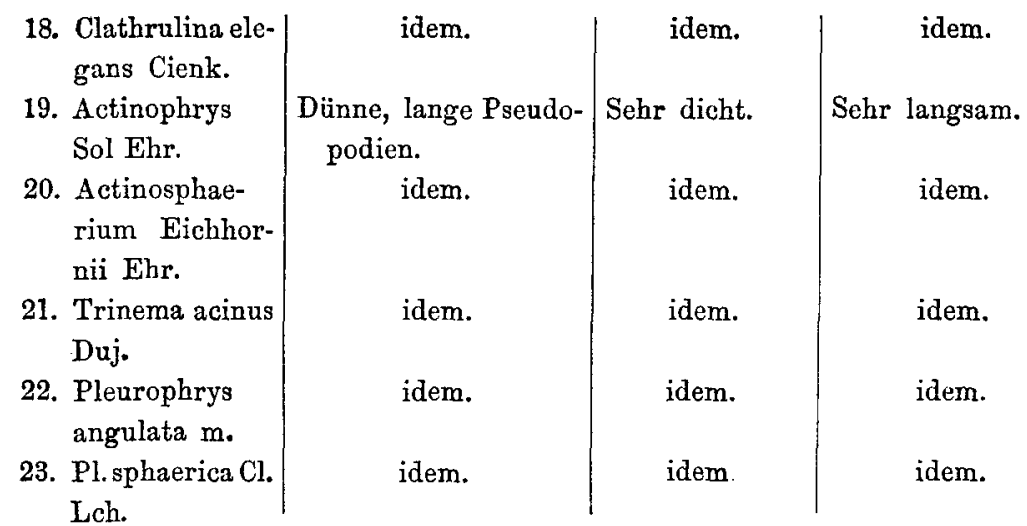

Ueberhaupt kann man sagen, dass alle Heliozoa von mehr oder weniger dichter Consistenz sind, so war es wenigstens in allen jenen Fällen, die mir aus eigener Anschauung bekannt wurden.

Dasselbe schreibt Häckel von den Radiolarien. Er schreibt nämlich 1): „Die Consistenz der Sarcodegallerte ist meist ziemlich bedeutend und, so vicl sich unter dem Mikroskop aus dem Verhalten gegren Druck ete. alonehmen laisst, etwa gleich derjenigen der Gallertscheibe der höheren Medusen." Mit dem steht wohl die äusserste Diinnheit ihrer Psendopodien im Zusammenhang. Was die Foraminiferen betrifft, so hatte ich keine Gelegenheit dieselben lebendig zu untersuchen. Doch scheinen auch die marinen Foraminiferen, wenigstens uach denjenigen Süsswasser-Monothalamien zu urtheilen, die sich durch ihre dünnen fadenartig ausgezogenen Pseudopodien auszeichnen, auch von dichter, nicht flüssiger, fliessender Consistenz zu sein, wie z. B. bei Difflugia prote iformis und bei anderen, die Gruppe Lobosa zusammensetzenden Süsswasserrhizopoden.

Schliesslich will ich noch eine Stelle aus der interessanten Arbeit Strassburger's über das Protoplasma anführen ${ }^{2}$ ), wo er durch Anwendung der Osmiumsäure nachwies, dass die äussere Plasma-Schicht bei Sehwärmsporen aus ziemlich flüssigem Plasma besteht, in welchem senkrecht stehende Stäbehen eingelagert sind; die Cilien, welche Strassburger's Beobachtangen zu Folge

1) Die Radiolarien, 1862, p. 109.

2) Strassburger, Studien über Protoplasma 1876. 
bald verschwinden, bald wieder erscheinen können, gehen eben von diesem dichten Theile des-Protoplasma ab und offenbar darum erscheinen sie als dïnne Härchen.

Also bestätigen im Grossen und Ganzen die oben angefïhrten Thatsachen, dass die Form der Pseudopodien und folglich auch der ganze Habitus eines Rhizopoden oder eines überhaupt amöbenïhnlichen Organismus in erster Linie von der Consistenz des Plasma abhingt, diss je dichter, minder flüsig dasselbe ist, desto dïnner länger und mehr fadenähnlich die Pseadopodien werden. Doeh kann man gegen diese Behanptung scheinbar auch sehr wichtige Einwürfe machen. Man kann mehrere Thatsachen anfiihren, die gleichsam meiner Ansicht vollkommen widersprechen, sogar dieselbe vernichten. So erwälne ich z. B. die allgemein bekannte.Amoeba terricola Greeff, die nicht im Wasser, sondern in feuchter Erde lebt, sowie ihre Varietait A. solidula, die Herr 0. Grimm unlingst in grosser Menge in seinem Aquarium fand 1). Das Plasma dieser Form ist ohne Zweifel von höchst dichter Consistenz; dem entsprechend sind auch ihre Bewegnngen höchst langsam und schwer bemerkbar, wie ich mich sellst iiberzeugen konnte. Doch erscheinen bei ihr die Pseudopodien gar nicht diun und fadenartig, wie es nach meiner Ansicht zu erwarten wäre; viclmehr sind sie ganz kurz, lappenartig, am Ende zugerundet, oder leicht kegelförmig. Eine andere Art gleichsam widersprechender Thatsachen bietet z. B. das ebenfalls von $O$. Grimm gefundene Protastrum marinum ${ }^{2}$ ) und andere Formen, bei denen wir während einer Lebensperiode lange und dünne, mehr oder weniger fadenartige Pseudopodien sehen; dann ziehen sich aber dieselben ein, verschwinden und das Thier fängt sich amöbenartig $z \mathfrak{u}$ bewegen an, indem es stumpfe und breite, am Ende zugerundete Lappen aussendet; gleichzeitig bleibt aber die Consistenz, die Dichtigkeit des Plasmas die ganze Lebensdauer hindurch unverändert. Also kann ein Thier bei gleicher Consistenz des Plasmas bald solche Pseudopodien, die dichtem, bald solche, die flüssigem Plasma entsprechen, anssenden.

Man kann noch andere ähnliche Thatsachen finden. Dessen-

1) 0. Grimm, Beiträge z. Kenntniss der Urthiere (russisch), 1867, p. 56.

2) O. Grimm, Caspisches Meer und seine Fauna (russisch), Heft I, Lief. 2, 1876, S. 64; Taf. I, Fig. 4. 
ungeachtet halte ich sie für keine eigentlichen, sondern nur scheinbaren Einwendungen gegen meine Schlüsse. Denn immer muss man berücksichtigen, dass alle Lebensvorgänge höchst complicirte Erscheinungen vorstellen; folglich sind ihre Ursachen ebenso complicirt. Selbst viel einfachere Erscheinungen der anorganischen Natur werden nur selten durch eine einzige Ursache hervorgebracht, vielmehr treten dabei immer mehrere ins Spiel und nur ihre Wechselwirkung bedingt den Character der Erscheinung. Lassen wir es zu, dann sind 3 Fälle möglich: entweder wirken alle Ursachen in gleichem Sinne, dann wird ibr Resultat höchst dentlich und intensiv sein; oder die Wirkung einiger von ibnen ist ganz der der anderen entgegensetzt, dann wird das Resultat schwächer als im vorigen Falle sein, kann sogar bis 0 , d. h. bis vollständige Abwesenheit irgend welchen Ausdruckes der Ursachen (Kräfte), bis vollkommenes Gleichgewicht herabsinken; oder endlich können einige (stärkere) der in entgegengesetzter Richtung wirkenden Ursachen iberhand nehmen, dann kann der Character der Erscheinung ganz umgekehrt werden. Und je complicìrter die Erscheinung sein wird, desto mehr Ursachen werden im Hervorbringen derselben betheiligt sein, desto eher kann es geschehen, dass das zu erwartende gar nicht $z u$ Stande kommen wird, desto öfter auch A usnahmen zu treffen sind. Eben darum erscheinen in der organischen Natur Ausnahmen aus allgemeinen Regeln, aus empirischen Gesetzen viel öfter, als in der anorganischen.

Nach dem wohlbekannten Gesetze z. B. werden alle Körper von der Erde angezogen; darum müssen sie ohne Stïtze oder nicht aufgehängt auf dieselbe herunterfallen. Doch sehen wir, dass ein Luftballon, anstatt auf die Erde wie alle tibrigen Körper zu fallen, im Gegentheil aufsteigt. Hier liegt uns eine Ausnahme von der allgemeinen Regel vor; wer wird aber daraus schliessen wollen, dass die allgemeine Regel nicht allgemein, unrichtig sei, dass das Aufsteigen des Luftballons wirklich eine Ausnahme vorstelle? Wenn die Menscheit ebenso wenig mit den physischen Erscheinungen und ihrem Wesen, wie sie jetzt mit den (versteht sich nächsten) Ursachen der Lebenserscheinungen vertraut wäre, so hielten sie eine solche Thatsache für eine wirkliche Ausnahme. Doch verstehen wir jetzt, dass beim Aufsteigen des Luftballons mehrere Ursachen zusammenwirken, dass er dem Gesetze der Anziehung durch die Erde sich unterordnet, dass gerade dank diesem 
Gesetze er aufsteigt, indem er von der schwereren Luft verdrängt wird. Dieses Beispiel zeigt deutlich, dass jene wenigen Ausnahmen aus meiner allgemeinen Regel, wie Amoeba terricola, Protastrum u. andere, keine wirklichen Ausnahmen vorstellen und die Bedeutung der ziemlich ansehnlichen Menge von Thatsachen zu erschüttern nicht im Stande sind, die meinen Schluss unterstützen. Als scheinbare Ausnahmen sollen sie nur bedeuten, dass die Lebenserscheinungen und die sie bedingenden Ursachen uns noch zu wenig bekannt sind.

Nach allem oben Gesagten, glaube ich, bleibt in meiner Darstellung Nichts unverständliches mehr. Ohne Zweifel wird eine so complicirte Erscheinung als das Aussenden der Pseudopodien von mehreren Ursachen hervorgebracht; doch spielt unter diesen letzteren die Consistenz des Plasmas die wichtigste Rolle und meistens ubberwältigt sie alle übrigen. In einigen Fällen aber können uns unbekannte Ursachen so mächtig einwirken, dass sie das Gesammtresultat maskiren und dabei Erscheinungen hervorrufen, die mehr oder weniger von der allgemeinen Regel abweichen.

Wenn es also fest steht, dass die Schlankheit der Pseudopodien, d. h. der Bewegungsorgane, vorwiegend von der Consistenz des Plasma abhängt (wie es eben erörtert wurde), wenn die Infusorien aus den Amöben durch Erhärtung der äusseren Schichten des Protoplasma derselben entstanden, so wird es von selbst verständlich, dass die Bewegungsorgane der Infusorien nur als dünne fadenartige Fortsätze oder als eigenthümlich modificirte Pseudopodien erscheinen können. Das Plasma der Infusorien hat die schwächste Consistenz im Innern und die dichteste in der äussersten Schicht. Da ich aber die Wimpern der Infusorien (wie es schon längst E. Häckel gut nachwies) für modificirte Pseudopodien halten muss, so versteht sich ron selbst, dass das dichte Ectosark nur dïnne Fortsïtze, als fadenartige Wimpern aussenden kann. Lassen wir nur zu, dass Ursachen wirkten, die das Erscheinen von Bewegungsorganen nothwendig machten, so könnten die letzteren keine andere Form bekommen. Es bleibt uns also übrig zu erklären, was für Ursachen die Bildung so energischer Bewegungsorgane als Geisseln und Wimpern hervorgerufen haben; zweifellos waren sie für rasche Bewegungen nöthig. Warum aber waren den Infusorien solche Bewegungen nöthig? Im nachfolgenden will ich einen Versuch machen, diese Frage zu erörtern. 
Bei einer Amőbe kann die Nahrungsaufnahme durch jeden beliebigen Punkt der Körperoberfläche geschehen; wenn sie sich bewegt, dringen darum die auf ihrem Wege liegenden Nahrungstheilchen durch die ganze vordere Fläche des Körpers ins Innere desselben ein. Anders ist es bei irgend welchem Infusorium, bei einer Monadine z. B. Die ganze äussere Oberfläche hat sich bei ihr so stark verdichtet, dass sie für Nahrungstheilchen ganz undurchdringlich wird, und nur an einem unbedeutenden Körpertheile, am Vorderende, liegt gewöhnlich eine kleine Mundöffnung, wo das Plasma seine ursprüngliche weiche Consistenz bewahrt hat und wodurch die Nahrung ins Innere der Monadine, in das flüssigere Endosark gelangen kann. Da bei niederen Organismen das einzige und wichtigste Bedürfniss in gentigender Nahrungserwerbung besteht, so ist die Monadine scheinbar in unginstigere Lage gestellt, da sie, caeteris paribus, wegen ihrer kleinen Mundöffnung, zu gleicher Zeit weniger Nahrung aufnehmen kann, als eine Amöbe. Um diese ungünstige Bedingung auszugleichen bedarf sie einer weit grösseren Schnelligkeit der Bewegung, als die Amöben. Bekanntlich vermögen solche Organismen wie z. $B$. Actinophrys, die fast gar unbeweglich sind, die Nahrung nicht nur durch ihre Gesammtoberflïche anfzunehmen, sondern die letztere wird noch durch eine besondere Anpassung, nämlich eine Menge langer, radiär gestellter Pseudopodien vergrössert, was natürlich die Nahrungsaufnahme entsprechend verstärkt und somit den schädlichen Einfluss der vollständigen Unbeweglichleit ausgleicht. Die Amöben haben keine solche Anpassung, gerade für sie ist sie aber übrig, denn sie sind zu einer zicmlich schnellen Bewegung fähig. Die Infusorien, hei denen die Nahrung aufnehmende Fläche ganz bedeutend verkleinert ist, müssen dafür durch eine sehr bedeutende Schnelligkeit der Bewegung entschädigt werden. Denn wenn z. B. eine Amöbe, indem sie in einer Minute $1 \mathrm{~mm}$ zuriucklegt, durch ihro Durchschnittfläche mit drei Nahrungskörnern in Berïhrung kommt und dieselben aufnimmt, so muss ein Infusorium während desselben Zeitraumes $3 \mathrm{~mm}$ zurücklegen, damit ihre nur eine kleine Fläche einnehmende Mundöffunng auch drei Nahrungskörnern begegmen könne. Sonst wird der Vortheil, der von der Verdichtung der Integumente gewährt wird und darin besteht, dass äussere. Einfliisse nicht so verderblich auf den Körper einwirken, zum Nachtheil und bringt dem Infusorium nur Schaden. Um diesen Einfluss auszugleichen, 
ist eine stärkere Entwickelung der Bewegungsorgane unumgänglich, die, wie oben erörtert, nur als Wimpern erscheinen müssen und, indem sie sich immer mehr entwickeln, einen sehr bedeutenden Vorzug vor den sich langsam bewegenden Amöhen gewähren können. Ein Blick auf eine blitzschnell nach allen Richtungen fliehende und uberall nach Nahrung schnappende Aspidisca oder Oxytricta veranschaulicht vollkommen die ganze Wichtigkeit und den Nutzen, die das Infusorium von ihren urspriinglich als die einfache Monadengeissel erscheinenden Wimpern bekommt. Natürlich ist es für ein Infusorium vortheilhafter kürzere und differenzirte Wimpern, als eine einfache Geissel der Monaden zu besitzen. Dank diesem Umstande sind zwei Typen der Infusorien entstanden, so 1. freischwimmende, mit vielen Wimpern, und 2. sitzende, aber einen sehr starken Strudel mittelst ihrer Wimpern erzeugende, der ihnen Nahrungstheilchen zufuihrt.

Also brachte bei den Amöben die Verdichtung der äusseren Schichten die Nothwendigkeit einer bedentenden Schnelligkeit der Bewegungen, d. h. der Erscheinung der Bewegungsorgane hervor ; dieselbe Ursache aber bedingte auch den Umstand, dass die betreffenden Bewegungsorgane, welche, wie es allgemein vorkommt, nur Körperauswiichse vorstellen, auch die Form dünner, fadenartiger Bildungen bekamen, entweder als eine lange Geissel oder mehrere kürzere Wimpern erscheinend.

\section{Erklärnng der Abbildungen.}

Taf. $\mathrm{X}$.

Fig. 1-5. Cothurnia nodosa. Verschiedene Variationen aus dem Weissen Meere Fig. 1 und 2 mit einer runden oder ovalen Anschwellung des Stieles, Fig. 3, 4, 5 mit einer dreieckigen Anschwellung. Fig. 1 und 3 sind dem unteren verengerten Theile, Fig. 2 u. 4 dem zugerundeten Boden nach ähnlich. Endlich stellt Fig. 5 die Var. longipes vor (mittelst der Camera lucida gezeichnet).

Fig. 7. Eine Abnormität von Stilonychia mytilus.

Fig. 8. Cothurnia arcuata, nova species. Im Innern des Körpers sieht man 
eine Vacuole. Fig. 8a. Der untere Theil der Schale im optischen Durchschnitt gesehen; sie veranschaulicht dies bei grosser Vergrösserung hervortretende Verbältniss zwischen dem Stiele und der Schale.

Fig. 9-10. Oxytricha oculata, nova species. Fig. 9 bei Ansicht von oben, Fig. 10 bei Seitenansicht.

Fig. 11. Balantidium Medusarum, nova species. nc - nucleus; vc zwei contractile Vacuolen.

Fig. 12. Tintinus inquilinus, vordere Theil des Körpers ohne Schale.

Fig. 14 und 14a. Pleurophrys angulata, nova species. Fig. 14 Längsansicht; 14a Ansicht von oben. Nach der Hauptaxe betrachtet, stellt sie deutlich den sechseckigen Umriss der Scbale dar.

Fig. 15. Difflugia spiralis Ehr., obne Sandkörner an der Oberfläche; im Innern des Körpers selbst sieht man mehrere runde Kügelchen.

Fig. 16. Das obere, bandförmige Ende von Epiclinthes auricularis Cl: \& L. An beiden Seiten sieht man kurze, stäbchenförmige Körperchen; in der Mitte - 5 oder 6 schiefe Borstenreiben.

Fig. 17. Difflugia Solowetzkii, nova species, mit stark umgebogenen Rändern.

Fig. 18-25. Polytoma uvella in den verschiedenen Zuständen ihrer Entwicklung. Fig. 18 völlig erwachsenes Exemplar; Fig. 19 und $20 \mathrm{im} \mathrm{Zu-}$ stande der Zweitheilung; Fig. 21 und 22 Viertheilung; Fig. 23 Zustand der Morula aus 8 Segmenten einer uvella ähnelnd; Fig. 24 ein junges Thier aus dem Zerfall der Morula entstanden; Fig. 25 Cysten-Zustand.

Fig. 26. Acineta mystacina, varietas longipes, nova varietas mit ausgezeichnet langem Stiele; vo Vacuole.

Fig. 27. Glaucoma Wrzesniowskii, nova species. An den Rändern sieht man Trichocysten im optischen Durchschnitt des Infusoriums. In der Mitte aber ist dassolbe bei Oberflächenansicht abgebildet, und hier treten die senkrecht stehenden Trichocysten als Kreise hervor. $27 \mathrm{~b}$ stellt gesondert und mehr vergrössert den Lippenapparat vor; 1 beide Lippen; $f$ der von ihnen begrenzte Spalt; $m$ jener Theil des Körperparenchyms, der die Lippen umgiebt und deutlich gestreift ist. Die das gestreifte Feld umgebende Reihe von Kreisen stellt die senkrecht stehenden Trichocysten vor.

Fig. 28. Podophrya cylindrica Perty, mit mehr weniger eingezogenen Saugröhren.

Fig. 29 u. 30 . Holophrya Kessleri, nova species, 39 in Seitenansicht; 30 von oben betrachtet, in der Mitte sieht man die runde Mundöffnung.

Fig. 31, 22. Vorticella Pyr u m, nova species. 2 Individuen, sowohl der birnenförmige Körper, als der Stiel sind in verschiedenem Grade der Contraction. Das Peristom ist nicht vollständig abgebildet.

Fig. 33. Astasia deformis Fromentel mit amöboiden Pseudopodien.

Fig. 34. Clathrulina Cienkowskii nova species. 
Fig. 35. Oxytricha Wrzesniowskii, nova species.

Fig. 36. Zoothamnium marinum, nova species. Ein Stock mit Individuen von verschiedener Lage. Bei allen sieht man deutlich den kleinen, ovalen Kern; a eigenthümliche Zacken oder Falten, die ihren Ursprung der Contraction des Körpers verdanken.

Fig. 37. Epistylis Balanorum, nova species. Ein vergrössertes Individuum, ganz entfaltet.

Fig. 38. Euglena Pyrum Ehr. in Zweitheilung begriffen.

Fig. 39. Podophrye conipes nov. spec. spec. (vergrössert). Der Körper ist mit dem Stiele fast von gleicher Breite, in 39a sieht man das trichterartig verbreiterte Saugröhren-Ende bei grösserer Vergrösserung.

Fig. 40. Tintinnus Ussowi, nova species. Die Schale ohne das Thier.

Fig. 41. Merotricha bacillata nov. genus et nov. species. Im oberen Körpertheile befindet sich ein Büschel Stäbchen, die Trichocysten ïhnlich sind; unter ihnen sieht man eine Vacuole. An der Seite ist ein Grübchen vorhanden, aus dessen Tiefe eine Geissel ansgeht.

Fig. 42. Aspidisca Andreewi, nova species, von der Bauchseite gesehen.

\section{Taf. XI.}

Fig. 1. Urceolus Alenizini nov. gen. et spec. mit geöffnetem Munde.

Fig. 2. Oberer Theil derselben Monadine mit zugeschlossenem Munde.

Fig. 3 A moeba angulata, nova species, mit 3 contractilen Vacuolen und einem kleinen runden Kern; der körnerlose Körper enthält ziemlich viele kleine F'ettropfen.

Fig. 4. Heteromita ad unca, nova species.

Fig. 5. Haeckelina borealis novum genus et nova species. Im Innern des kugelförmigen, körnigen Körpers sieht man Fetttropfen. Der lange, dünne Kern sitzt auf einer Conferve.

Fig. 6-11. A moeba emittens, nova species. Der körnerlose Körper enthält einen Kern und eine Vacuole, die immer in Hintertheile des Körpers liegt. 7 und 8 die Vacuole hat sich schon ganz dem Hinterende genähert; 9, 10,11 stellen bei stärkerer Vergrösserung das Ende der Amoebe und das allmälliche Heraustreten der Vacuoie; 11 die Vacuole platzte und da bleibt die Amoebe eine kurze Weile ohne dieselbe.

Fig. 12. Eine noch näherer Untersuchung bedïrftige Heteromita, die zusammen mit der in Fig. 4 abgebildeten gefunden war und die entweder eine Uebergangsform zwischen Heteromita sulcata und den nicht gestreiften Heteromiten oder eíne junge, noch nicht ganz ausgebildete Heteromita sulcata vorstellt.

Fig. 13. Heteromita sulcata, nova species, Varietas truncata. Thr Hinterende ist abgestutzt und mit Körnern überfüllt; im vorderen, körnerlosen Theile sieht man eine grosse contractile Vacuole. 
Fig. 14. Heteromita sulcata, varietas ovata, mit zugerundetem Hinterende. Auch wie bei der obigen sieht man hier längslaufende Furchen.

Fig. 15. Podophrya conipes, nova species. Ein ausgewachsenes Individuum mit ausgestreckten Saugröhren. Am Stiele sieht man neben der Mitte desselben zwei Ringe $a^{\prime}$ und $a^{\prime \prime}$.

Fig. 16. Podophrya cylindrica Perty.

Fig. 17. Epistylis Balanorum nov. spec. Eine Colonie aus 2 Individuen; das Thier hat sich contrahirt (siehe Taf. X, Fig. 37).

Fig. 18. Heteromita cylindrica, nova species.

Fig. 19. Dinophysis arctica, nova species. Die Oberfläche des Körpers ist fein chagrinartig; nahe der Oberfläche liegen im Körperparenchym bräunliche Körperchen.

Fig. 20-26. Hya lodiscus Korotnewi, nova species. Man sieht die Vacuole und den Kern. Fig. 20 der Zustand, in dem weder das den Körper umsäumende Häutchen, noch zugespitzte Pseudopodien, sondern nur stumpfe und kurze Scheinfüsschen sichtbar sind; Fig. 21 der Beginn der Häutchenbildung; Fig. 24 das Häutchen ist noch mehr entwickelt und die kurzen, stumpfen Pseudopodien sind schon ganz verschwunden; Fig. 26 - das Häutchen ist schon vollständig entwickelt, indem es den ganzen Körper umgiebt; an ihm sieht man sich zuspitzende und den Rand des Häutchens äberragende Pseudopodien; Fig. 22 das Häutchen bleibt noch, aber die eben erwähnten Pscudopodien zogen sich ein, statt ihrer erschienen aber kurze und stumpfe Scheinfüsschen; Fig. 25 der kugelförmige Körper ist ganz ohne Pseudopodien, es blieb nur das Häutchen; ein Stadium, dem auf den Fig. 24 oder 26 ähnlich.

Fig. 27. Amoeba minuta, nova species.

Fig. 26. Amoeba crassa Duj. Man sieht den grossen, runden Kern und Diatomeen.

Fig. 29-30. A moeba elaginia, nova species. a und b verschiedene Formen dieser Amoeba; im Innern sieht man den Kern und zuweilen 2, zuweilen 3 contractile Vacuolen.

Fig. 31. A moeba papillata, nova species. Im Innern sielut man die grosse contractile Vacuole, und seitlich ist der Kern sichtbar.

Fig. 32. Dieselbe, einen besonderen Lappen für die Bewegung aussendend.

Fig. 33-35. A moeba verrucosa (?) Ehr. Unten sieht man eine kleine Knospe, (a), die sich vom Ektosark abschnürt, in $a^{\prime}$ hat sie sich schon mehr vom Mutterorganismus abgesondert und steht mit demselben nur mittelst eines engen Verbindungsstückes im Zusammenhange; a" die Knospe hat sich schon vollständig abgesondert und bewegt sich in einer kleinen Amoebe; gleich vor ihr, neben der Mutter schwimmt eine eben solche kleine, vollkommen hyaline Amoebe, die wahrscheinlich auch durch Knospung von der grossen entstanden ist. 
Fig. 36-37. Protam o eba Grimmi nova species. Der körnerlose, durchsichtige Körper mit langen, fadenförmigen Pseudopodien.

Fig. 38. Euglen a viridis Ehr., mit dem von Paramilkörnern überfüllten Hinterende.

Fig. 39. Euglena viridis Ehr., encystirt. Der grüne Inhalt ist von einer kugelförmigen, doppelt contourirten Hülle umgeben. Ihren rothen Augenfleck sieht man im Innern des grünen Cysteninhaltes; a die äusserst dünne Hülle, welche die im Innern des grünen Cysteninhaltes gebildete kugelförmige Höhle umgiebt; $\mathbf{b}$ ein kugelförmiger Haufen Paramilkörner innerhalb dieser dünnen Hülle.

Fig. 40. A moeba a lveolata nova species. Im Innern des Körpers im Endosark sieht man eine grosse Menge nicht contractiler mit Flüssigkeit erfüllter Vacuolen; ausserdem noch 4 kleine Fett-(?)tropfen und einen kleinen runden Kern, in der oberen linken Ecke, im Ektosark.

Fig. 41 und 42. Amoeba filifera nova species. Ohne Kö̈rner mit zwei Vacuolen und einem Kerne.

\section{Die Knorpelzelltheilung.}

Ein Beitrag zur Lehre der Theilung von Gewebezellen.

Von

\section{W. Schleicher.}

(Aus dem histologischen Laboratorium in Gent.)

Hierzu' Tafel XII. XIII. XIV.

\section{Vorbemerkung.}

Einige Zeit nach Erscheinen unserer vorläufigen Mittheilung (Centralbl. f. d. med. Wissenschaften 1878) erhielten wir von Herrn Mayzel aus Warschau einen Brief, worin er uns darauf aufmerksam machte, wie wir zu ignoriren schienen, dass unter anderen Objecten er auch den Knorpel bezüglich der Kerntheilung untersucht, und auch dort die sonst aufgefundenen Theilungsbilder gesehn habe. Wir danken Herrn Mayzel für die freundliche Weise, 